\title{
Cr-Catalyzed Direct ortho-Aminomethylation of Phenols
}

Junbin Shi, ${ }^{\mathrm{a}, \mathrm{b}}$ Yubin Wang, ${ }^{\mathrm{a}, \mathrm{b}}$ Qingqing Bu, ${ }^{\mathrm{b}}$ Binyuan Liu, ${ }^{\mathrm{b}, \mathrm{c}}$ Bin Dai, ${ }^{\mathrm{b}}$ and Ning Liu ${ }^{*, \mathrm{~b}}$ aJ.S. and Y.W. contributed equally.

${ }^{\mathrm{b}}$ School of Chemistry and Chemical Engineering, Key Laboratory for Green Processing of Chemical Engineering of Xinjiang Bingtuan, Shihezi University, North Fourth Road, Shihezi, Xinjiang 832003, China, E-mail: ningliu@ shzu.edu.cn; ninglau@163.com

${ }^{c}$ Hebei Key Laboratory of Functional Polymers, School of Chemical Engineering and Technology, Hebei University of Technology, Tianjin 300130, China 


\section{Table of Contents}

1. X-Ray Dada for 4b and C3....................................................S3-6

2. Condition optimization table, data comparison table.............................S7-8

3. FT-IR and UV-vis spectra............................................S9-10

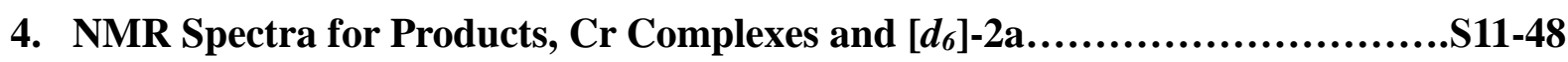




\section{X-Ray Dada for $4 \mathrm{~b}$ and $\mathrm{C3}$}

1.1 CCDC 2058383 (4b) contains the supplementary crystallographic data for this paper. The data can be obtained free of charge from The Cambridge Crystallographic Data Centre via https://www.ccdc.cam.ac.uk/

\section{Crystal Data}

Identification code

$11 \_\mathrm{a}$

Empirical formula

$\mathrm{C}_{16} \mathrm{H}_{16} \mathrm{BrNO}_{3}$

Formula weight

350.21

Temperature

173(2) K

Wavelength

$0.71073 \AA$

Crystal system

Monoclinic

Space group

Unit cell dimensions

Volume

$\mathrm{C} 2 / \mathrm{c}$

$\mathrm{a}=22.6966(6) \AA$

$\alpha=90^{\circ}$.

$\mathrm{b}=10.3128(2) \AA$

$\beta=103.2300(10)^{\circ}$

$\mathrm{c}=12.6787(2) \AA$

$\gamma=90^{\circ}$.

Z

Density (calculated)

2888.88(11) $\AA^{3}$

8

$1.610 \mathrm{Mg} / \mathrm{m}^{3}$

Absorption coefficient

$2.855 \mathrm{~mm}^{-1}$

$\mathrm{F}(000)$

1424

Crystal size

$0.240 \times 0.220 \times 0.210 \mathrm{~mm}^{3}$

Theta range for data collection

2.603 to $26.728^{\circ}$.

Index ranges

$-28 \leq \mathrm{h} \leq 28,-11 \leq \mathrm{k} \leq 13,-16 \leq 1 \leq 13$

Reflections collected

8758

Independent reflections

$3054[\mathrm{R}(\mathrm{int})=0.0314, \mathrm{R}(\operatorname{sigma})=0.0325] 0.2060]$

Completeness to theta $=25.242^{\circ}$

$99.5 \%$

Refinement method

Full-matrix least-squares on $\mathrm{F}^{2}$

Data / restraints / parameters

$3054 / 1 / 194$

Goodness-of-fit on $\mathrm{F}^{2}$

1.024

Final $\mathrm{R}$ indices $[\mathrm{I}>2 \operatorname{sigma}(\mathrm{I})]$

$\mathrm{R} 1=0.0286, \mathrm{wR} 2=0.0683$

$\mathrm{R}$ indices (all data)

$\mathrm{R} 1=0.0351, \mathrm{wR} 2=0.0721$

Extinction coefficient

$\mathrm{n} / \mathrm{a}$

Largest diff. peak and hole

0.356 and -0.267 e. $\AA^{-3}$ 


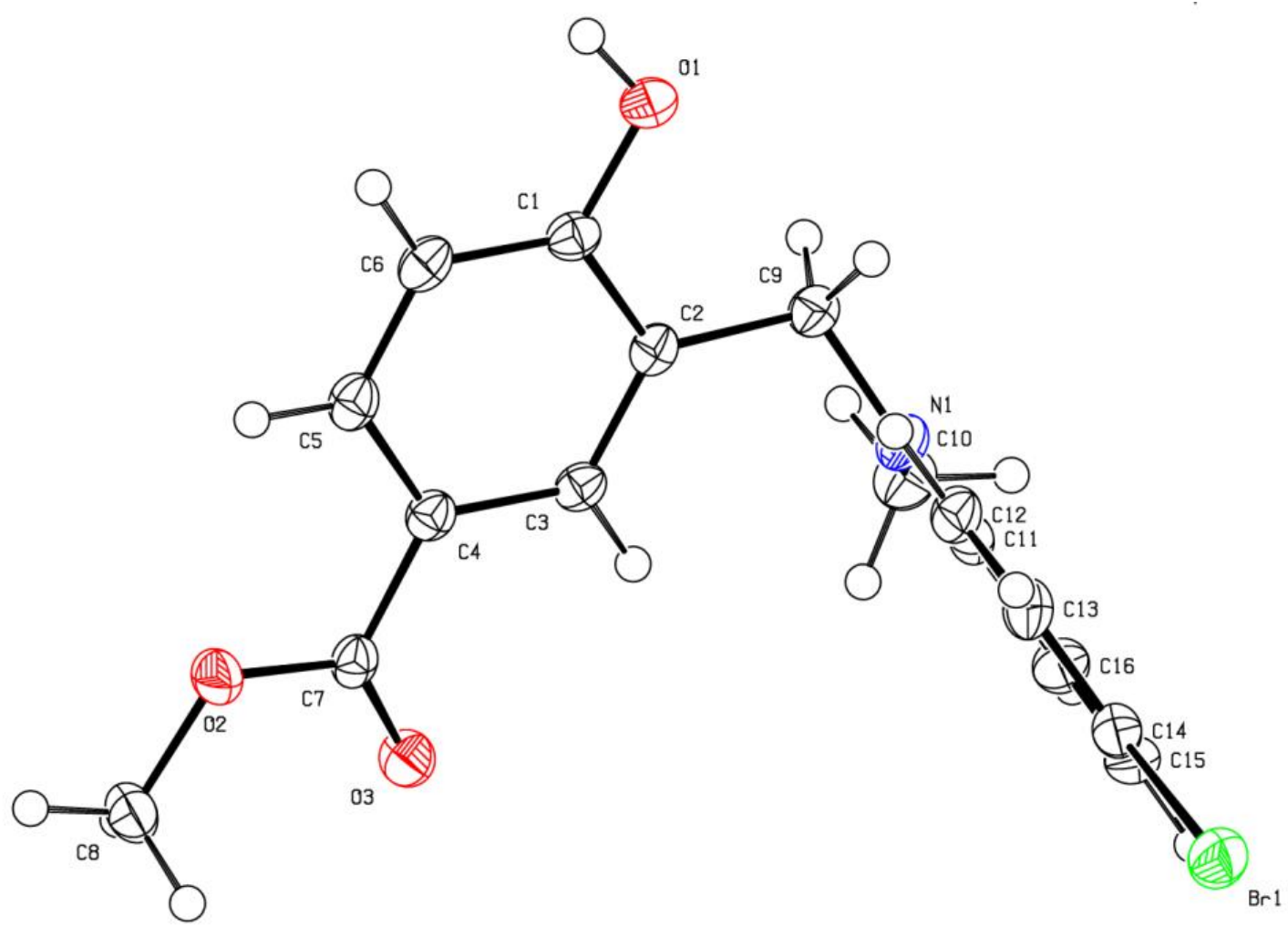

ORTEP of $\mathbf{4 b}$ (at $30 \%$ level)

Figure S1. X-ray data and structure of $\mathbf{4 b}$. 
1.2 CCDC 2024308 (C3) contains the supplementary crystallographic data for this paper. The data can be obtained free of charge from The Cambridge Crystallographic Data Centre via https://www.ccdc.cam.ac.uk/

\section{Crystal Data}

Identification code

$11 \_\mathrm{a}$

Empirical formula

$\mathrm{C}_{19} \mathrm{H}_{15} \mathrm{CrN}_{3} \mathrm{O}_{4}$

Formula weight

401.34

Temperature

$173.0 \mathrm{~K}$

Wavelength

$0.71073 \AA$

Crystal system

Monoclinic

Space group

Unit cell dimensions

P 1 21/n 1

$\mathrm{a}=10.2248(3) \AA$

$\alpha=90^{\circ}$.

$\mathrm{b}=17.2160(6) \AA$

$\beta=111.900^{\circ}(1)$

$\mathrm{c}=10.8226(3) \AA$ $\gamma=90^{\circ}$.

Volume

1767.62(10) $\AA^{3}$

Z

Density (calculated)

4

$1.5080 \mathrm{Mg} / \mathrm{m}^{3}$

Absorption coefficient

$0.678 \mathrm{~mm}^{-1}$

$\mathrm{F}(000)$

825.6742

Crystal size

$0.09 \times 0.07 \times 0.06 \mathrm{~mm}^{3}$

Theta range for data collection

Index ranges

2.34 to $27.11^{\circ}$.

Reflections collected

$-12 \leq \mathrm{h} \leq 13,-22 \leq \mathrm{k} \leq 22,-13 \leq 1 \leq 13$

22433

Independent reflections

$3898[\mathrm{R}(\mathrm{int})=0.0702, \mathrm{R}($ sigma $)=0.0421]$

Completeness to theta $=25.242^{\circ}$

$99.97 \%$

Refinement method

Full-matrix least-squares on $\mathrm{F}^{2}$

Data / restraints / parameters

$3898 / 0 / 244$

Goodness-of-fit on $\mathrm{F}^{2}$

1.0552

Final $R$ indices [I $>2 \operatorname{sigma}(\mathrm{I})]$

$\mathrm{R} 1=0.0388, \mathrm{wR} 2=0.0797$

$\mathrm{R}$ indices (all data)

$\mathrm{R} 1=0.0531, \mathrm{wR} 2=0.0899$

Extinction coefficient

$\mathrm{n} / \mathrm{a}$

Largest diff. peak and hole

$0.4128 /-0.3665$ e. $\AA^{-3}$ 


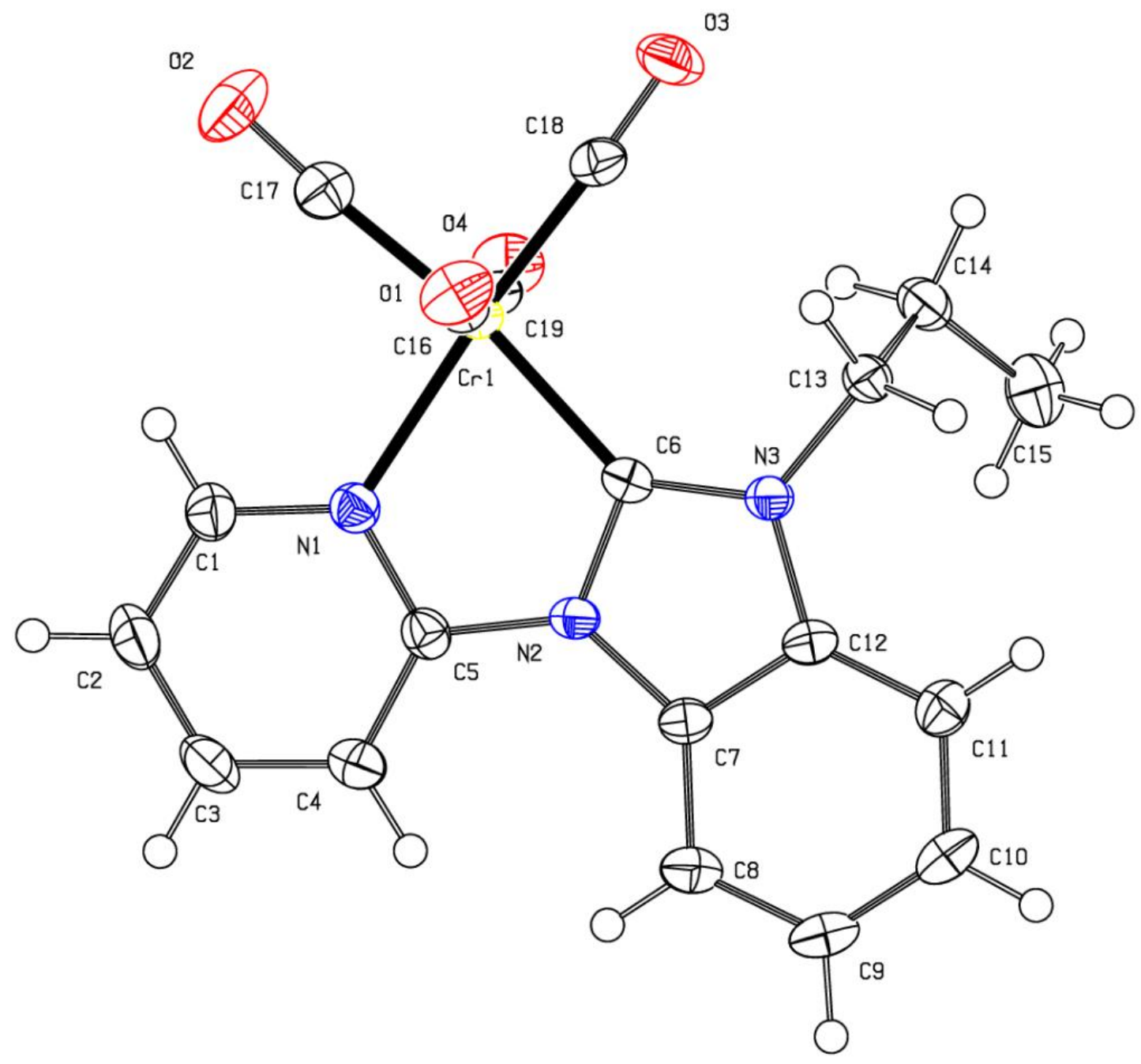

ORTEP of C3 (at 30\% level)

Figure S2. X-ray data and structure of C3. 
Table S1 Optimization of reaction conditions. ${ }^{a}$<smiles>Oc1ccccc1</smiles>

1a<smiles>CN(C)c1ccccc1</smiles>

2a<smiles>C[AsH2-]</smiles>

$3 a$<smiles></smiles>

C3

\begin{tabular}{ccccc}
\hline entry & cat. $(\mathrm{mol} \%)$ & oxidant & solvent & yield (\%) \\
\hline 1 & $\mathbf{C 3}(5)$ & TBHP & MT & 56 \\
2 & $\mathbf{C 3}(2.5)$ & TBHP & MT & 51 \\
$3^{b}$ & $\mathbf{C 3}(10)$ & TBHP & MT & 34 \\
$4^{c}$ & $\mathbf{C 3}(10)$ & TBHP & MT & 22 \\
$5^{d}$ & $\mathbf{C 3}(10)$ & TBHP & MT & 18 \\
$6^{e}$ & $\mathbf{C 3}(10)$ & TBHP & MT & 56 \\
$7^{f}$ & $\mathrm{Cr}(\mathbf{C O})_{6}(10)$ & TBHP & MT & 28 \\
$8^{g}$ & $\mathrm{Cr}(\mathbf{C O})_{6}(10)+\mathbf{L}(10)$ & TBHP & MT & 30 \\
$9^{h}$ & $\mathrm{Cr}(\mathbf{C O})_{6}(10)+\mathbf{L}(20)$ & TBHP & MT & 47 \\
\hline
\end{tabular}

${ }^{a}$ Reaction conditions: 1a $(0.5 \mathrm{mmol}), \mathbf{2 a}(2.5 \mathrm{mmol})$, TBHP $(1.0 \mathrm{mmol}), \mathrm{MT}(1 \mathrm{~mL}), 80{ }^{\circ} \mathrm{C}, 24 \mathrm{~h} ;{ }^{b}$ $60{ }^{\circ} \mathrm{C} ;{ }^{c} \mathbf{2 a}(1.0 \mathrm{mmol}) ;{ }^{d} \mathbf{2 a}(0.5 \mathrm{mmol}) ;{ }^{e} \mathrm{MT}(2 \mathrm{~mL}) ;{ }^{f} \mathrm{Cr}(\mathrm{CO}) 6(10 \mathrm{~mol} \%)$ instead of $\mathbf{C 3}(10 \mathrm{~mol} \%)$; ${ }^{g} \mathrm{Cr}(\mathrm{CO}){ }_{6}(10 \mathrm{~mol} \mathrm{\%})+\mathbf{L}(10 \mathrm{~mol} \%)$ instead of $\mathbf{C 3}(10 \mathrm{~mol} \mathrm{\%}) ;{ }^{h} \mathrm{Cr}(\mathrm{CO}){ }_{6}(10 \mathrm{~mol} \%)+\mathbf{L ~}(20 \mathrm{~mol} \%)$ instead of C3(10 mol \%). L = 3-propyl-1-(pyridin-2-yl)-1H-benzo[d]imidazol-3-ium iodide. 
Table S2 Comparision of the yield of the same substrate with Patureau.

\begin{tabular}{|c|c|c|c|c|}
\hline \multirow{2}{*}{ Entry } & \multirow{2}{*}{ phenol } & \multirow{2}{*}{ amine } & \multicolumn{2}{|c|}{ yield $(\%)$} \\
\hline & & & Patureau $^{a}$ & our work \\
\hline 1 & & $N, N$-dimethylaniline & 47 & 76 \\
\hline 2 & & $N, N$-dimethylaniline & 62 & 81 \\
\hline 3 & & $N, N$-dimethylaniline & 56 & 68 \\
\hline 4 & & $N, N$-dimethylaniline & 70 & 77 \\
\hline 5 & & $N, N$-dimethylaniline & 45 & 80 \\
\hline 6 & & $N, N$-dimethylaniline & 66 & 78 \\
\hline 7 & & $N, N$-dimethylaniline & 63 & 85 \\
\hline
\end{tabular}

${ }^{a}$ Yu, C.; Patureau, F. W. Cu-Catalyzed Cross-Dehydrogenative ortho-Aminomethylation of Phenols. Angew. Chem. Int. Ed. 2018, 57, 11807-11811. 


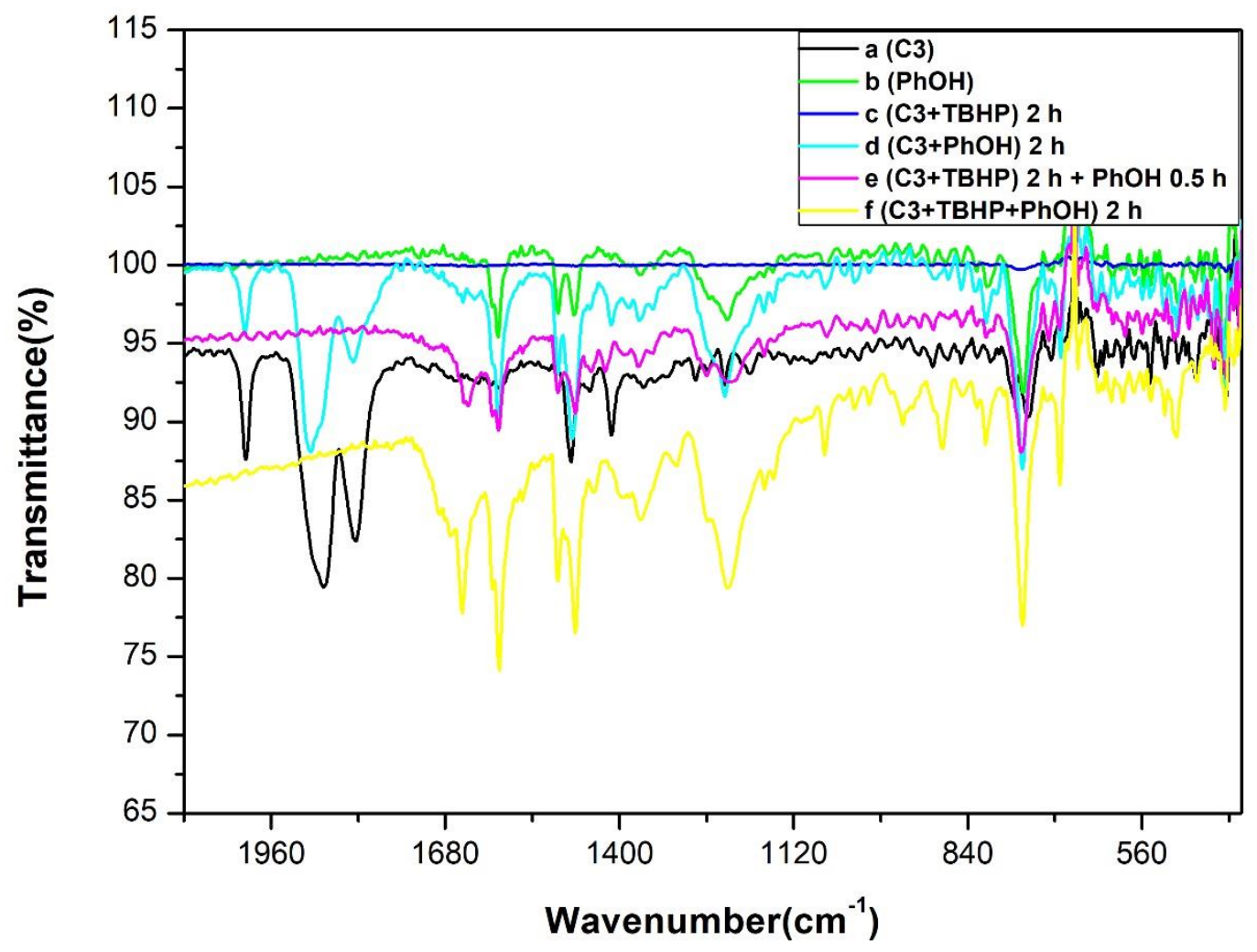

Figure S3 FT-IR experiments: (a) C3 (0.02 mmol) in Dichloromethane (DCM) (1 $\mathrm{mL})$;

(b) $\mathrm{PhOH}(0.2 \mathrm{mmol})$ in DCM (1 mL); (c) $\mathbf{C 3}(0.02 \mathrm{mmol})$, TBHP (0.4 mmol) in DCM (1 mL) $80{ }^{\circ} \mathrm{C}, 2 \mathrm{~h}$; (d) $\mathbf{C 3}(0.02 \mathrm{mmol}), \mathrm{PhOH}(0.2 \mathrm{mmol})$ in $\mathrm{DCM}(1 \mathrm{~mL}) 80^{\circ} \mathrm{C}, 2 \mathrm{~h}$; (e) $\mathbf{C 3}(0.02 \mathrm{mmol})$, TBHP $(0.4 \mathrm{mmol})$ in DCM $(1 \mathrm{~mL}) 80{ }^{\circ} \mathrm{C}, 2 \mathrm{~h}$, and then added $\mathrm{PhOH}$ (0.2 mmol) stirred for $0.5 \mathrm{~h}$; (f) $\mathbf{C 3}$ (0.02 mmol), TBHP (0.4 mmol) and $\mathrm{PhOH}$ (0.2 mmol) in DCM $(1 \mathrm{~mL}) 80{ }^{\circ} \mathrm{C}, 2 \mathrm{~h}$. 


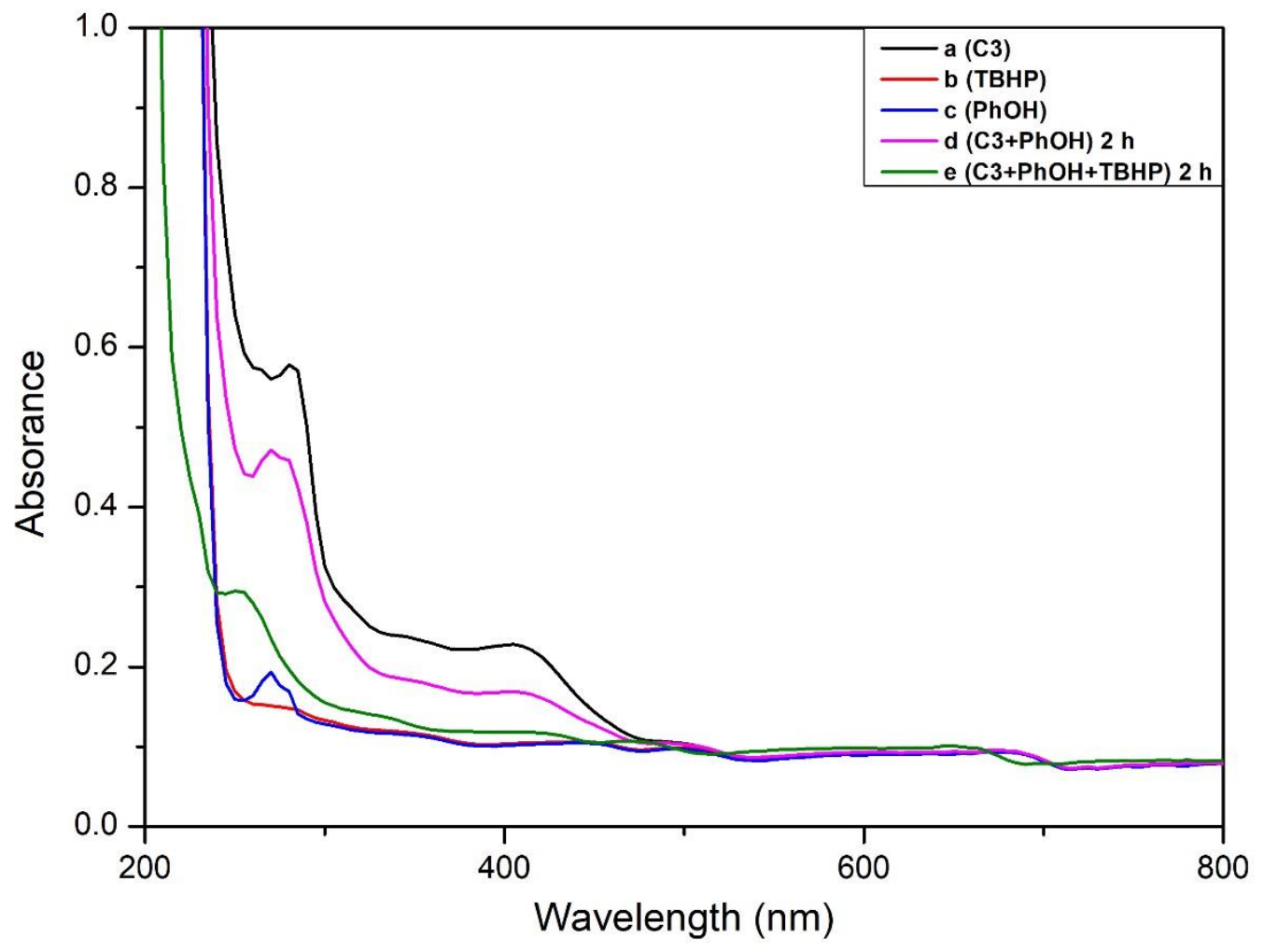

Figure S4 UV-vis spectra experiments: (a) C3 $\left(7.5 \times 10^{-5} \mathrm{~mol} / \mathrm{L}\right)$ in DCM; (b) TBHP $\left(6.0 \times 10^{-4} \mathrm{~mol} / \mathrm{L}\right)$ in $\mathrm{DCM}$; (c) $\mathrm{PhOH}\left(6.0 \times 10^{-5} \mathrm{~mol} / \mathrm{L}\right)$ in $\mathrm{DCM}$; (d) $\mathbf{C 3}\left(7.5 \times 10^{-5}\right.$ $\mathrm{mol} / \mathrm{L})$ and TBHP $\left(6.0 \times 10^{-4} \mathrm{~mol} / \mathrm{L}\right)$ in $\mathrm{DCM}$ were stirred for $2 \mathrm{~h}$ at $80{ }^{\circ} \mathrm{C}$; (e) $\mathbf{C 3}(7.5$ $\left.\times 10^{-5} \mathrm{~mol} / \mathrm{L}\right), \mathrm{TBHP}\left(6.0 \times 10^{-4} \mathrm{~mol} / \mathrm{L}\right)$ and $\mathrm{PhOH}\left(6.0 \times 10^{-5} \mathrm{~mol} / \mathrm{L}\right)$ in $\mathrm{DCM}$ were stirred for $2 \mathrm{~h}$ at $80^{\circ} \mathrm{C}$. 
2. NMR Spectra for Products, Cr Complexes and aa- $D_{6}$
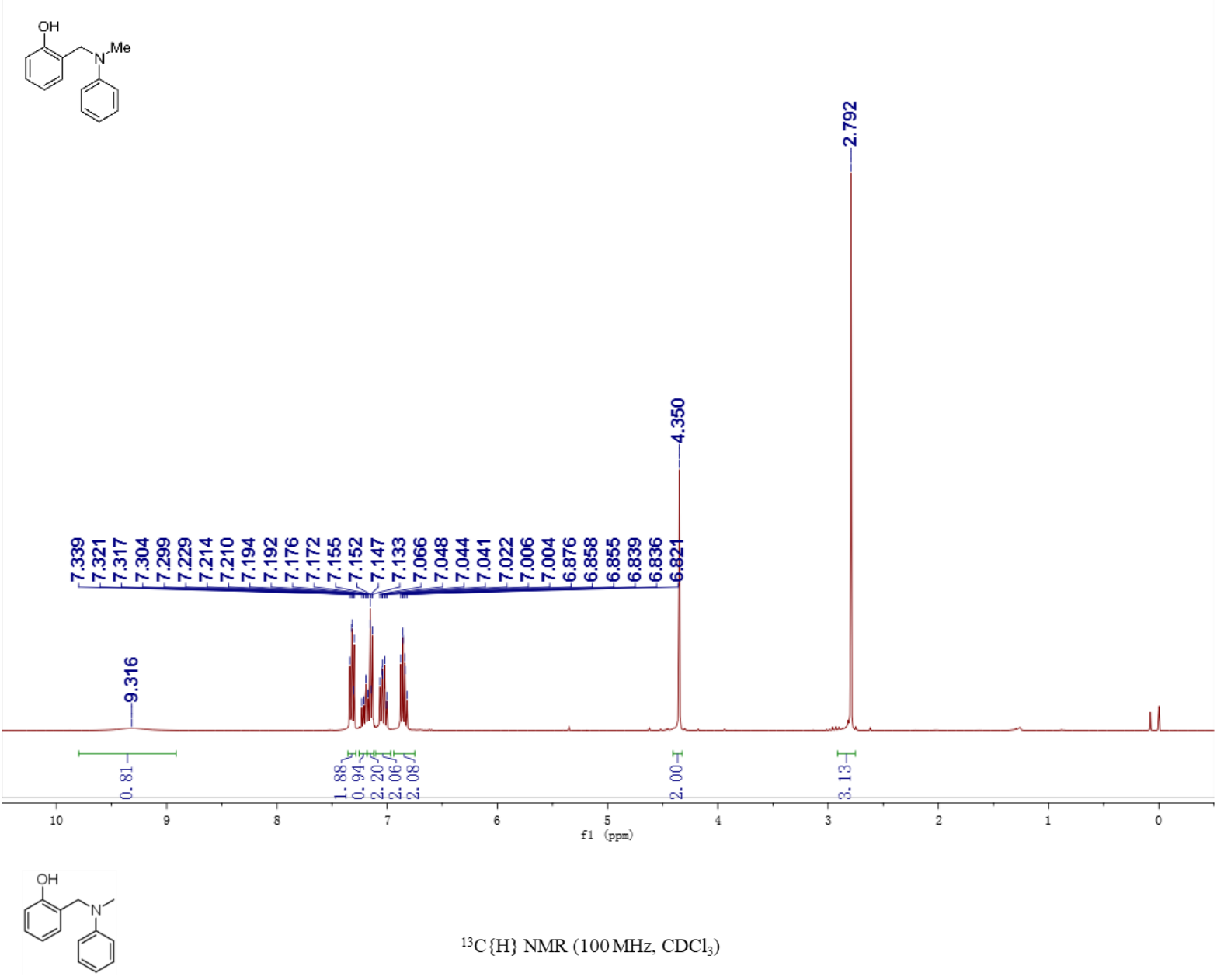

${ }^{13} \mathrm{C}\{\mathrm{H}\} \mathrm{NMR}\left(100 \mathrm{MHz}, \mathrm{CDCl}_{3}\right)$

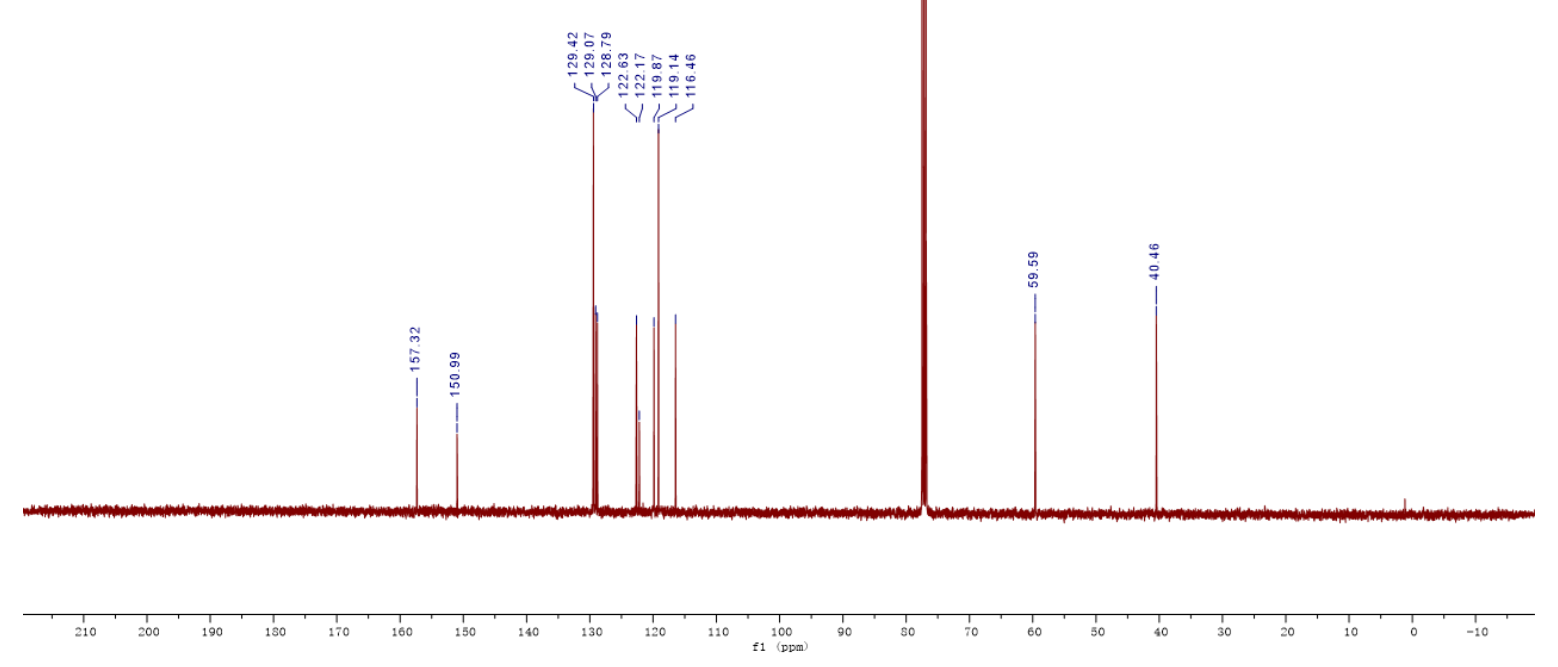

Figure S5. ${ }^{1} \mathrm{H}$ NMR and ${ }^{13} \mathrm{C}\left\{{ }^{1} \mathrm{H}\right\}$ NMR spectra of $\mathbf{3 a}$

S11 
'II NMR (400 MIIz, $\mathrm{CDCl}_{3}$ )
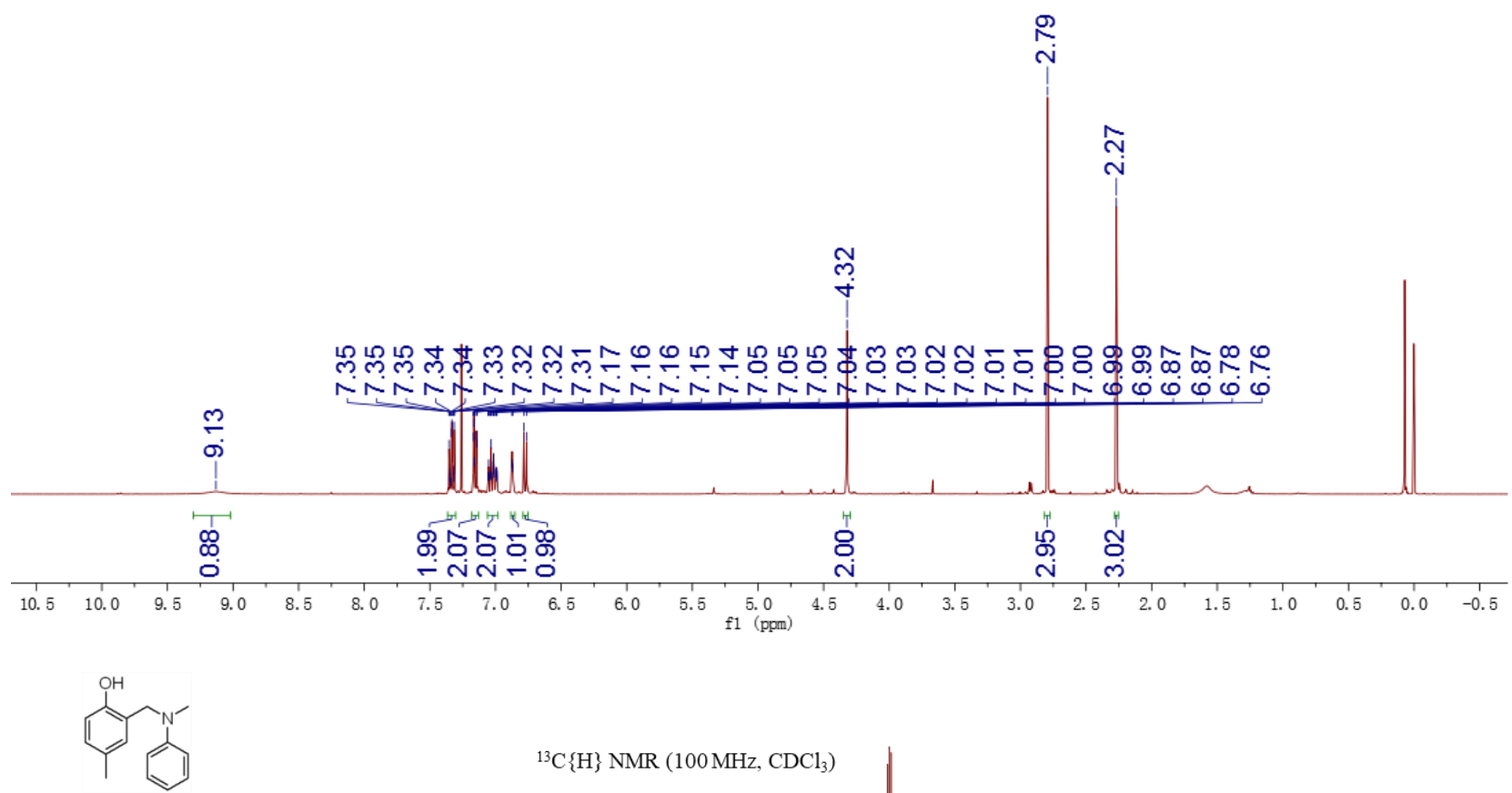

${ }^{13} \mathrm{C}\{\mathrm{H}\} \mathrm{NMR}\left(100 \mathrm{MHz}, \mathrm{CDCl}_{3}\right)$
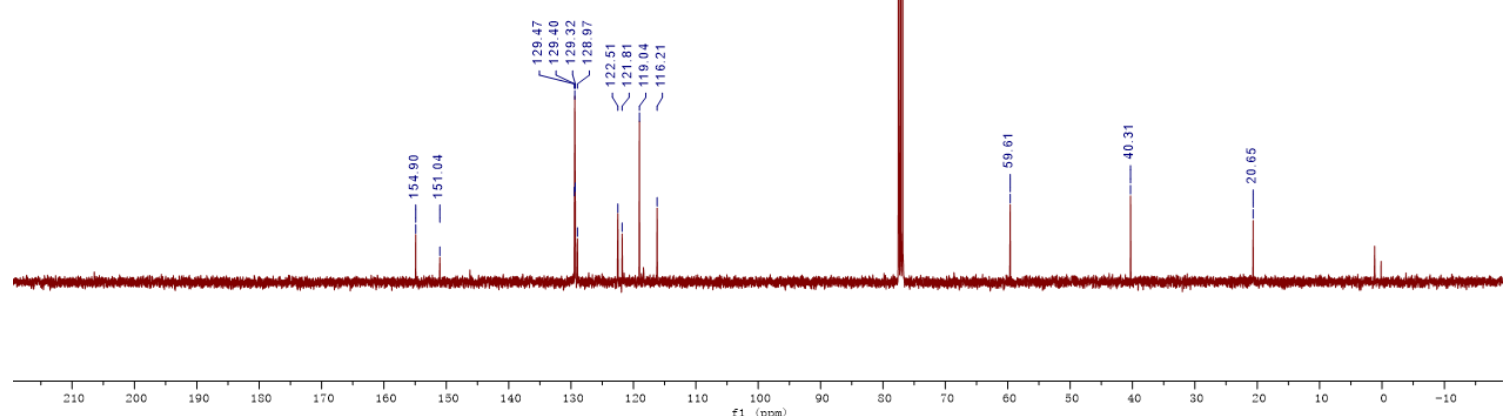

Figure S6. ${ }^{1} \mathrm{H}$ NMR and ${ }^{13} \mathrm{C}\left\{{ }^{1} \mathrm{H}\right\}$ NMR spectra of $\mathbf{3 b}$ 

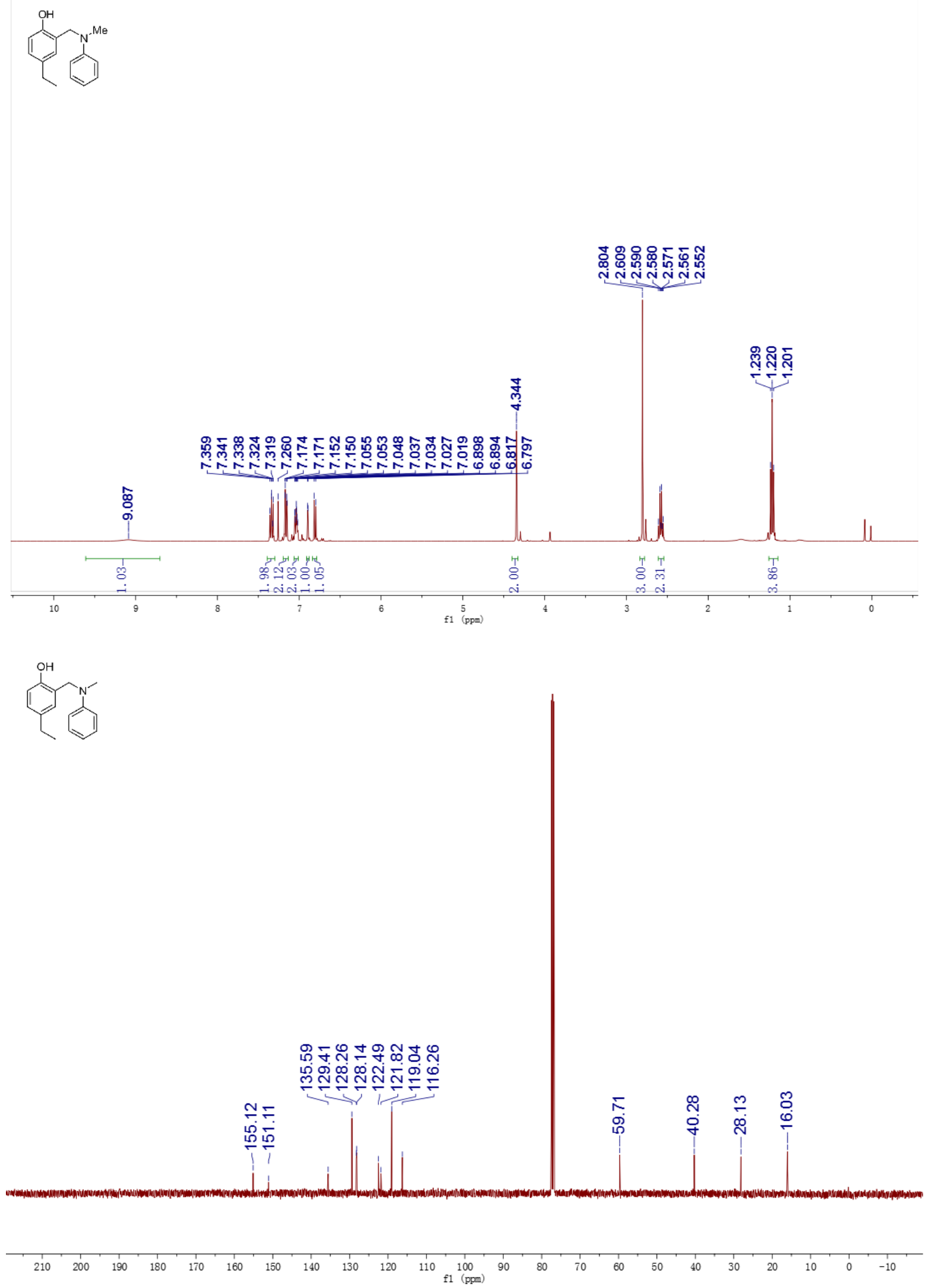

Figure S7. ${ }^{1} \mathrm{H}$ NMR and ${ }^{13} \mathrm{C}\left\{{ }^{1} \mathrm{H}\right\}$ NMR spectra of $\mathbf{3 c}$ 


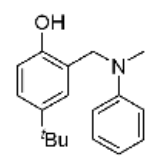

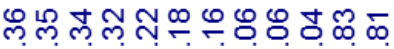

NNNNNNNNG

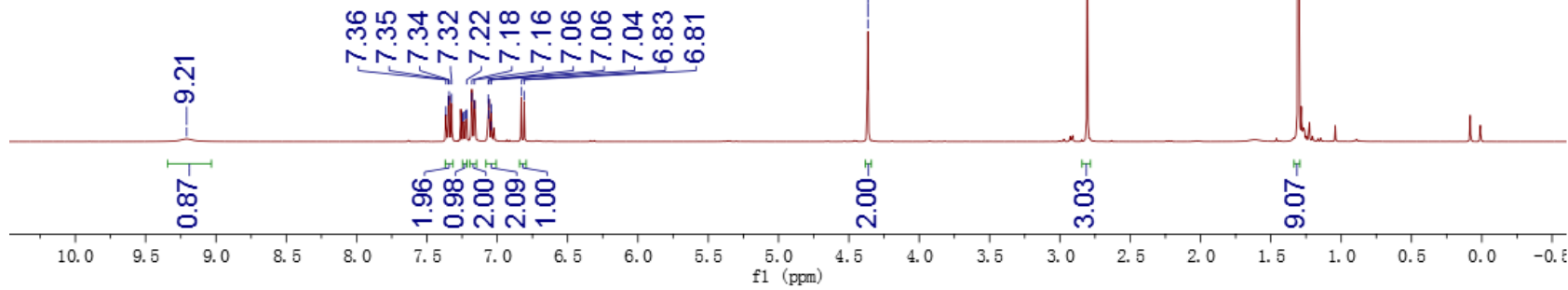

(-Bu

${ }^{13} \mathrm{C}\{\mathrm{H}\} \mathrm{NMR}\left(100 \mathrm{MHz}, \mathrm{CDCl}_{3}\right)$

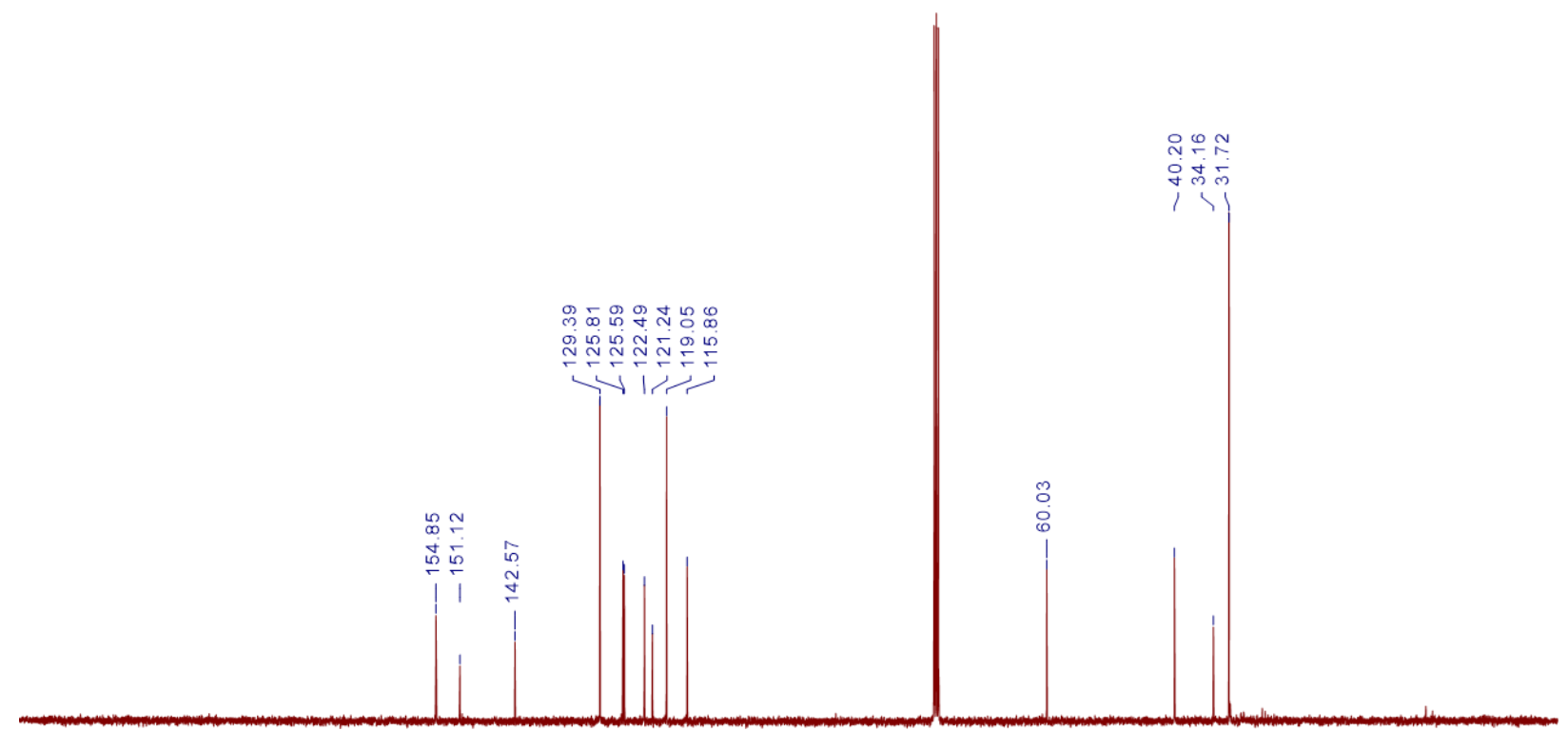

Figure S8. ${ }^{1} \mathrm{H}$ NMR and ${ }^{13} \mathrm{C}\left\{{ }^{1} \mathrm{H}\right\}$ NMR spectra of 3d 

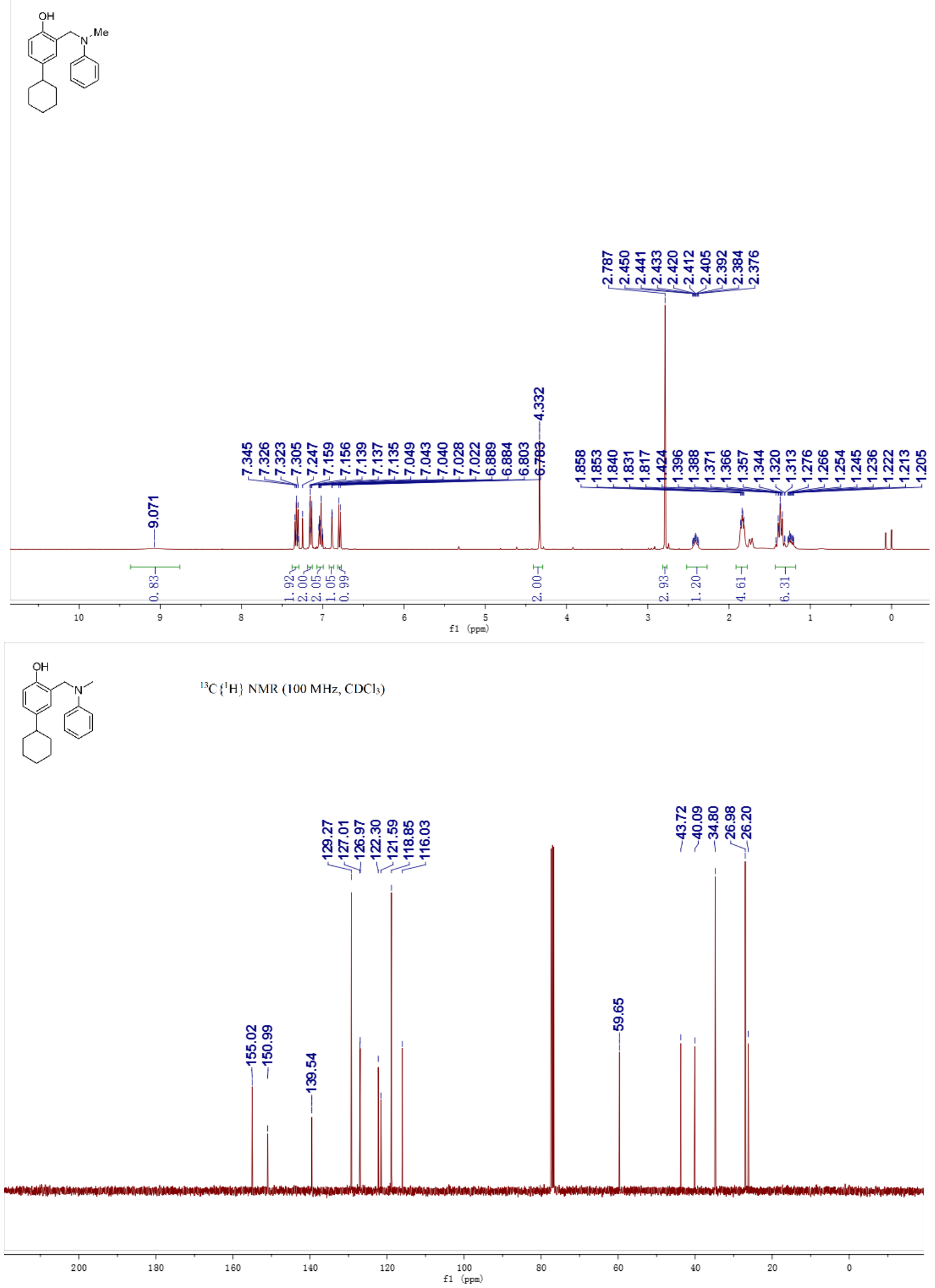

Figure S9. ${ }^{1} \mathrm{H}$ NMR and ${ }^{13} \mathrm{C}\left\{{ }^{1} \mathrm{H}\right\}$ NMR spectra of $\mathbf{3 e}$ 


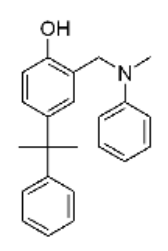

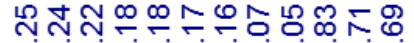

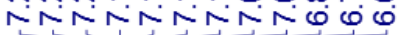

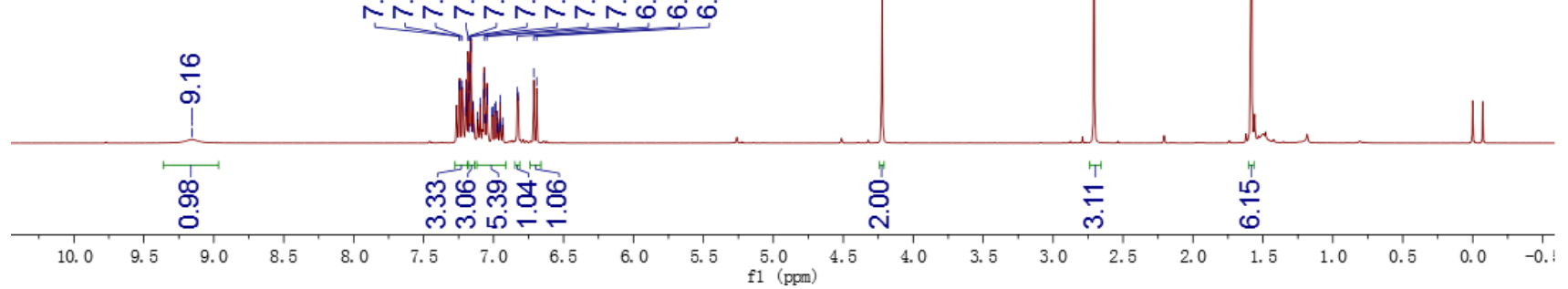

(1)

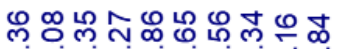

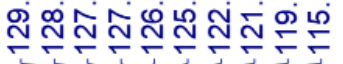

단으으

ม่าน

능우용

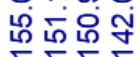

$\begin{array}{lllllllll}210 & 200 & 190 & 180 & 170 & 160 & 150 & 140 & 130\end{array}$

$110 \quad 100$

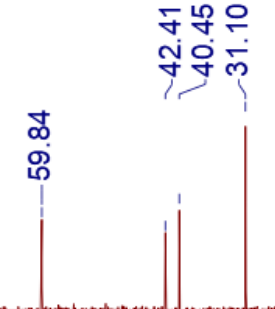


Figure S10. ${ }^{1} \mathrm{H}$ NMR and ${ }^{13} \mathrm{C}\left\{{ }^{1} \mathrm{H}\right\}$ NMR spectra of $\mathbf{3 f}$<smiles>CN(Cc1ccccc1)Cc1ccccc1-c1ccccc1</smiles>

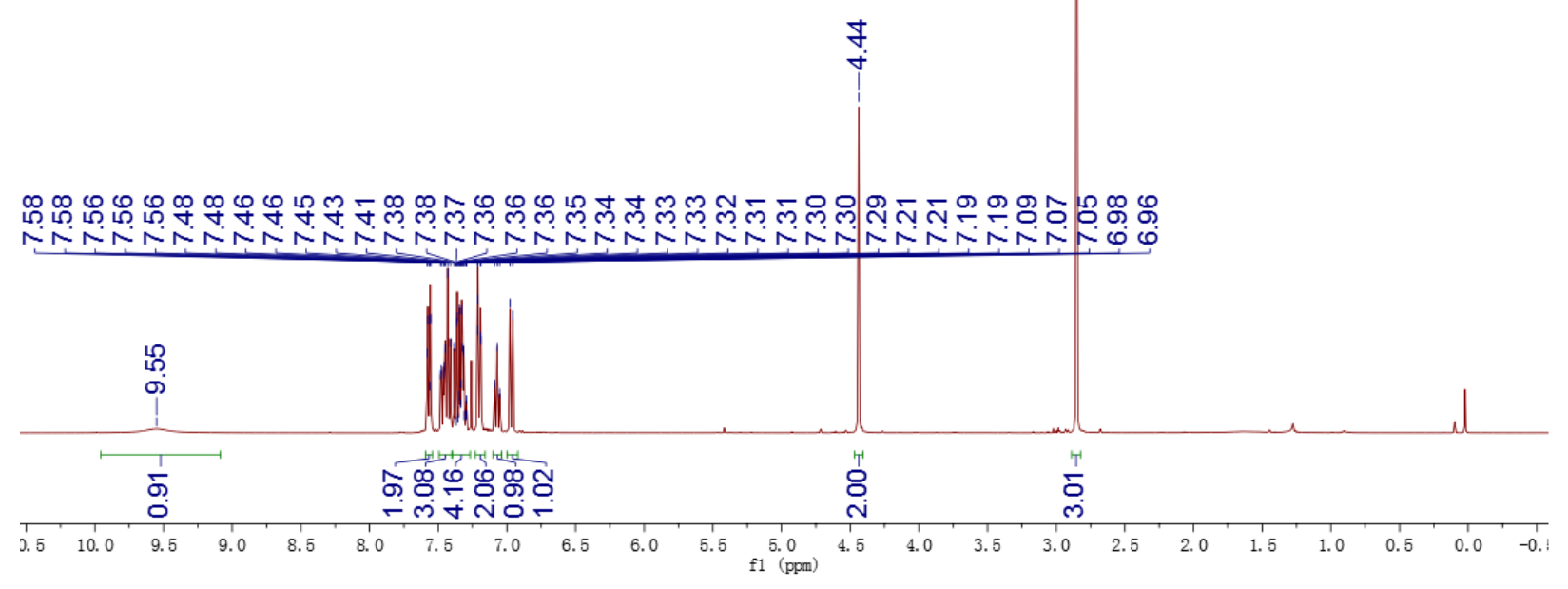
(1)

${ }^{13} \mathrm{C}\{\mathrm{H}\} \mathrm{NMR}\left(100 \mathrm{MHz}, \mathrm{CDCl}_{3}\right)$

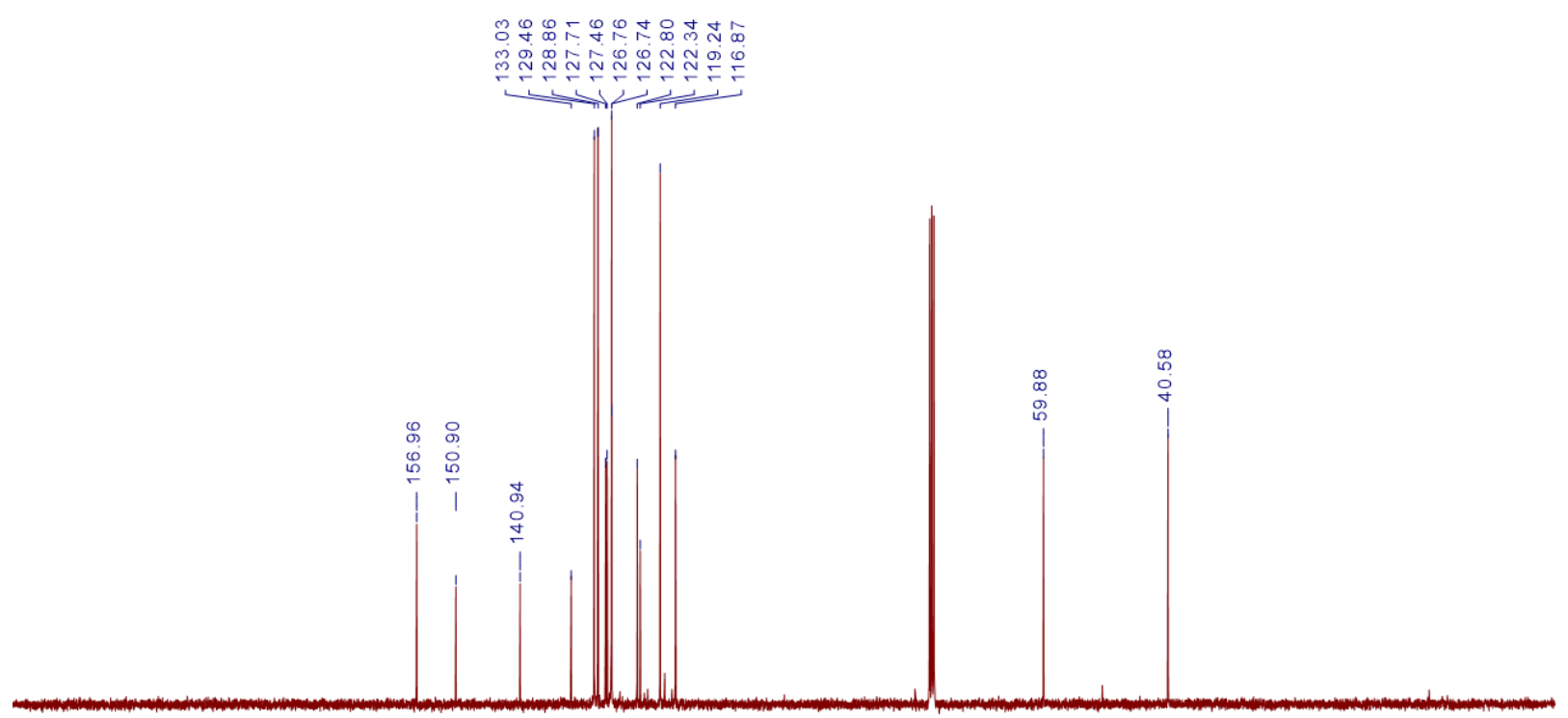

Figure S11. ${ }^{1} \mathrm{H}$ NMR and ${ }^{13} \mathrm{C}\left\{{ }^{1} \mathrm{H}\right\}$ NMR spectra of $\mathbf{3 g}$ 
<smiles>CN(Cc1ccccc1)c1cccc(O)c1</smiles>

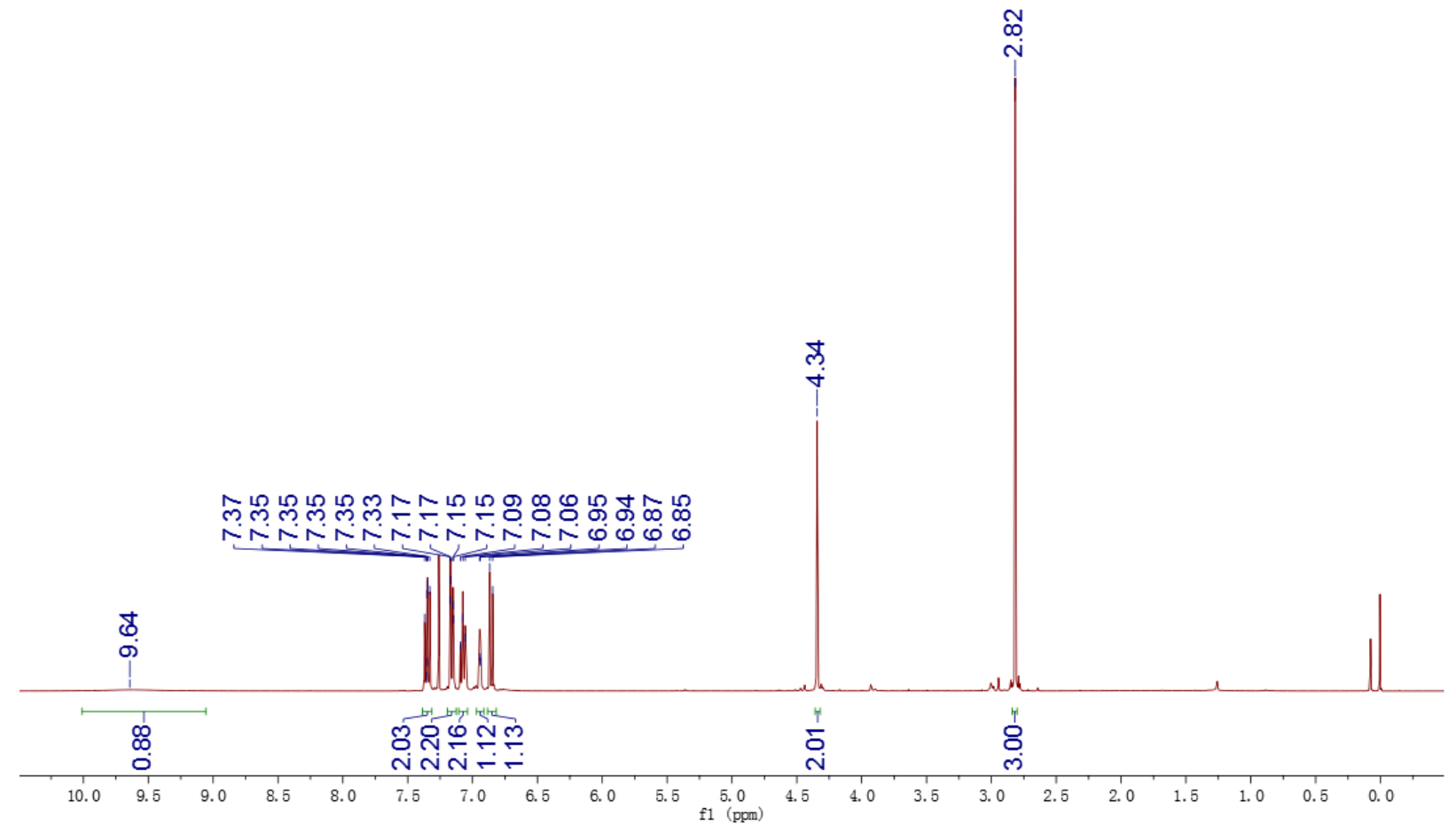

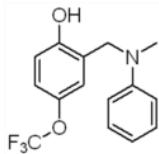

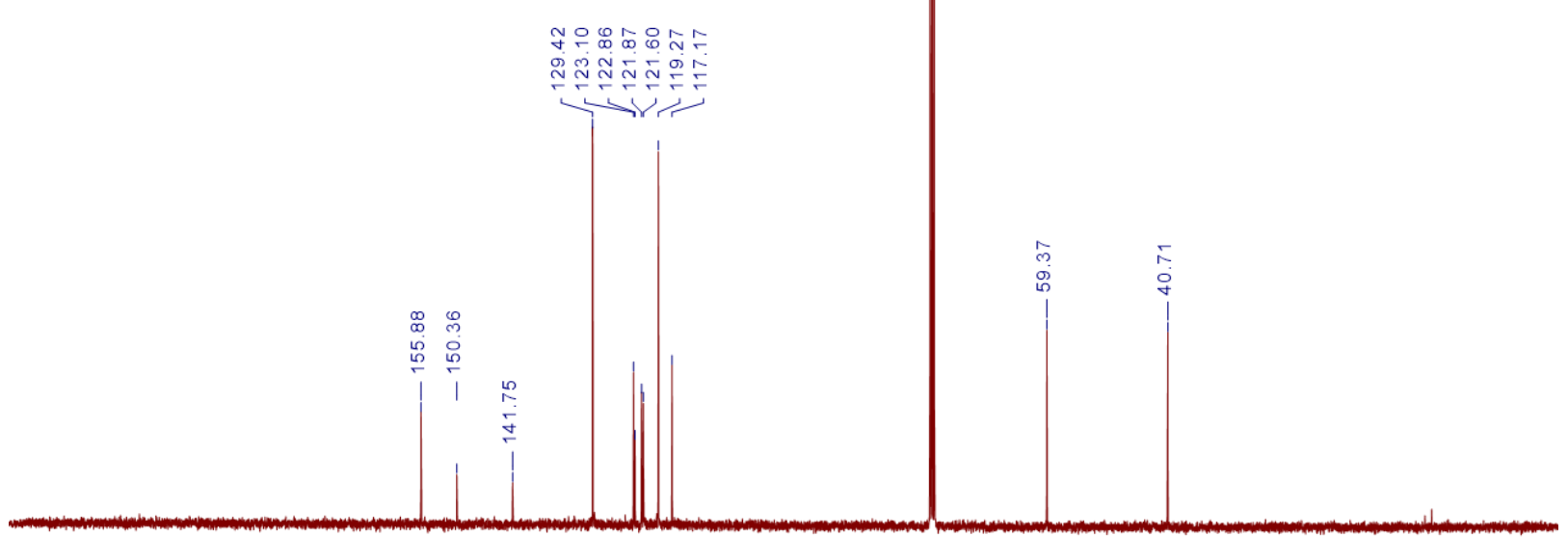

Figure S12 ${ }^{1} \mathrm{H}$ NMR and ${ }^{13} \mathrm{C}\left\{{ }^{1} \mathrm{H}\right\}$ NMR spectra of $\mathbf{3 h}$ 

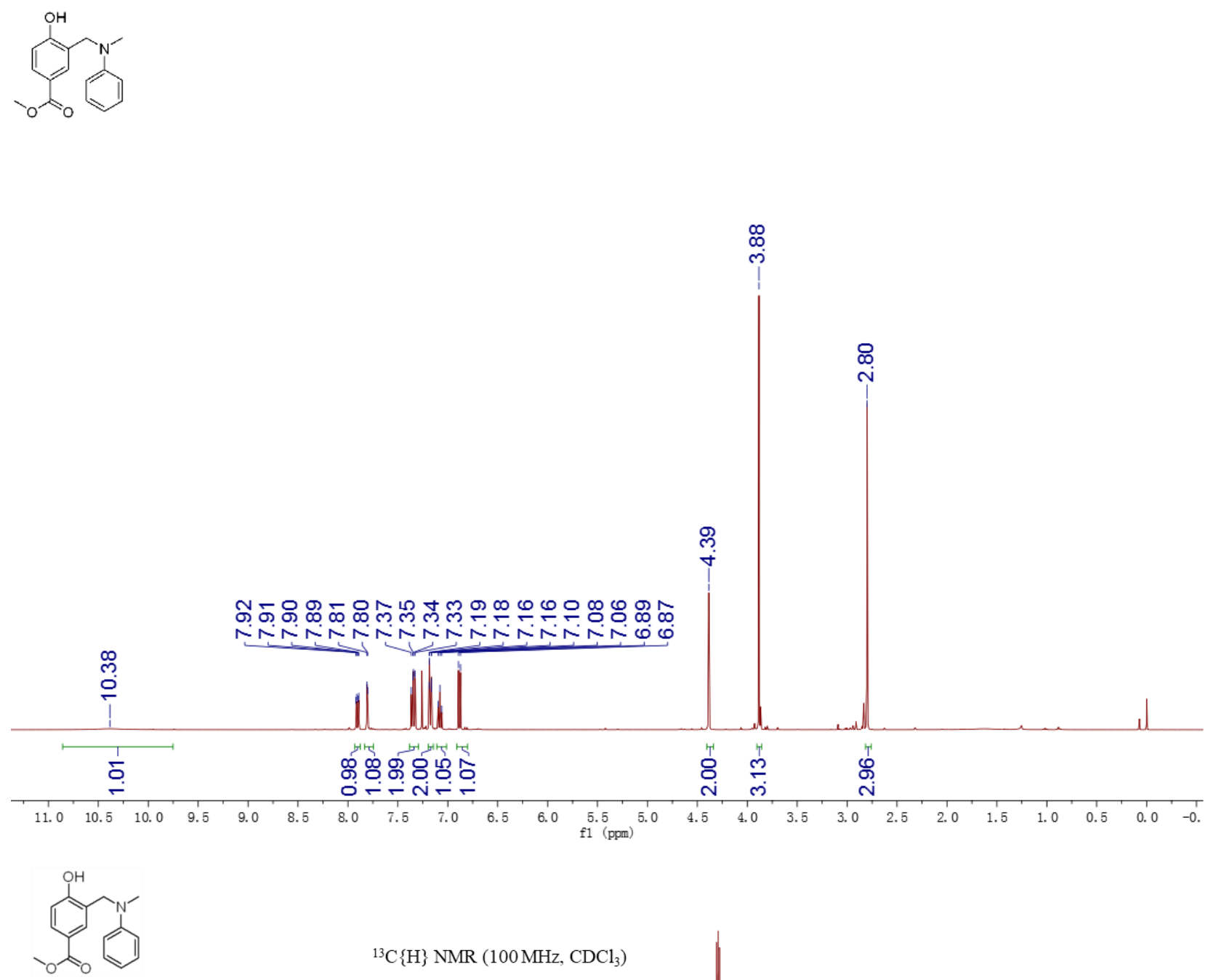

${ }^{13} \mathrm{C}\{\mathrm{H}\} \mathrm{NMR}\left(100 \mathrm{MHz}, \mathrm{CDCl}_{3}\right)$

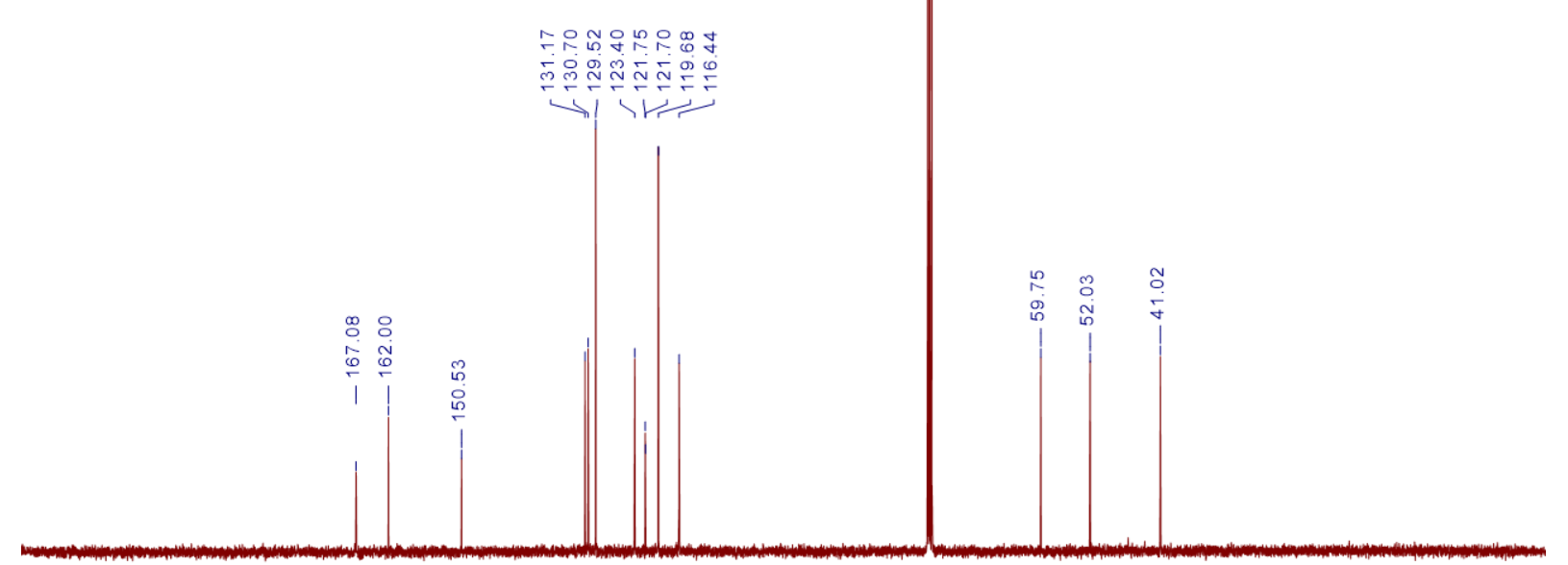

Figure S13. ${ }^{1} \mathrm{H}$ NMR and ${ }^{13} \mathrm{C}\left\{{ }^{1} \mathrm{H}\right\}$ NMR spectra of $\mathbf{3 i}$ 


\section{5}

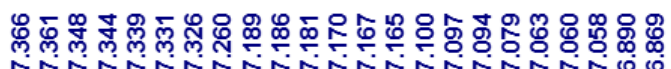
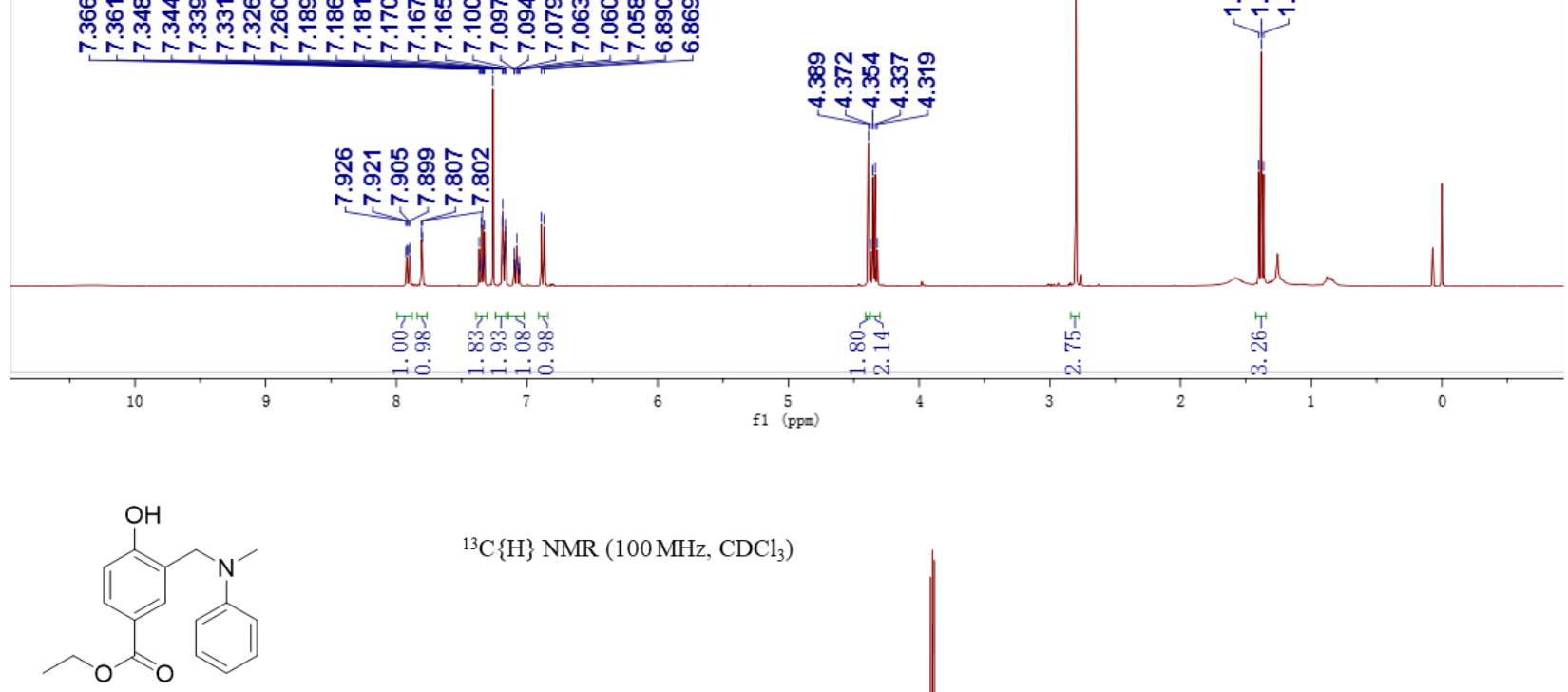

${ }^{13} \mathrm{C}\{\mathrm{H}\} \mathrm{NMR}\left(100 \mathrm{MHz}, \mathrm{CDCl}_{3}\right)$
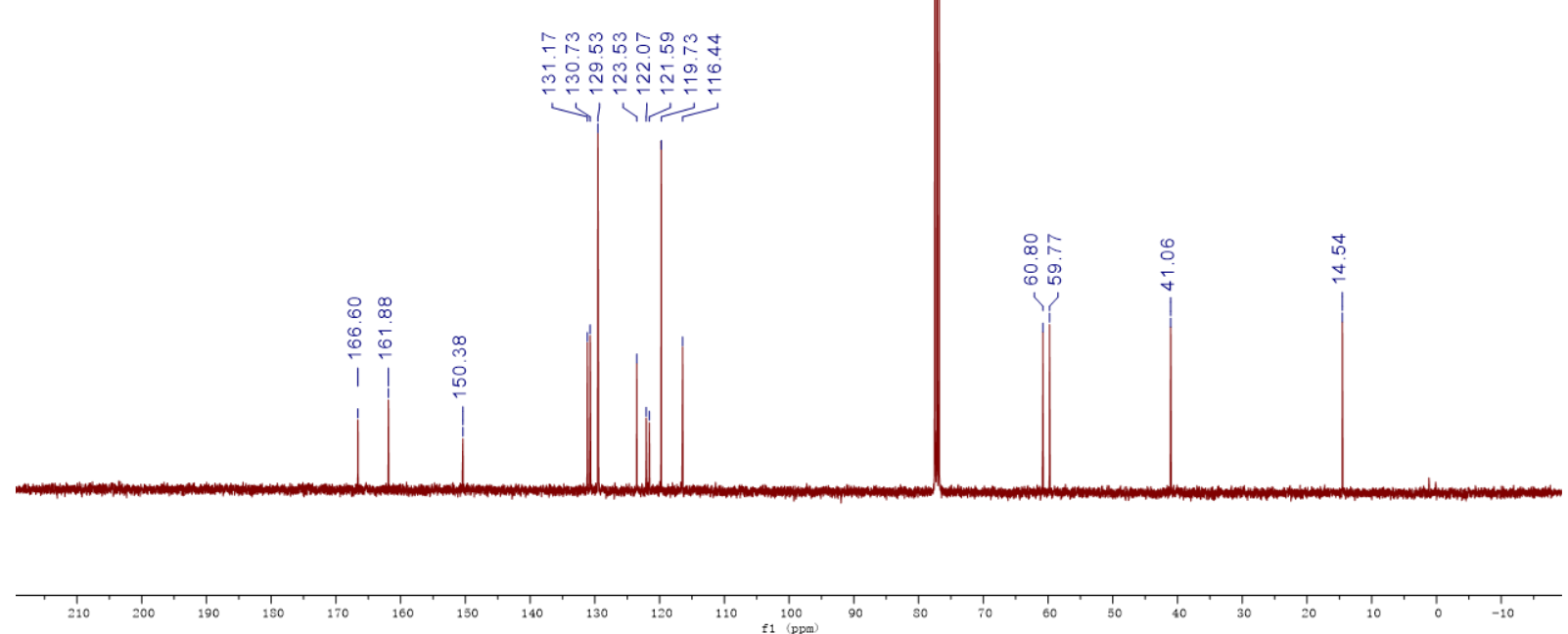

Figure S14. ${ }^{1} \mathrm{H}$ NMR and ${ }^{13} \mathrm{C}\left\{{ }^{1} \mathrm{H}\right\}$ NMR spectra of $\mathbf{3 j}$ 

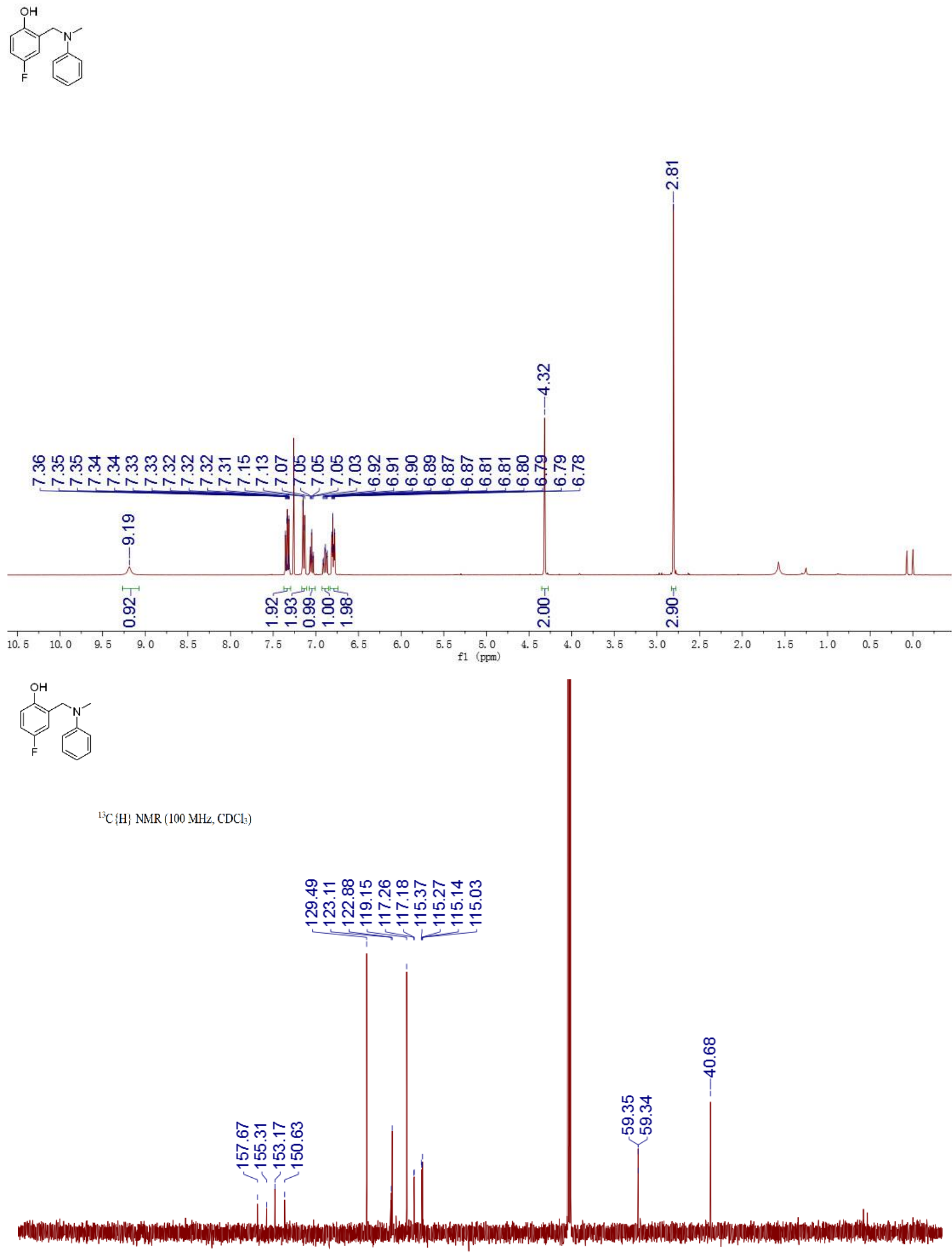

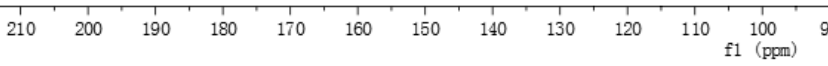

Figure S15. ${ }^{1} \mathrm{H}$ NMR and ${ }^{13} \mathrm{C}\left\{{ }^{1} \mathrm{H}\right\}$ NMR spectra of $\mathbf{3 k}$ 


\section{(1)}

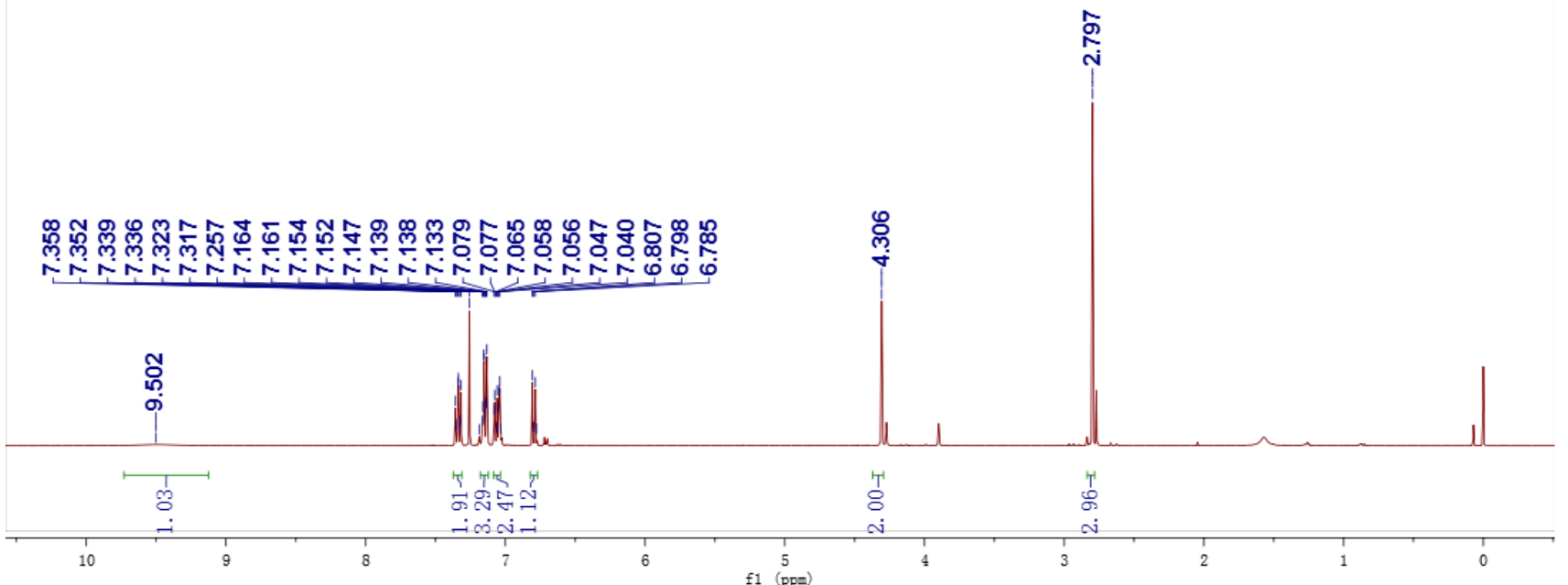

(1)

${ }^{13} \mathrm{C}\{\mathrm{H}\} \mathrm{NMR}\left(100 \mathrm{MHz}, \mathrm{CDCl}_{3}\right)$

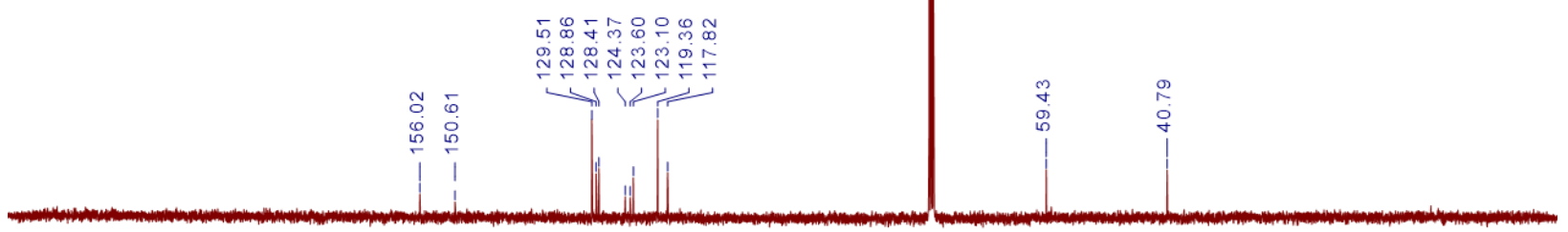

Figure S16. ${ }^{1} \mathrm{H}$ NMR and ${ }^{13} \mathrm{C}\left\{{ }^{1} \mathrm{H}\right\}$ NMR spectra of $\mathbf{3 l}$ 

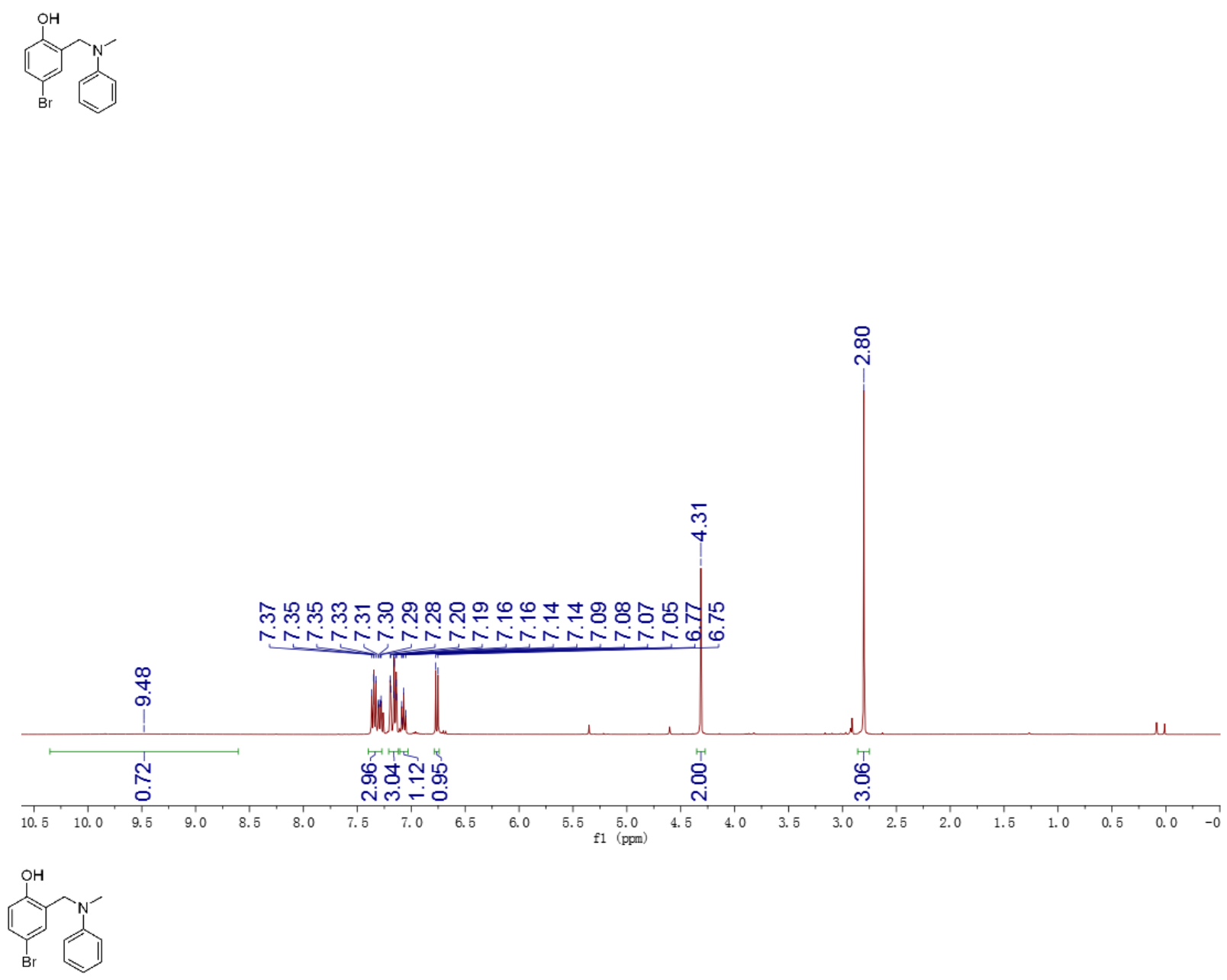

${ }^{19} \mathrm{C}\left\{\right.$ II $\left.^{\mathrm{H}}\right\}$ NMR (100 MH7, $\left.\mathrm{CDCl}_{3}\right)$
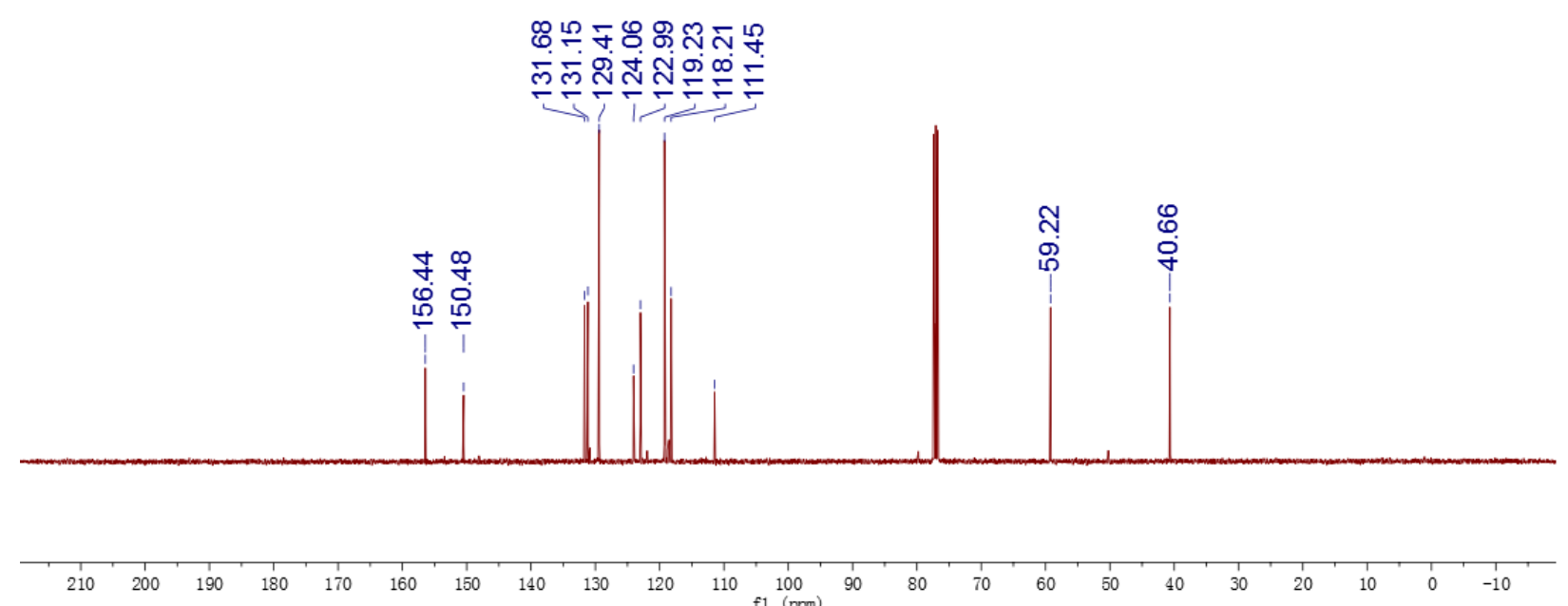

Figure S17. ${ }^{1} \mathrm{H}$ NMR and ${ }^{13} \mathrm{C}\left\{{ }^{1} \mathrm{H}\right\}$ NMR spectra of $\mathbf{3 m}$ 

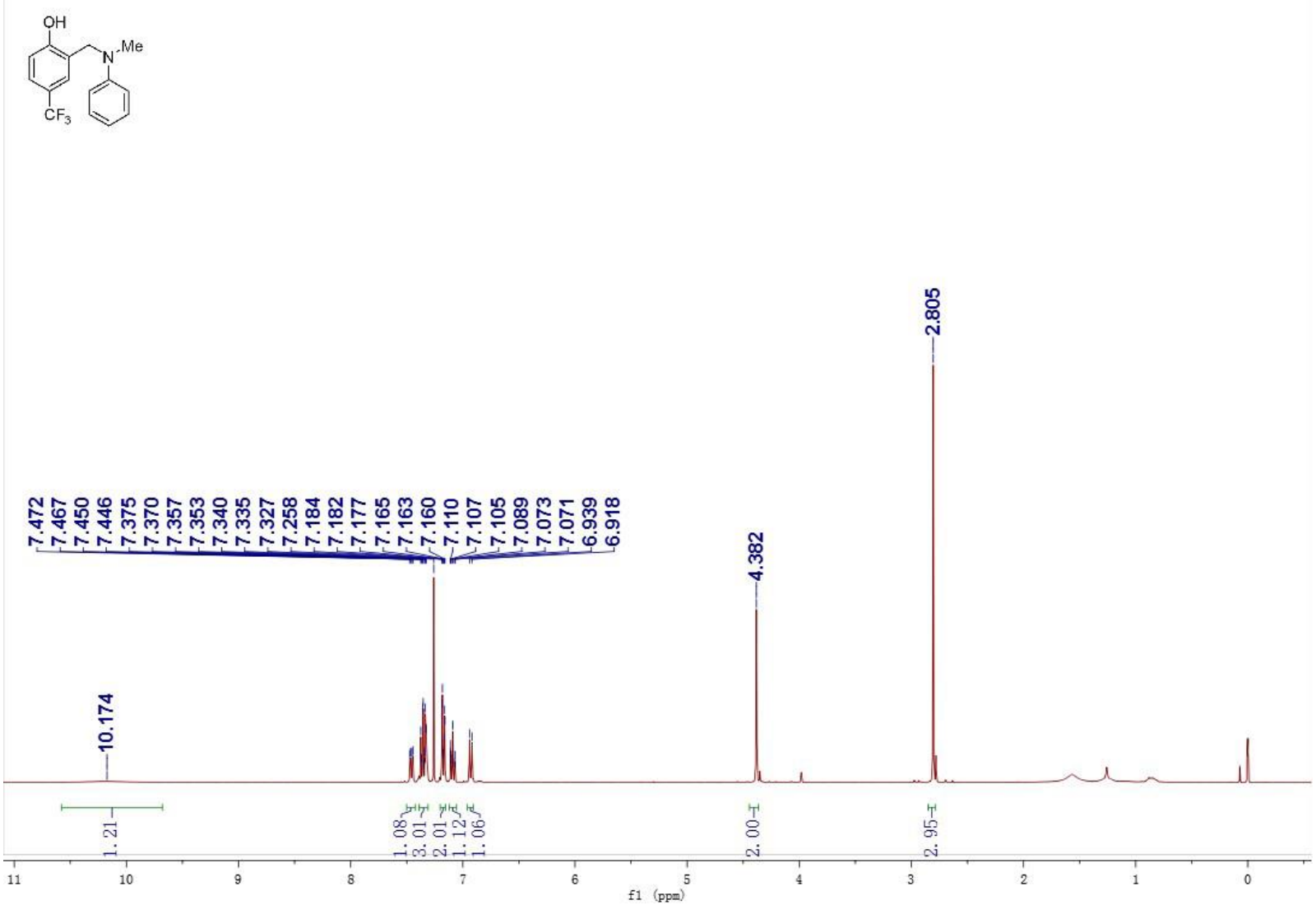

${ }^{13} \mathrm{C}\left\{{ }_{\{}^{1} \mathrm{H}\right\} \mathrm{NMR}(100 \mathrm{MHz}, \mathrm{CDCl} 3)$

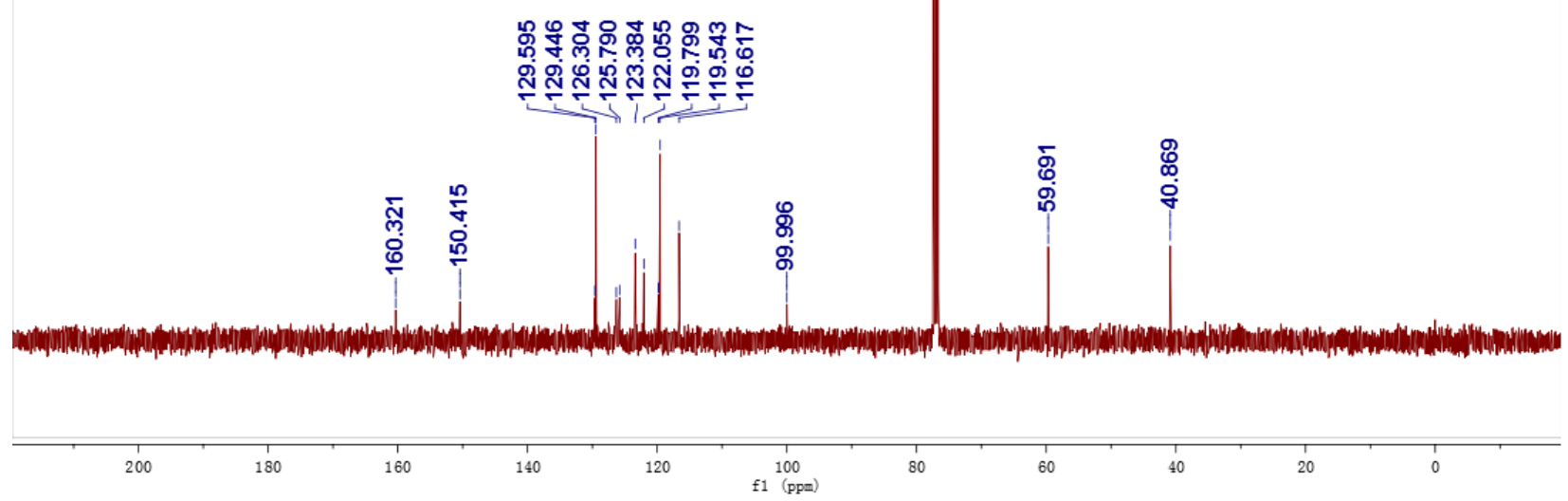

Figure S18. ${ }^{1} \mathrm{H}$ NMR and ${ }^{13} \mathrm{C}\left\{{ }^{1} \mathrm{H}\right\}$ NMR spectra of $\mathbf{3 n}$ 

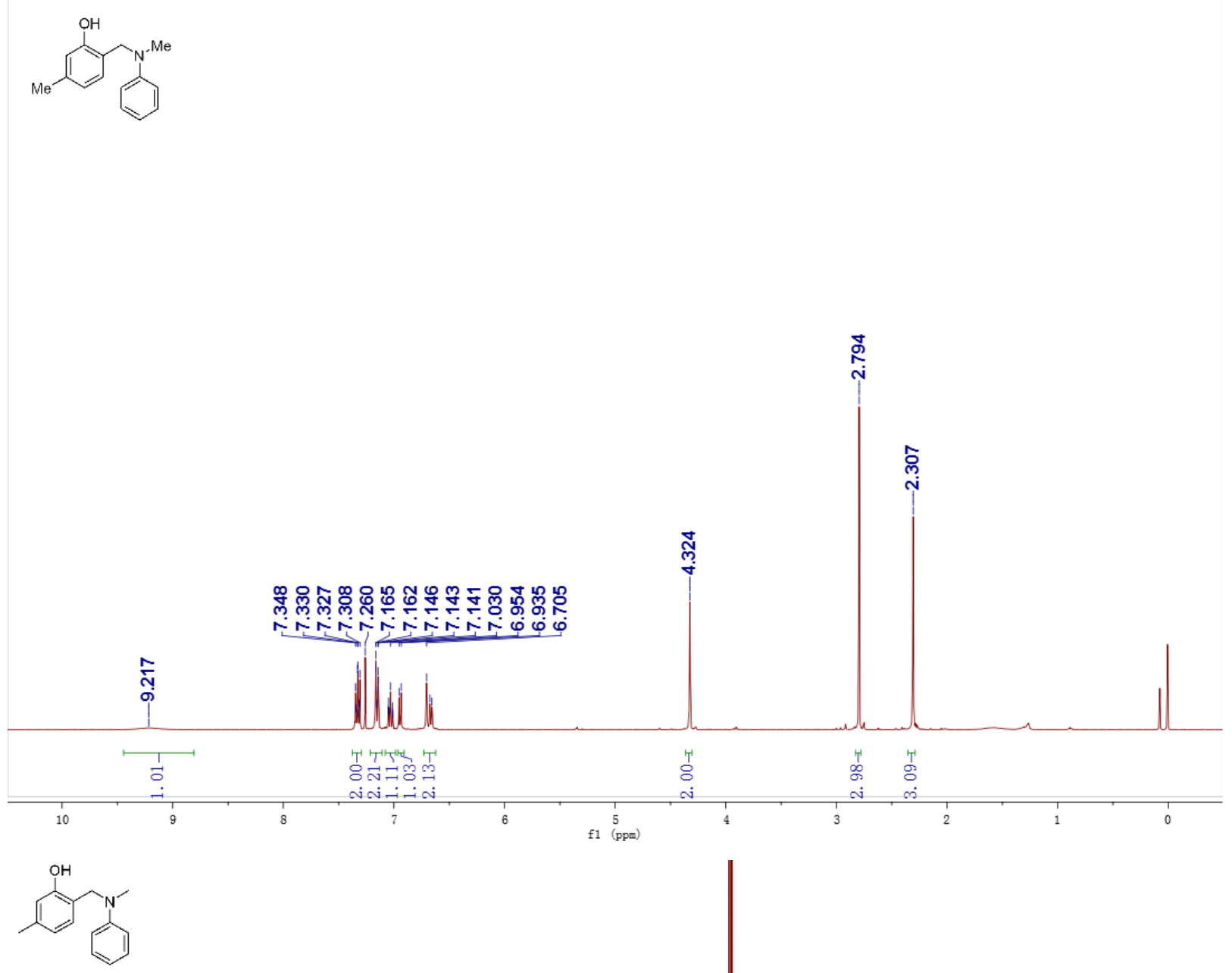

${ }^{\mathrm{I} C}$ (III\} NMR (100 Mllz, $\left.\mathrm{CDCl}_{3}\right)$

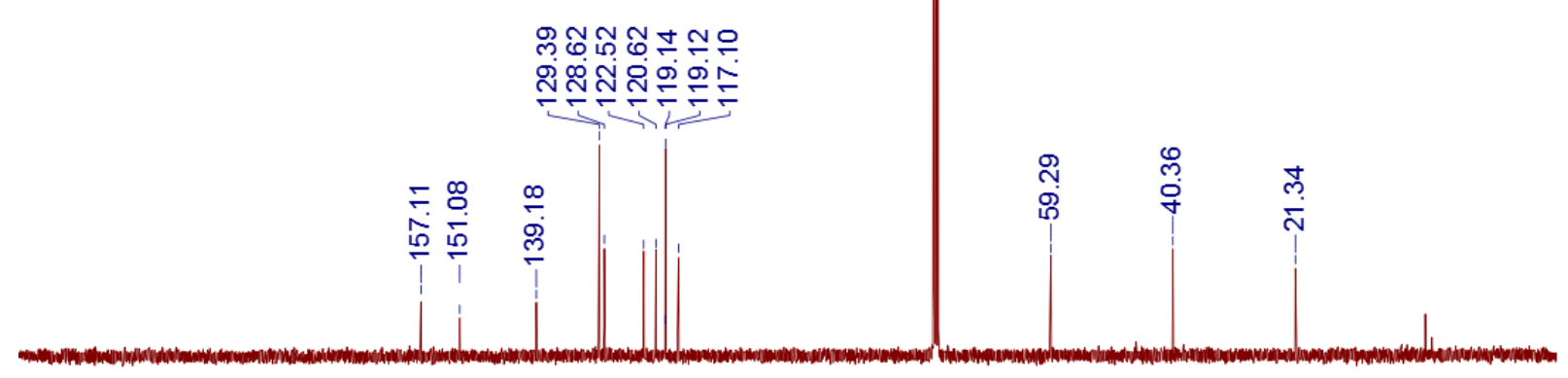

$\begin{array}{llllllllllll}210 & 200 & 190 & 180 & 170 & 160 & 150 & 140 & 130 & 120 & 110 & 100 \\ \mathrm{f} 1 & (\mathrm{pp})\end{array}$

Figure S19. ${ }^{1} \mathrm{H}$ NMR and ${ }^{13} \mathrm{C}\left\{{ }^{1} \mathrm{H}\right\}$ NMR spectra of 30 


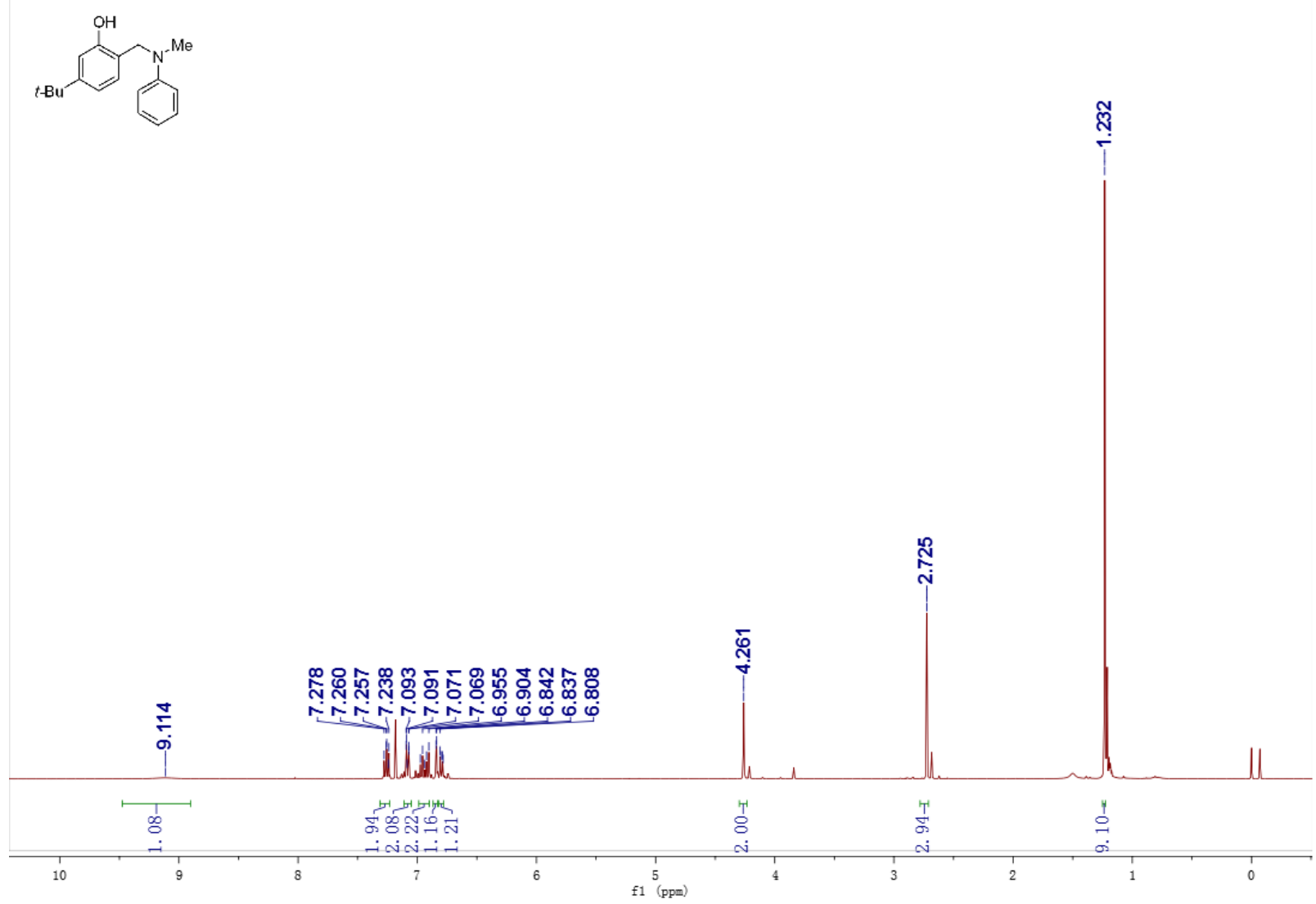<smiles>CCN1CC2CC3CC(C2)CC1C3</smiles>

${ }^{13} \mathrm{C}\{\mathrm{H}\}$ NMR $\left(100 \mathrm{MHz}, \mathrm{CDCl}_{3}\right)$
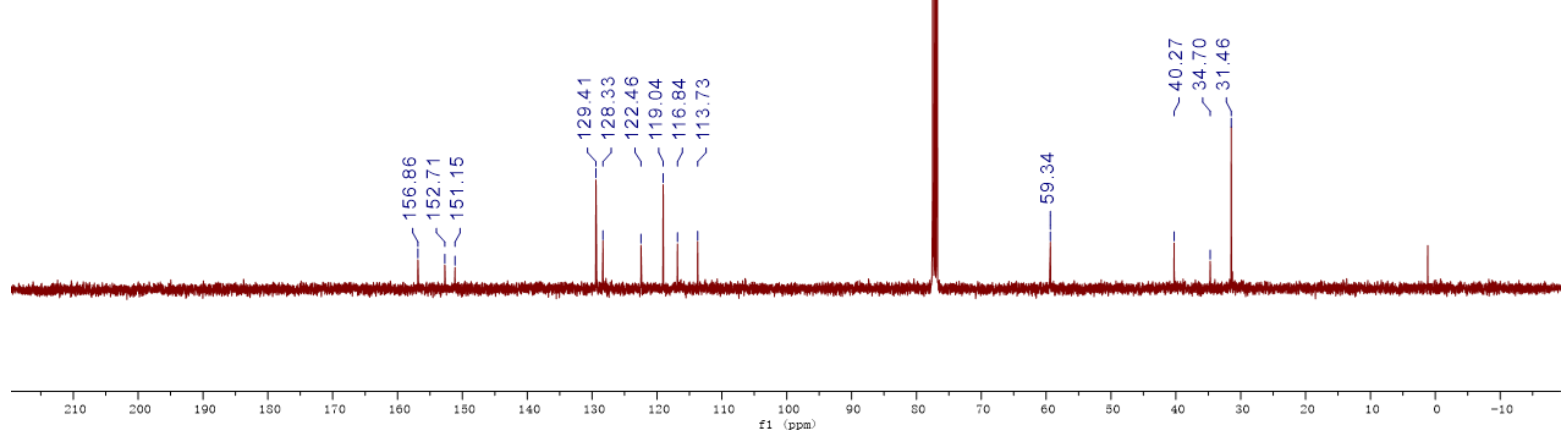

Figure S20. ${ }^{1} \mathrm{H}$ NMR and ${ }^{13} \mathrm{C}\left\{{ }^{1} \mathrm{H}\right\}$ NMR spectra of $\mathbf{3 p}$ 

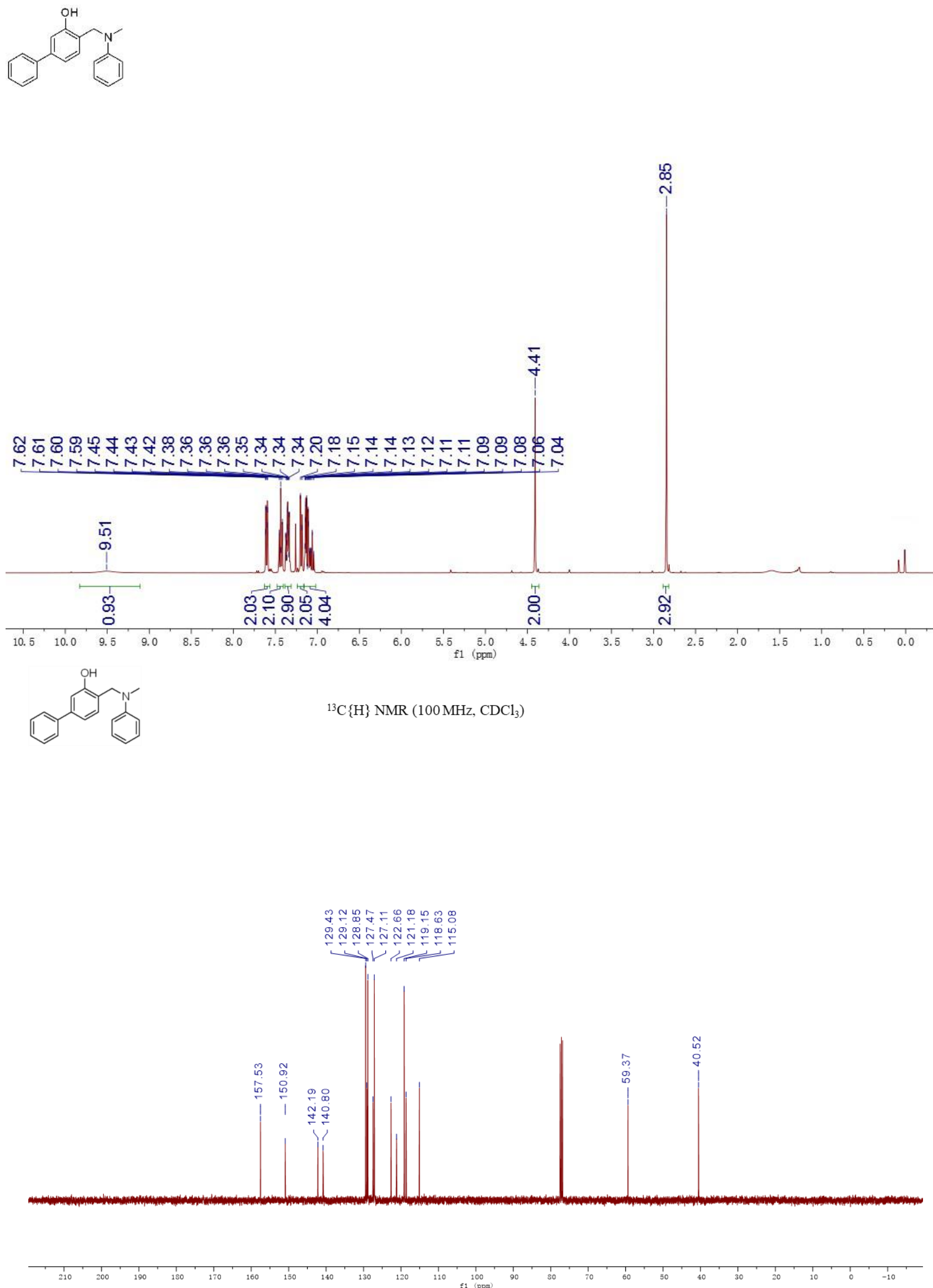

Figure S21. ${ }^{1} \mathrm{H}$ NMR and ${ }^{13} \mathrm{C}\left\{{ }^{1} \mathrm{H}\right\}$ NMR spectra of $\mathbf{3 q}$ 


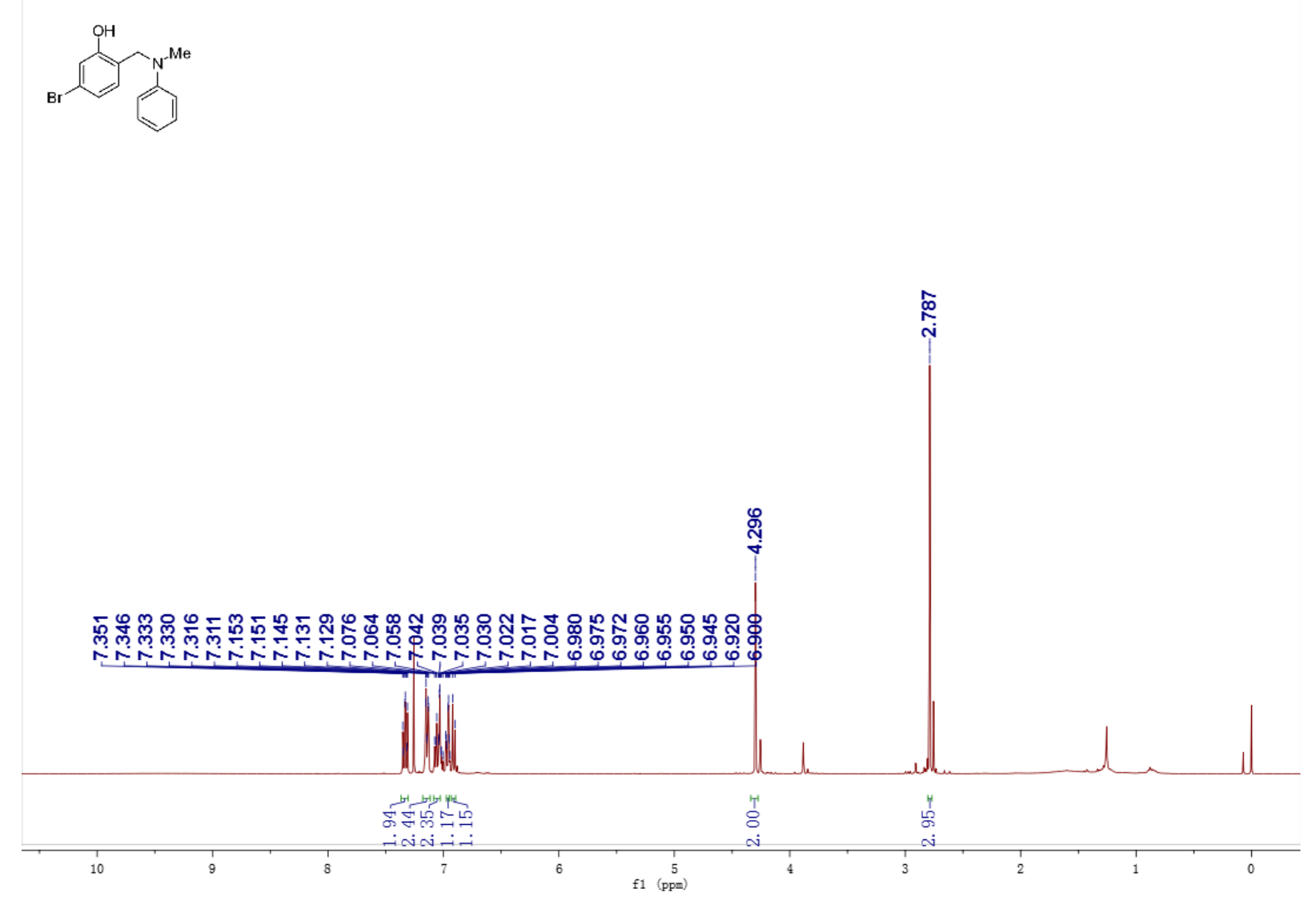
${ }^{13} \mathrm{C}\{\mathrm{H}\} \mathrm{NMR}\left(100 \mathrm{MHz}, \mathrm{CDCl}_{3}\right)$

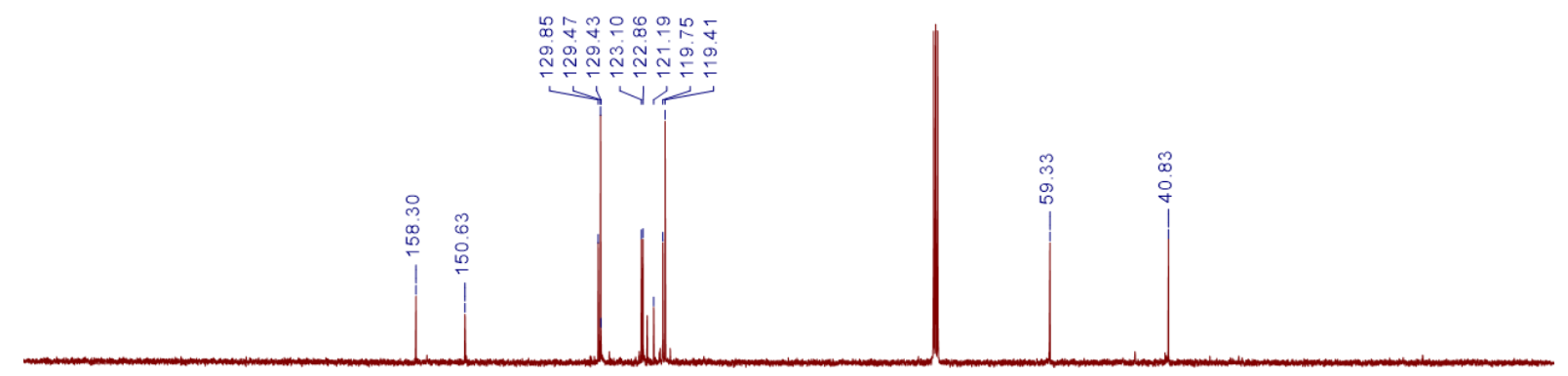

Figure S22. ${ }^{1} \mathrm{H}$ NMR and ${ }^{13} \mathrm{C}\left\{{ }^{1} \mathrm{H}\right\}$ NMR spectra of $\mathbf{3 r}$ 

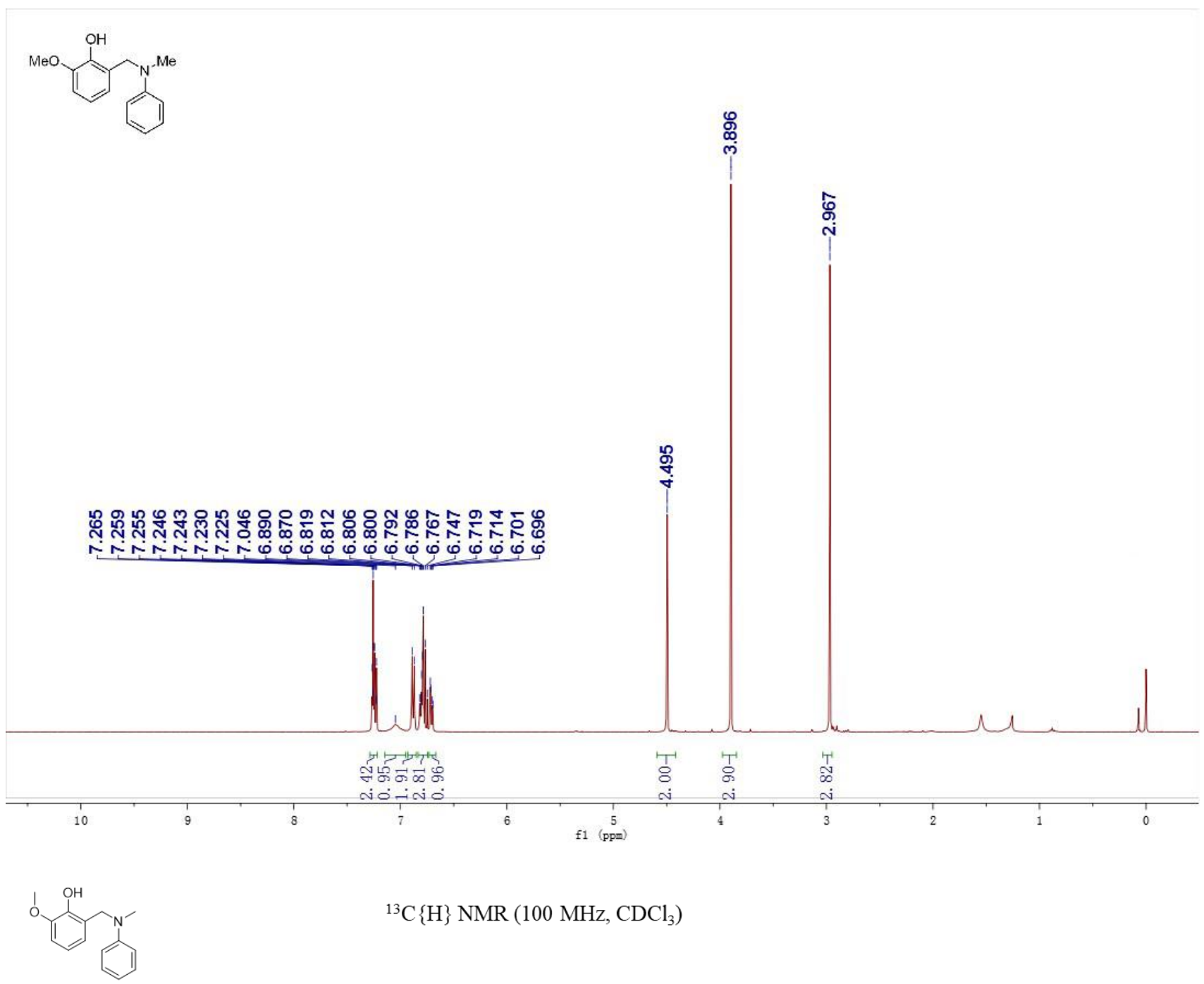

${ }^{13} \mathrm{C}\{\mathrm{H}\} \mathrm{NMR}\left(100 \mathrm{MHz}, \mathrm{CDCl}_{3}\right)$

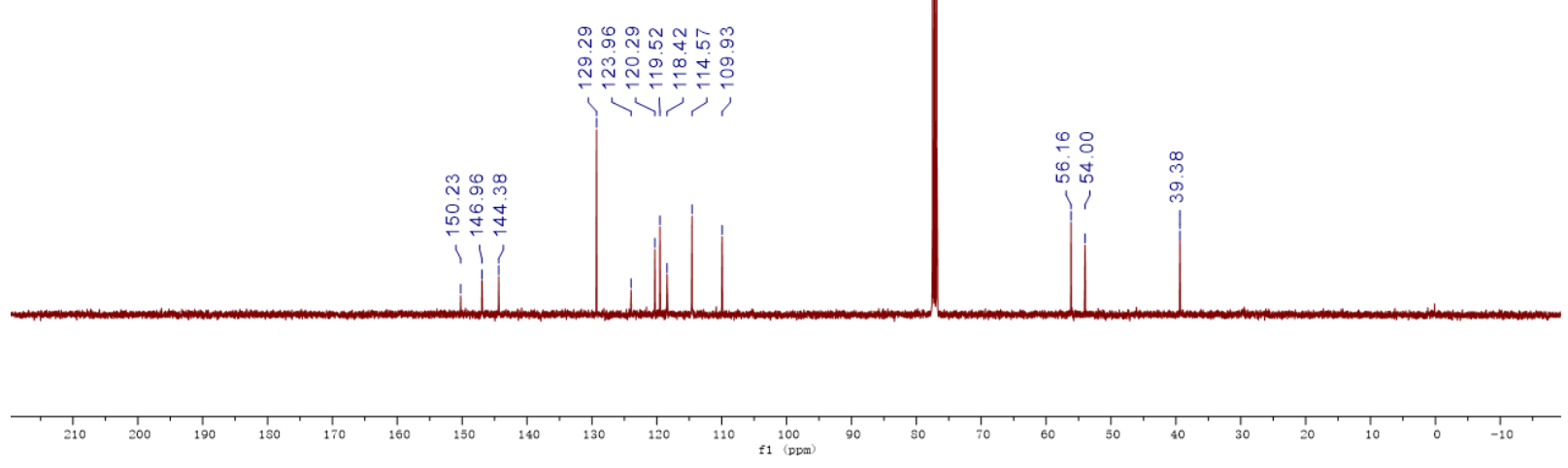

Figure S23. ${ }^{1} \mathrm{H}$ NMR and ${ }^{13} \mathrm{C}\left\{{ }^{1} \mathrm{H}\right\}$ NMR spectra of Bs

S29 

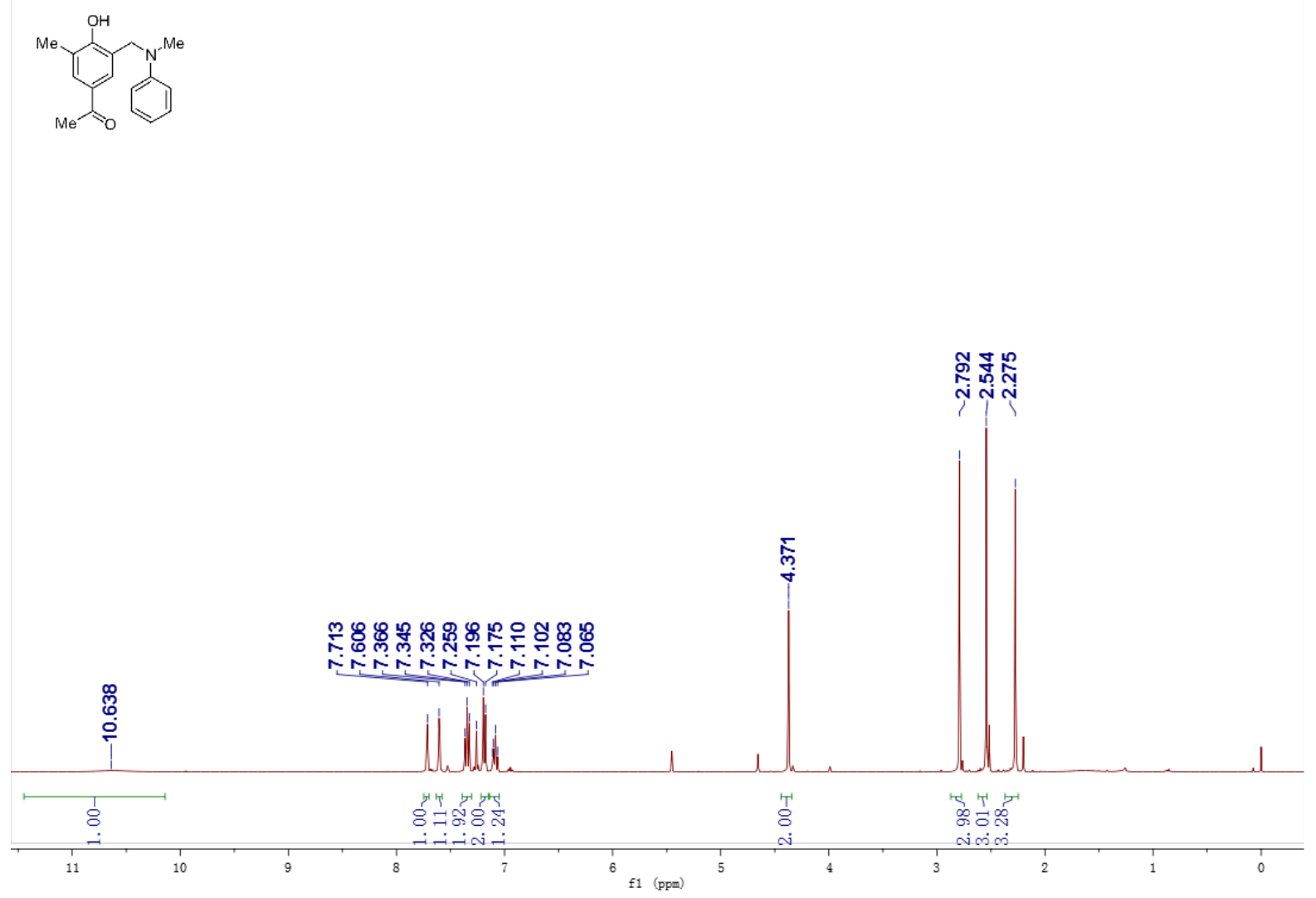

(1)

${ }^{13} \mathrm{C}\left\{{ }^{1} \mathrm{H}\right\} \mathrm{NMR}\left(100 \mathrm{MHz}, \mathrm{CDCl}_{3}\right)$

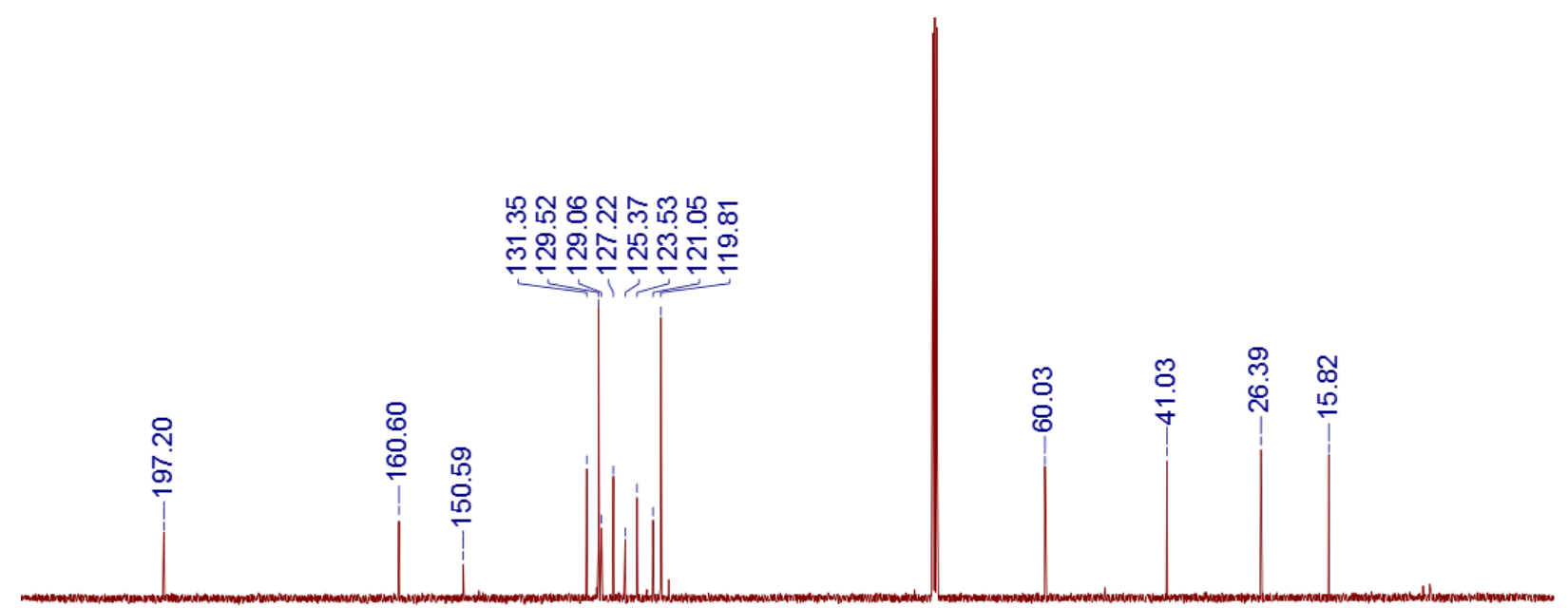

$\begin{array}{llllllllllll}210 & 200 & 190 & 180 & 170 & 160 & 150 & 140 & 130 & 120 & 110 & 100\end{array}$

Figure S24. ${ }^{1} \mathrm{H}$ NMR and ${ }^{13} \mathrm{C}\left\{{ }^{1} \mathrm{H}\right\}$ NMR spectra of $\mathbf{3 t}$ 

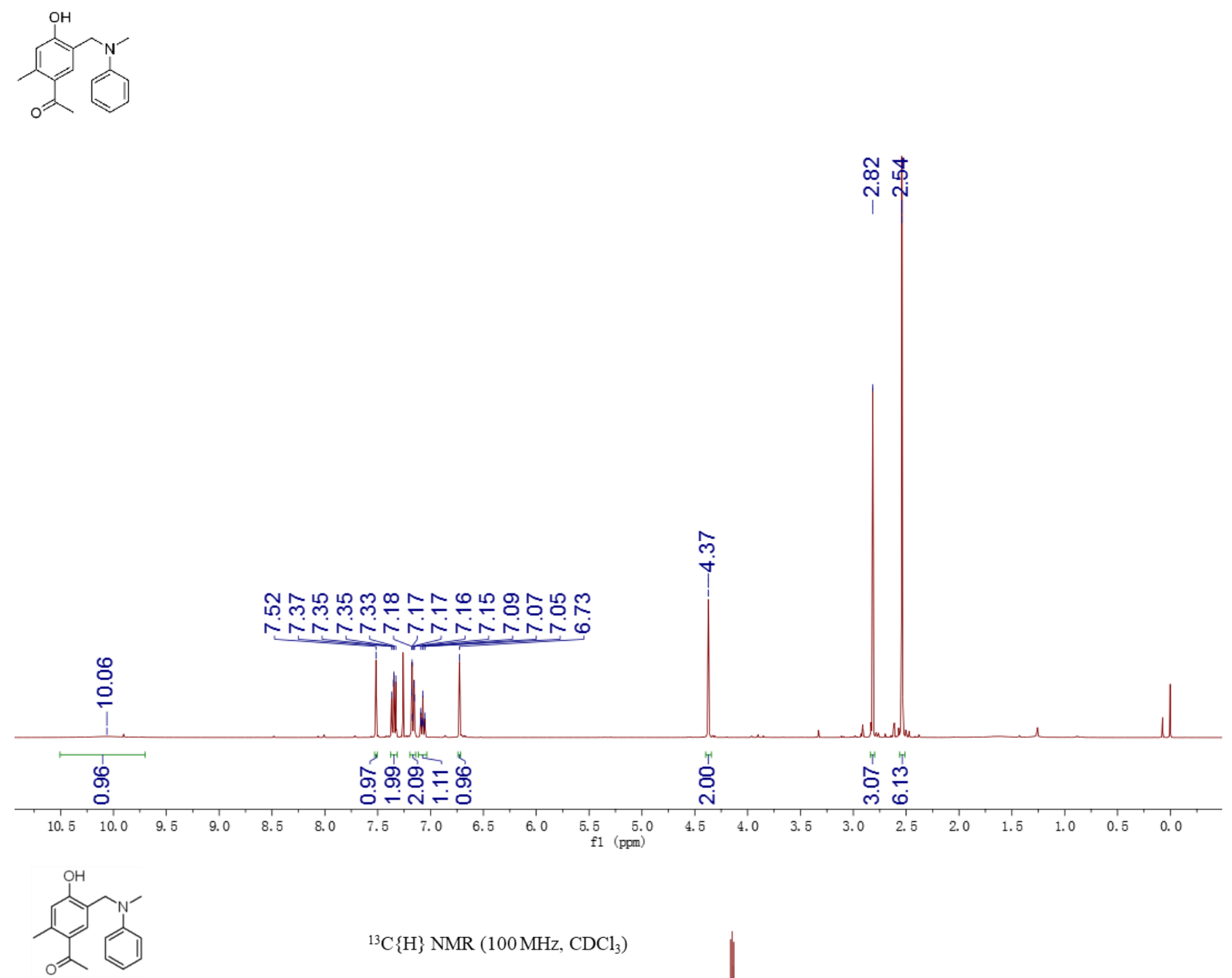

${ }^{13} \mathrm{C}\{\mathrm{H}\} \mathrm{NMR}\left(100 \mathrm{MHz}, \mathrm{CDCl}_{3}\right)$

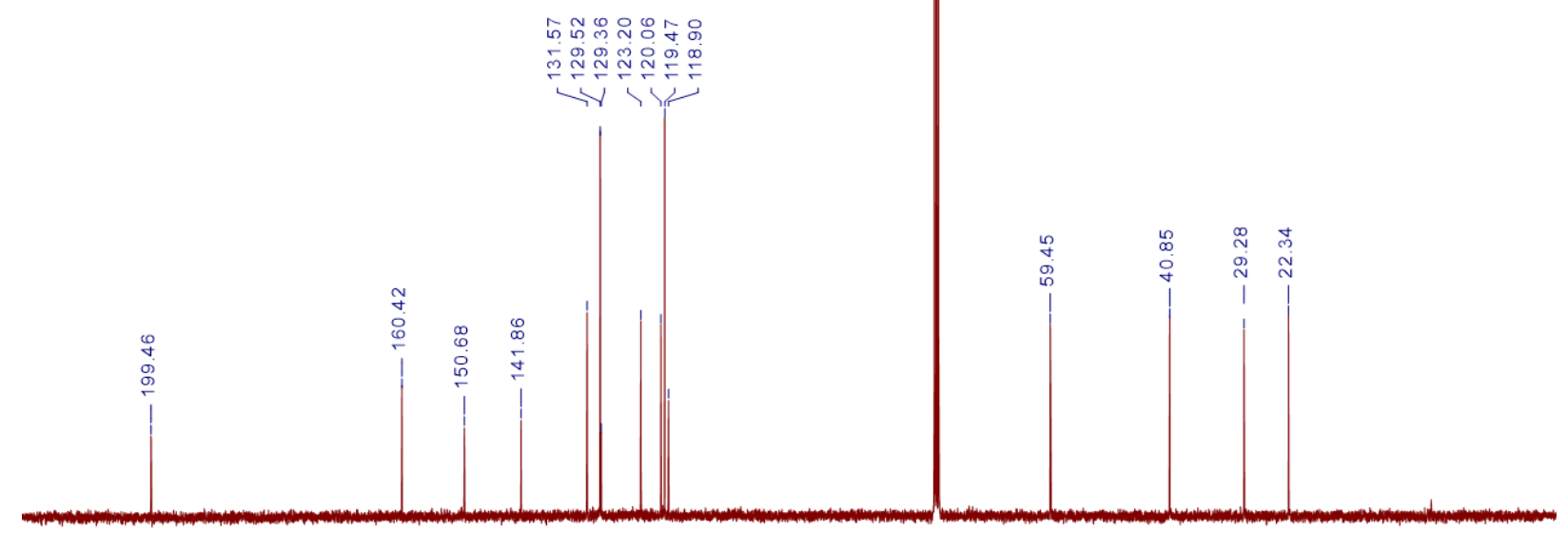

Figure S25. ${ }^{1} \mathrm{H}$ NMR and ${ }^{13} \mathrm{C}\left\{{ }^{1} \mathrm{H}\right\}$ NMR spectra of $\mathbf{3 u}$ 

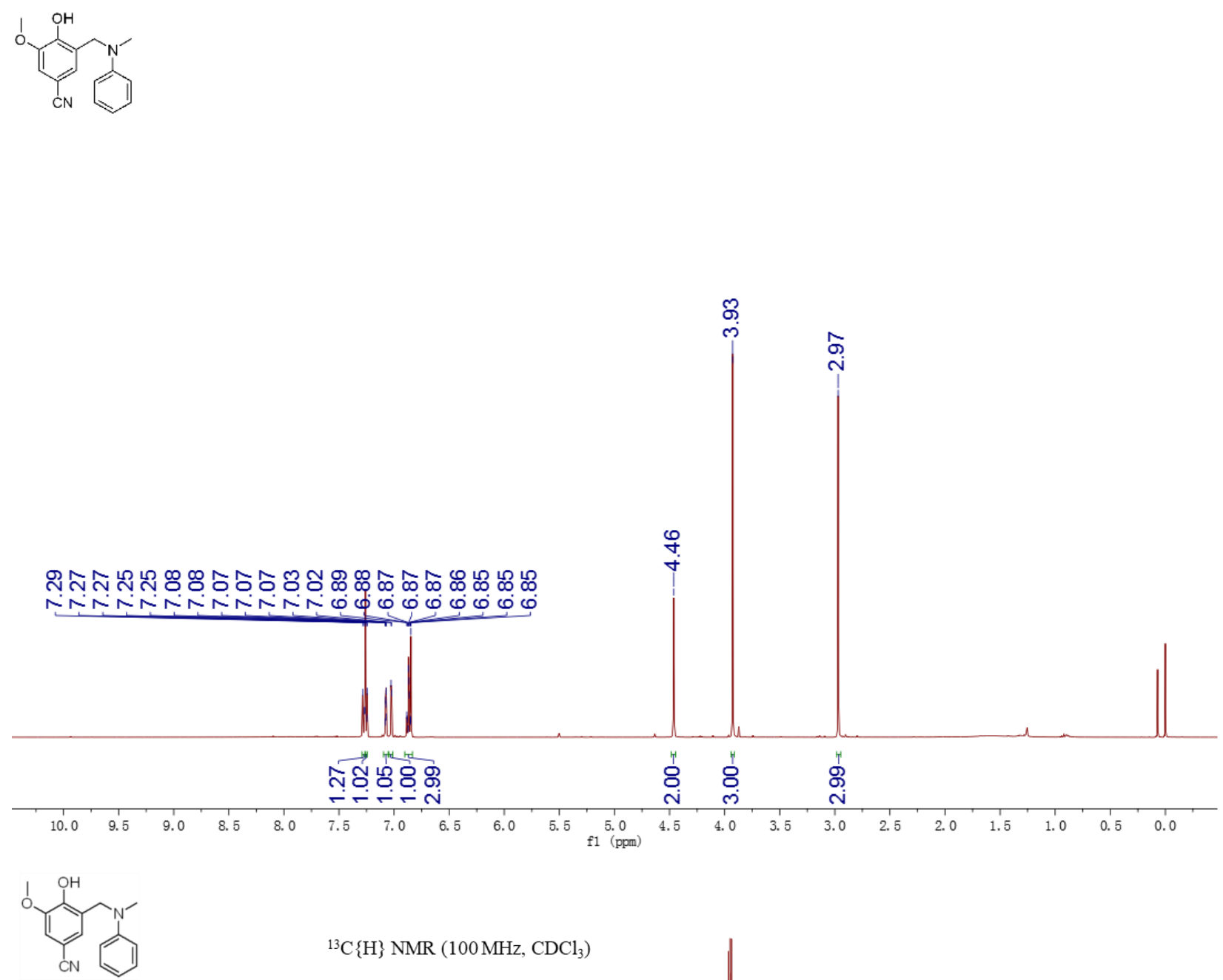

${ }^{13} \mathrm{C}\{\mathrm{H}\} \mathrm{NMR}\left(100 \mathrm{MHz}, \mathrm{CDCl}_{3}\right)$

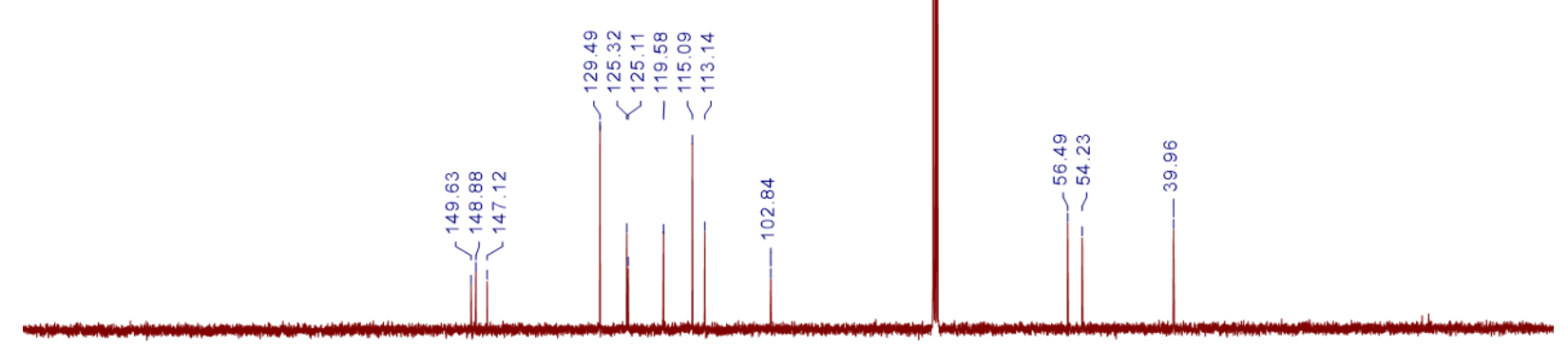

Figure S26. ${ }^{1} \mathrm{H}$ NMR and ${ }^{13} \mathrm{C}\left\{{ }^{1} \mathrm{H}\right\}$ NMR spectra of $\mathbf{3 v}$ 

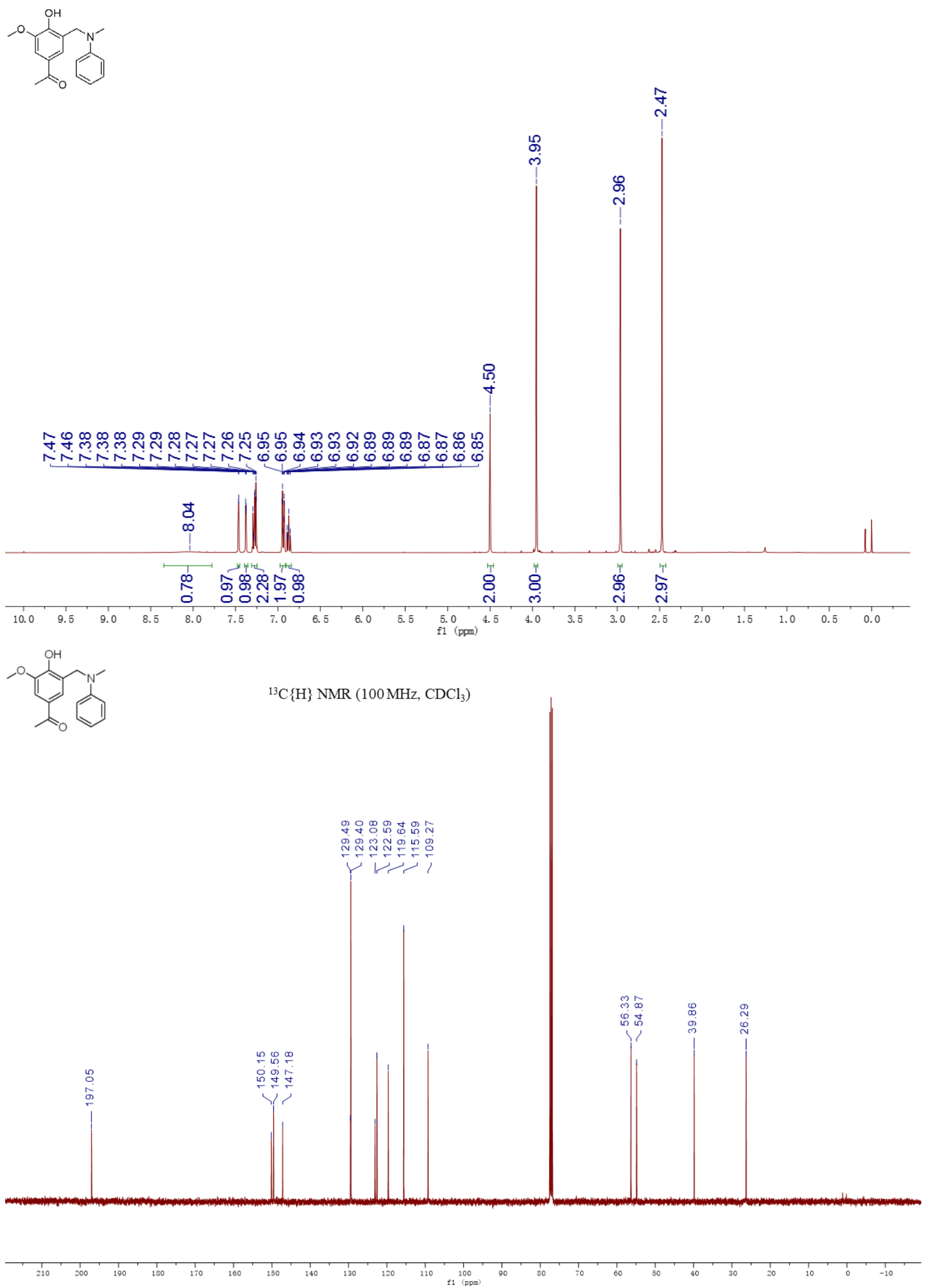

Figure S27. ${ }^{1} \mathrm{H}$ NMR and ${ }^{13} \mathrm{C}\left\{{ }^{1} \mathrm{H}\right\}$ NMR spectra of $\mathbf{3 w}$ 

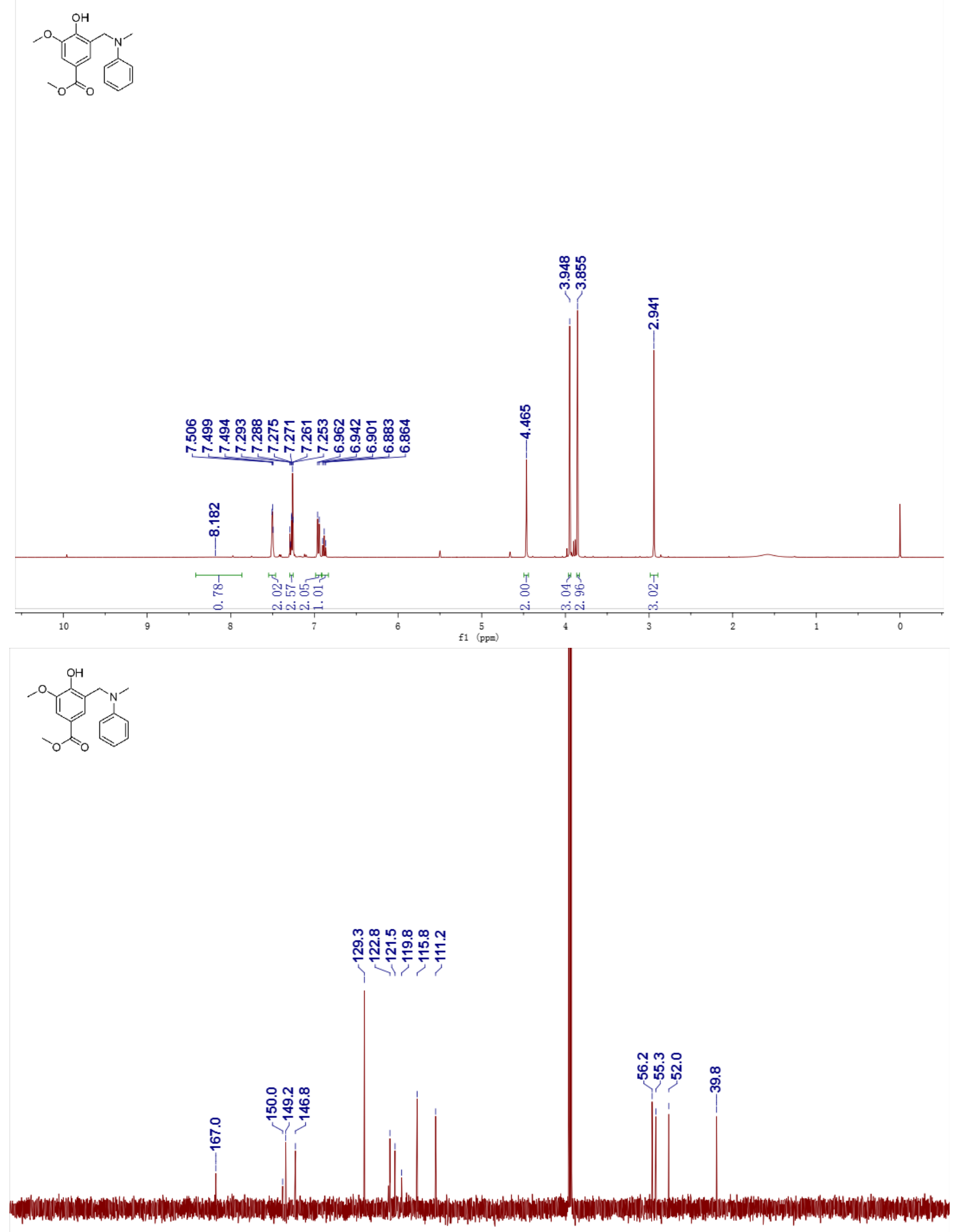

Figure S28. ${ }^{1} \mathrm{H}$ NMR and ${ }^{13} \mathrm{C}\left\{{ }^{1} \mathrm{H}\right\}$ NMR spectra of $\mathbf{3 x}$ 

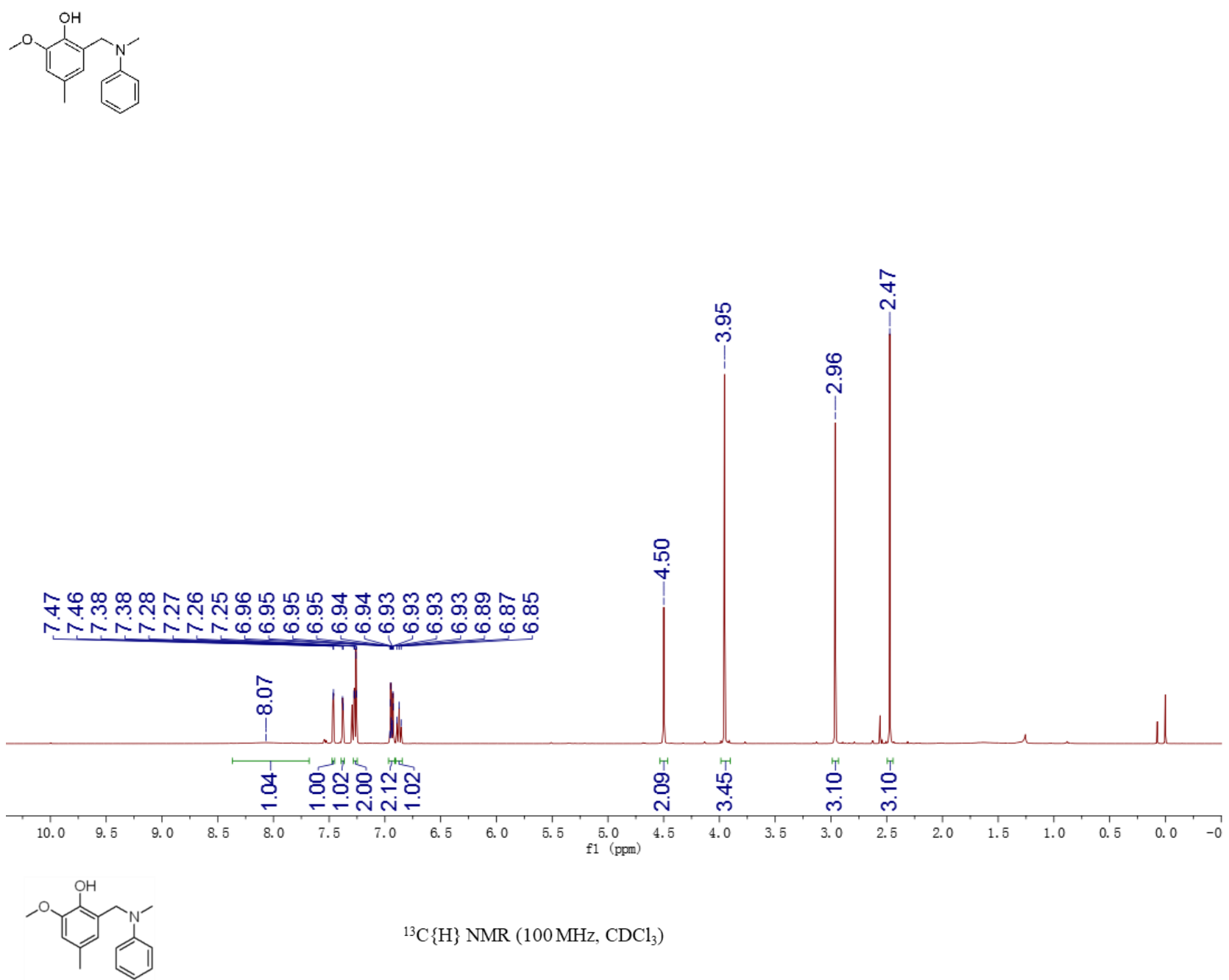

${ }^{13} \mathrm{C}\{\mathrm{H}\} \mathrm{NMR}\left(100 \mathrm{MHz}, \mathrm{CDCl}_{3}\right)$

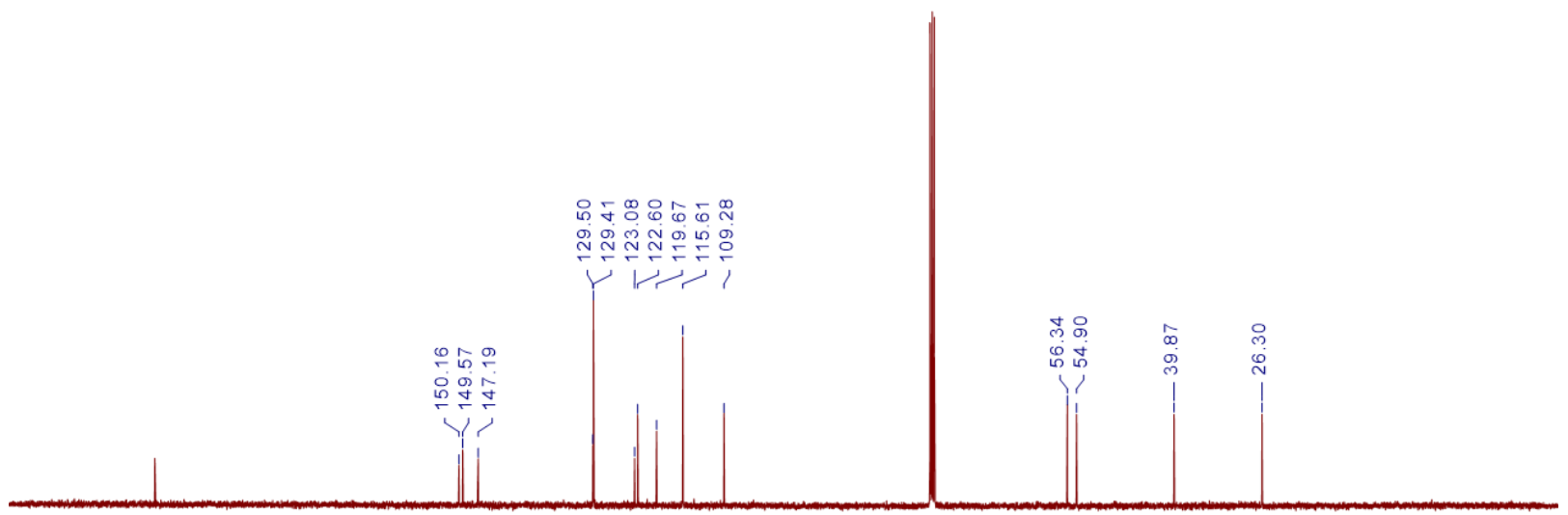

Figure S29. ${ }^{1} \mathrm{H}$ NMR and ${ }^{13} \mathrm{C}\left\{{ }^{1} \mathrm{H}\right\}$ NMR spectra of $\mathbf{3 y}$ 

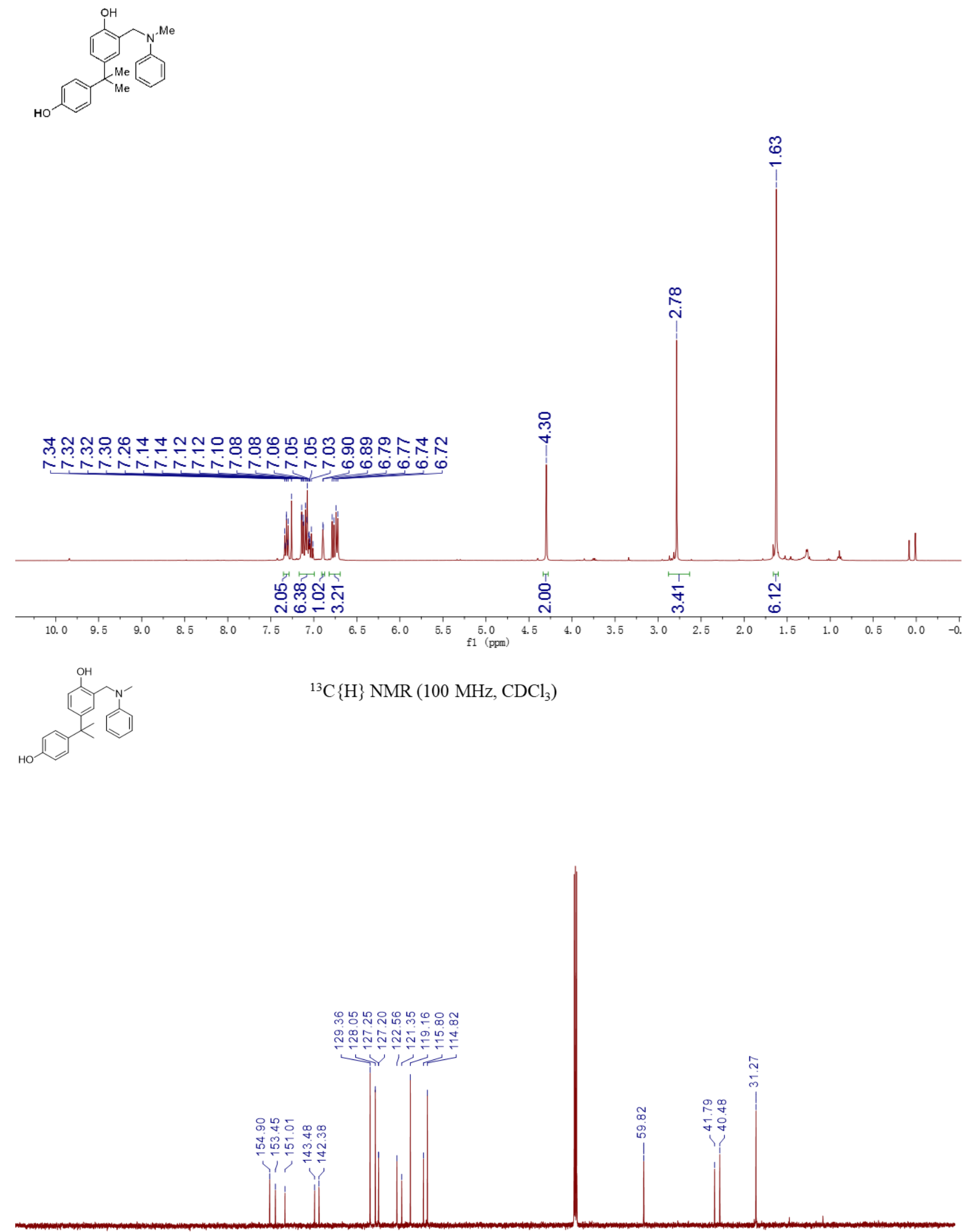

Figure S30. ${ }^{1} \mathrm{H}$ NMR and ${ }^{13} \mathrm{C}\left\{{ }^{1} \mathrm{H}\right\}$ NMR spectra of $\mathbf{3 z}$ 

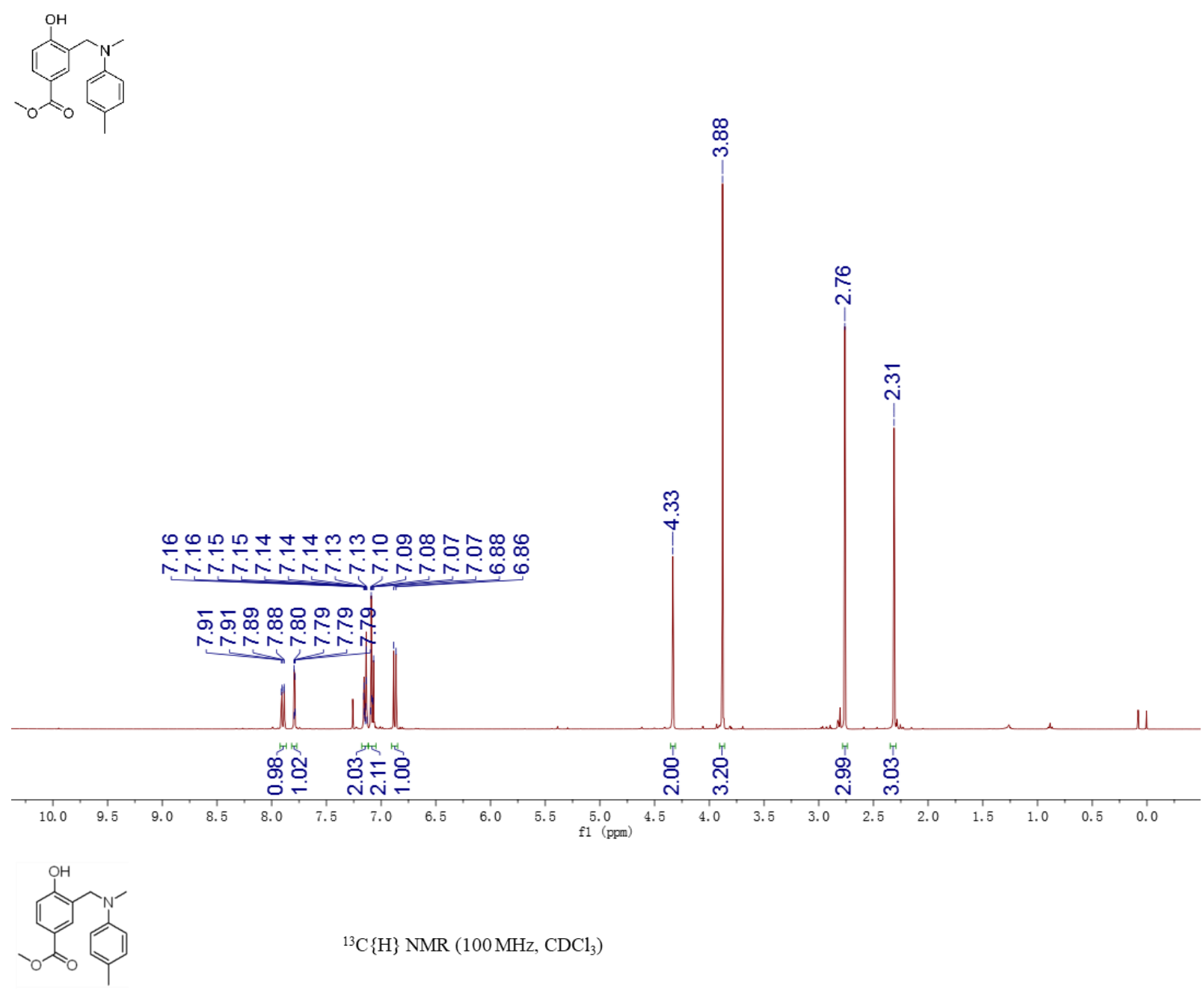

${ }^{13} \mathrm{C}\{\mathrm{H}\} \mathrm{NMR}\left(100 \mathrm{MHz}, \mathrm{CDCl}_{3}\right)$

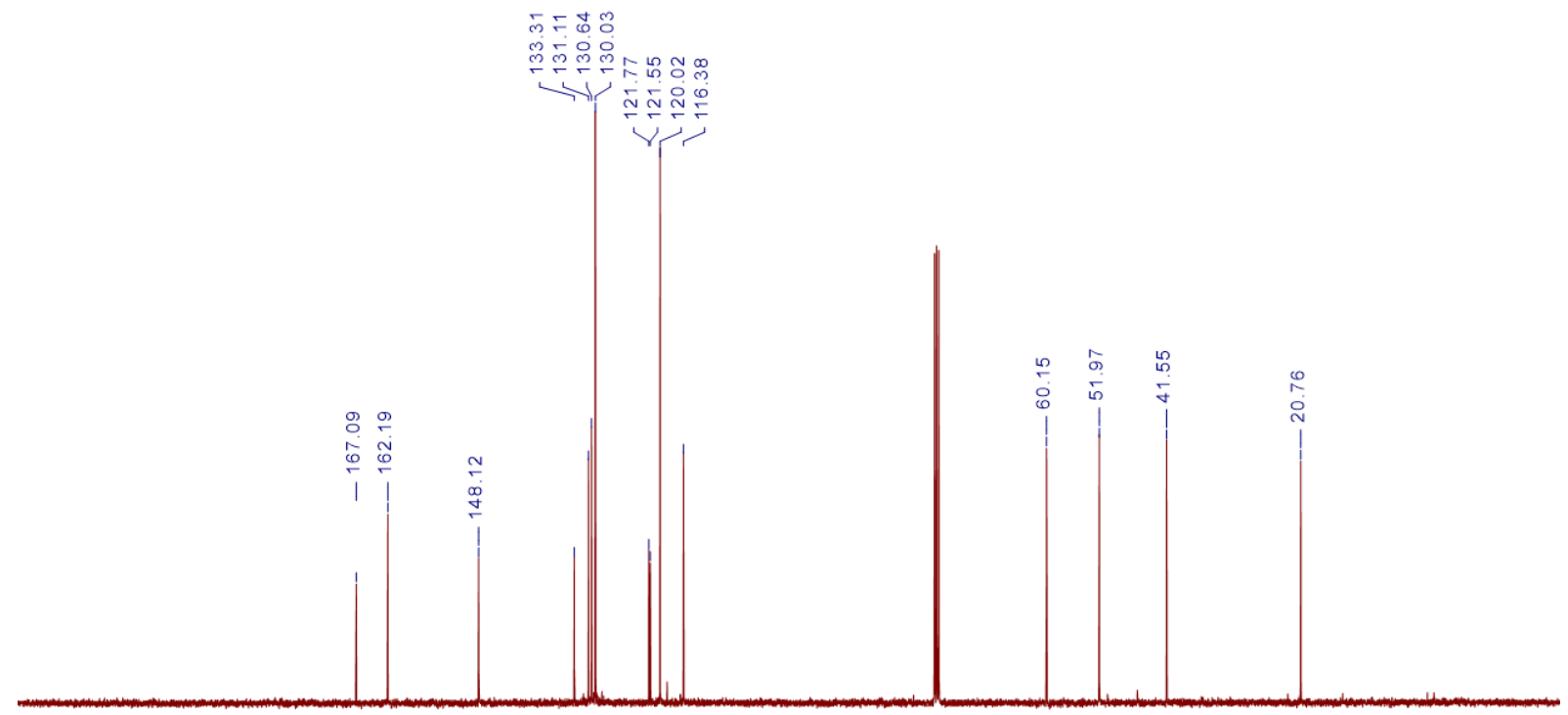

Figure S31. ${ }^{1} \mathrm{H}$ NMR and ${ }^{13} \mathrm{C}\left\{{ }^{1} \mathrm{H}\right\}$ NMR spectra of 4 a 


\section{(-}
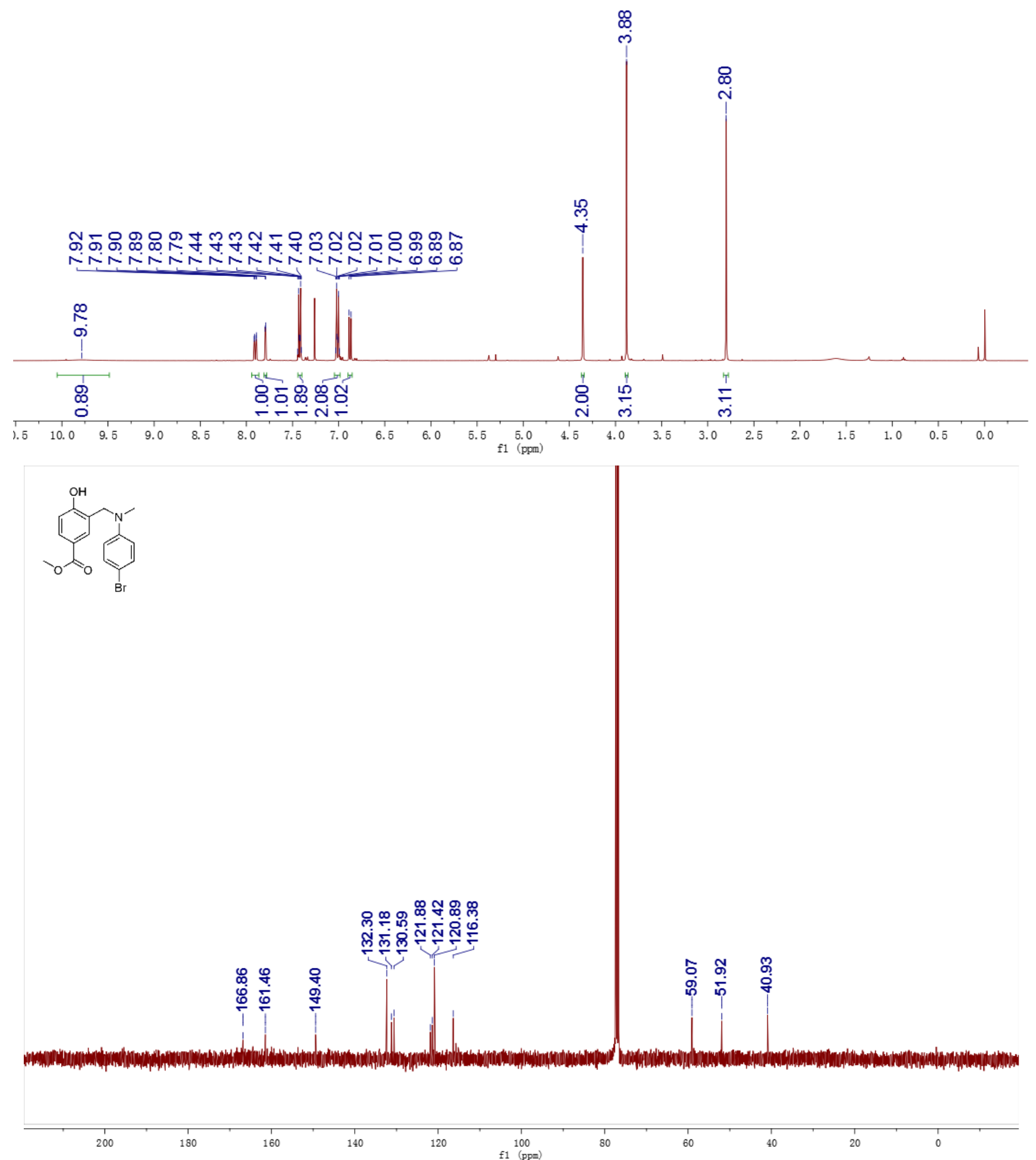

Figure S32. ${ }^{1} \mathrm{H}$ NMR and ${ }^{13} \mathrm{C}\left\{{ }^{1} \mathrm{H}\right\}$ NMR spectra of $\mathbf{4 b}$ 
<smiles>C[N+](C)(Cc1ccc(Cl)cc1)Cc1ccc(C(=O)O)c(O)c1</smiles>
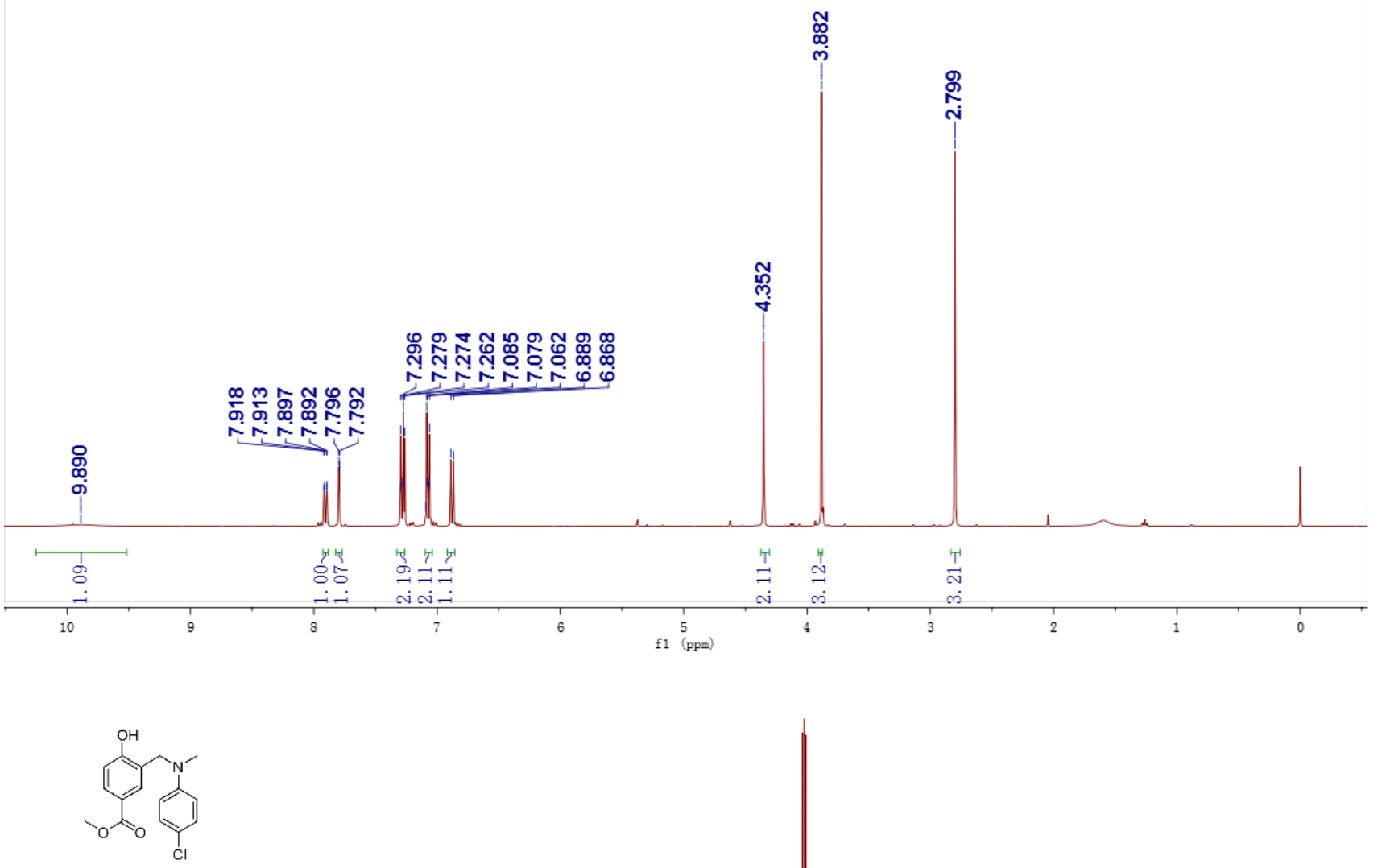

${ }^{13} \mathrm{C}\{\mathrm{H}\} \mathrm{NMR}\left(100 \mathrm{MHz}, \mathrm{CDCl}_{3}\right)$

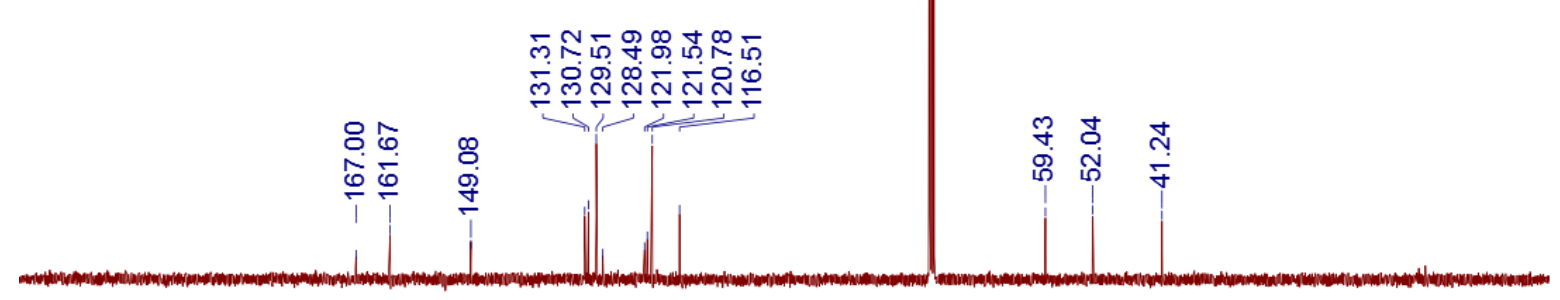

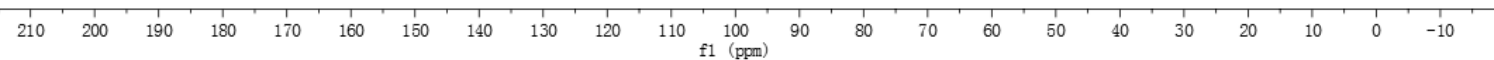

Figure S33. ${ }^{1} \mathrm{H}$ NMR and ${ }^{13} \mathrm{C}\left\{{ }^{1} \mathrm{H}\right\}$ NMR spectra of $\mathbf{4 c}$ 

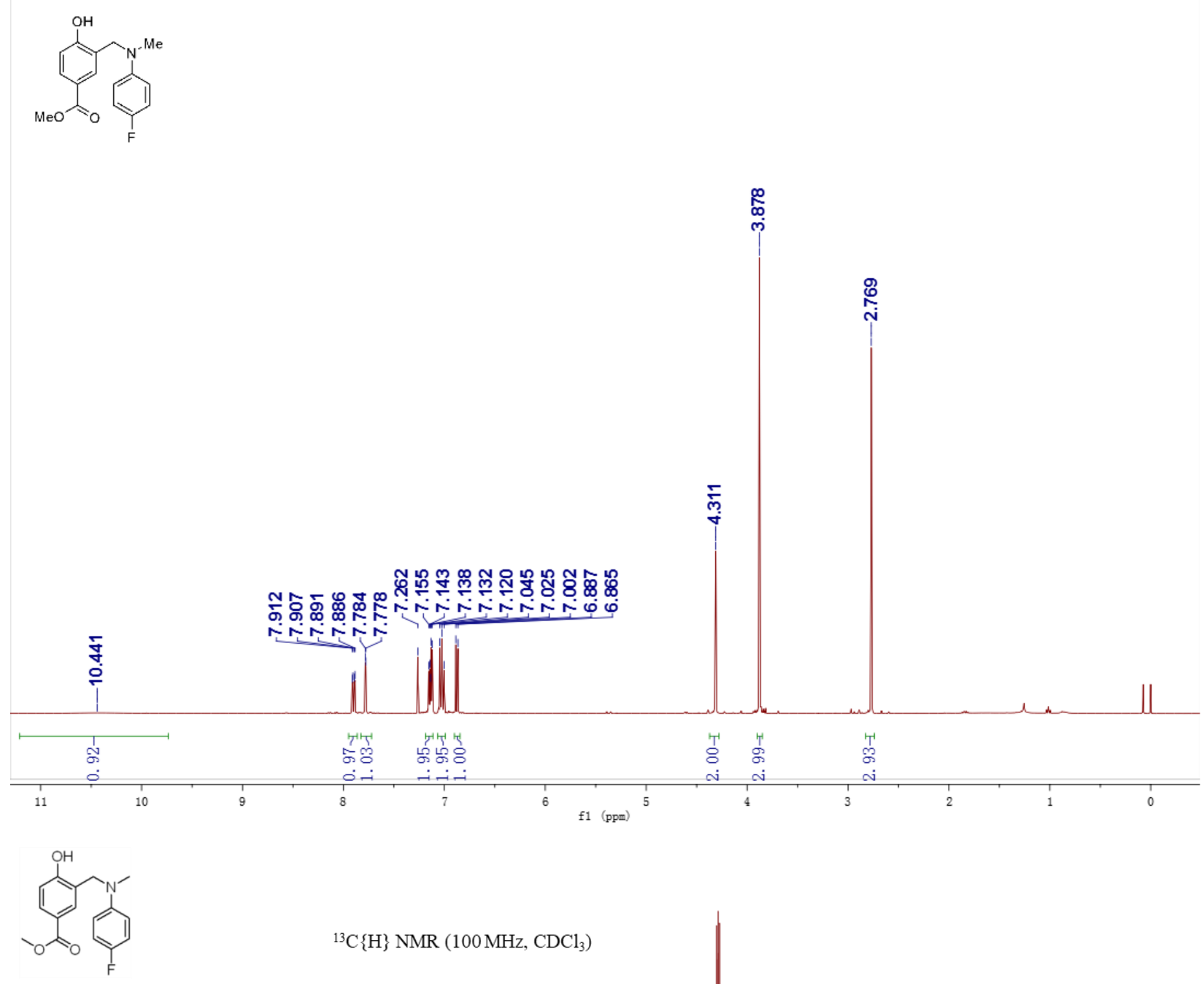

${ }^{13} \mathrm{C}\{\mathrm{H}\} \mathrm{NMR}\left(100 \mathrm{MHz}, \mathrm{CDCl}_{3}\right)$

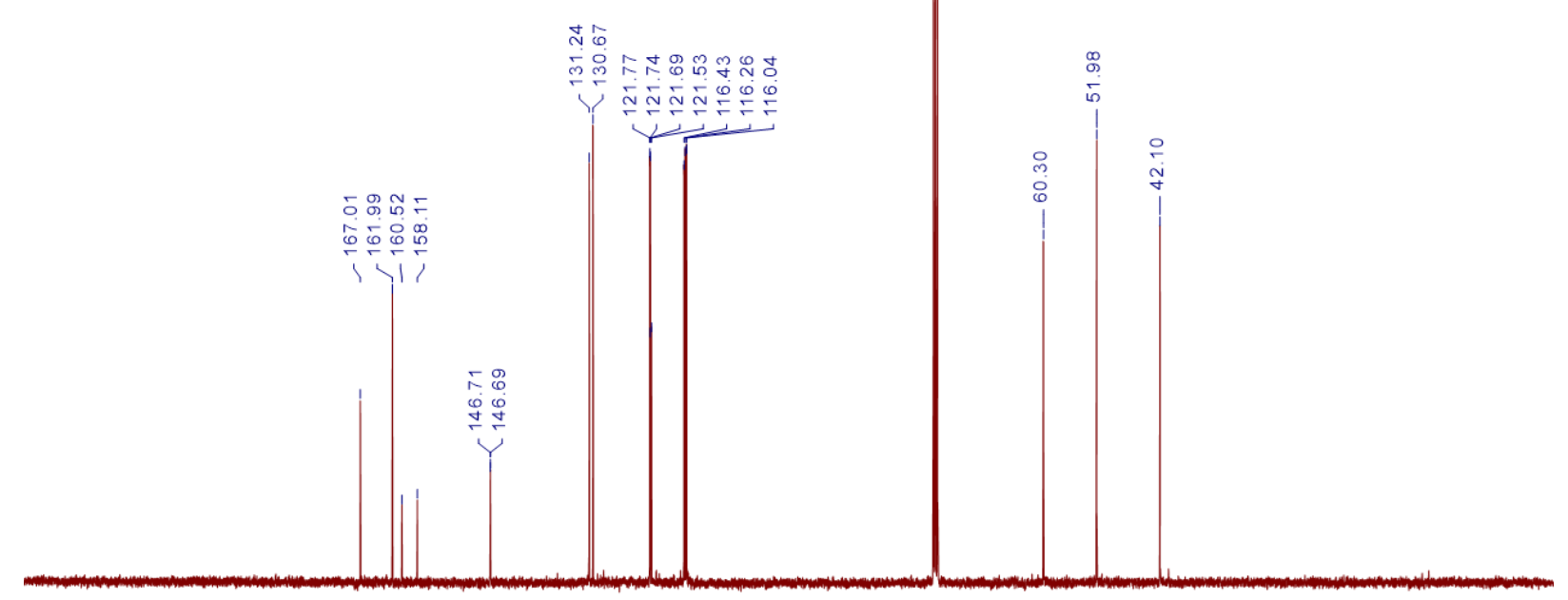

Figure S34. ${ }^{1} \mathrm{H}$ NMR and ${ }^{13} \mathrm{C}\left\{{ }^{1} \mathrm{H}\right\}$ NMR spectra of $\mathbf{4 d}$ 

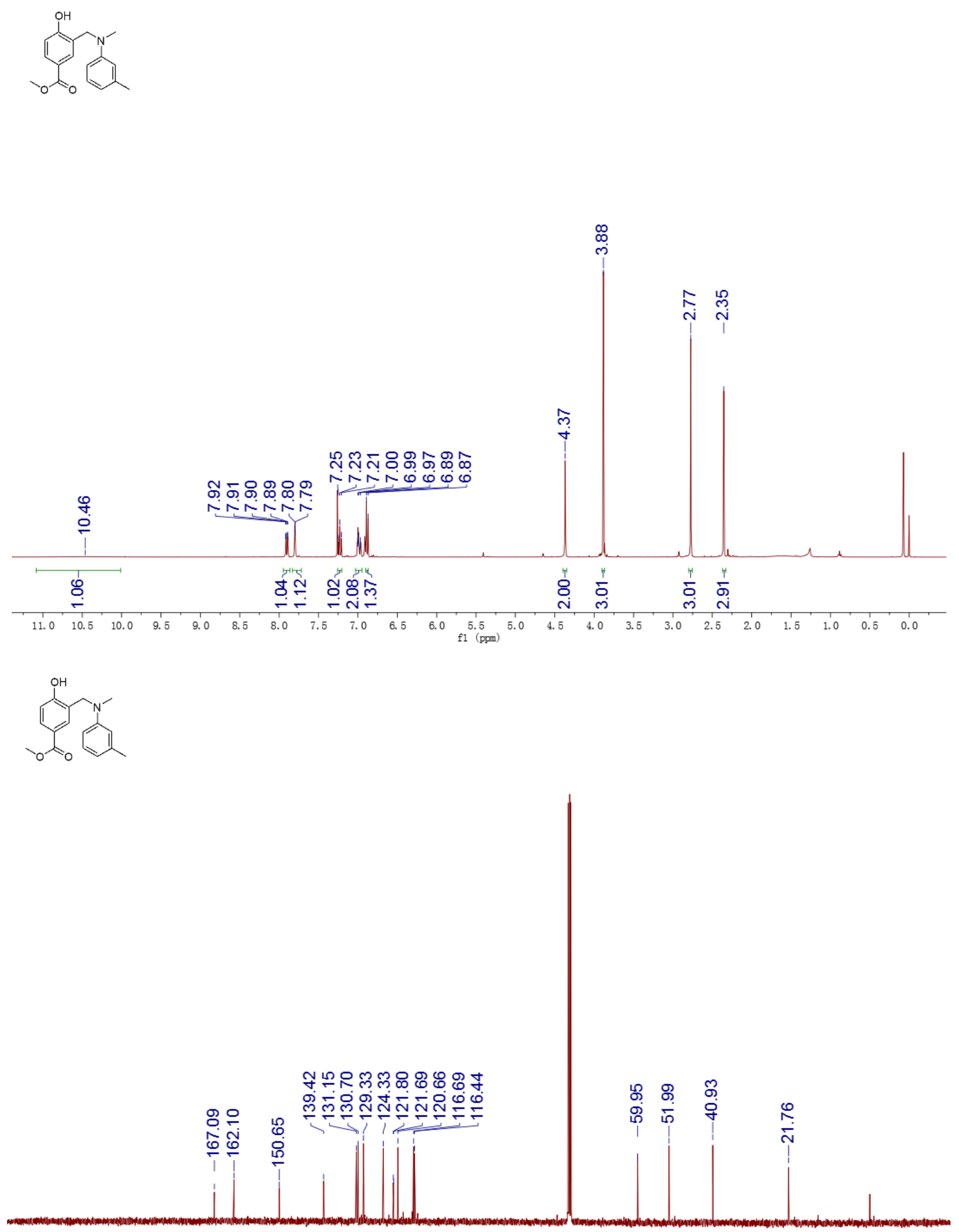

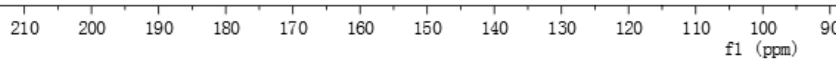

Figure S35. ${ }^{1} \mathrm{H}$ NMR and ${ }^{13} \mathrm{C}\left\{{ }^{1} \mathrm{H}\right\}$ NMR spectra of $4 \mathbf{e}$ 

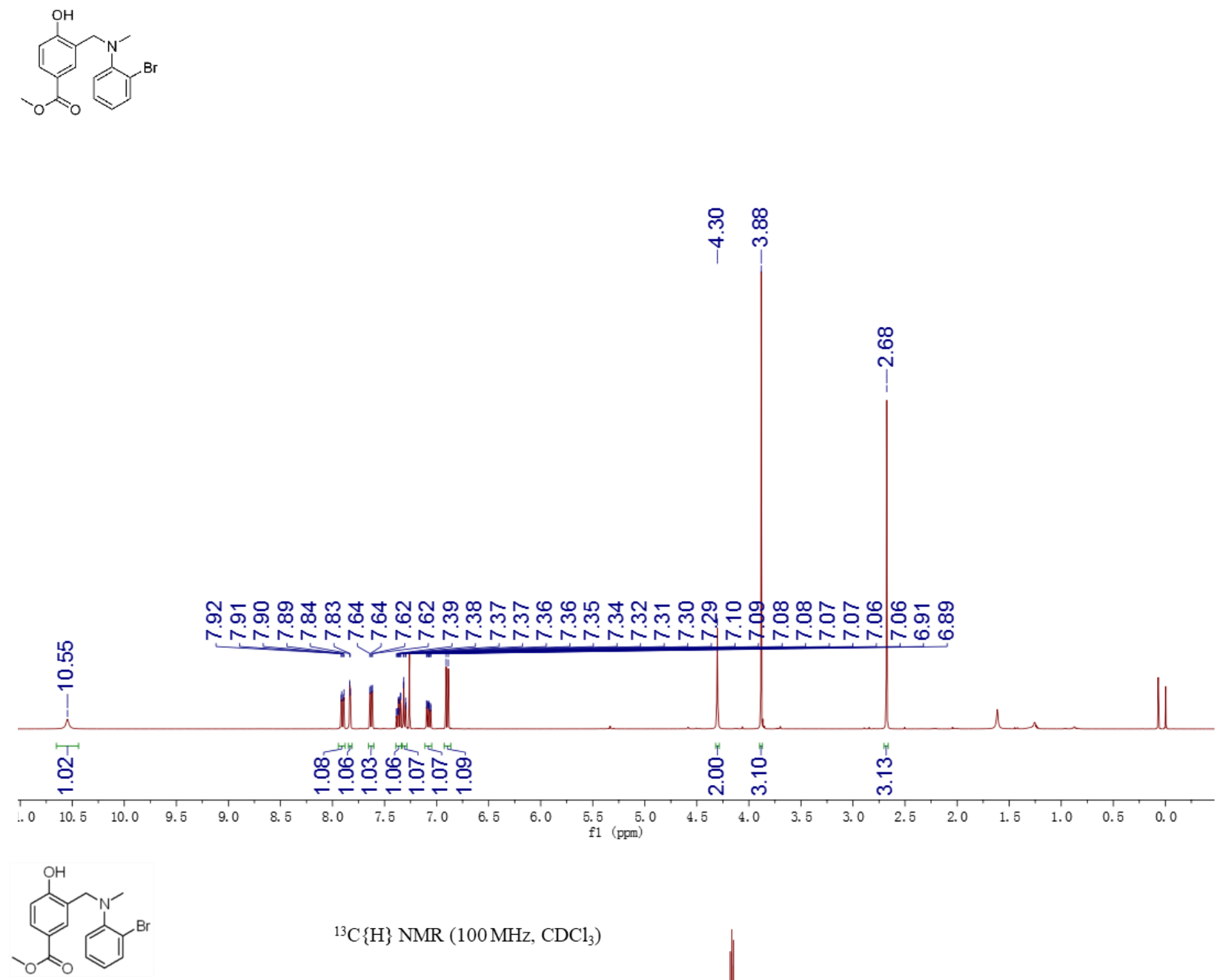

${ }^{13} \mathrm{C}\{\mathrm{H}\} \mathrm{NMR}\left(100 \mathrm{MHz}, \mathrm{CDCl}_{3}\right)$

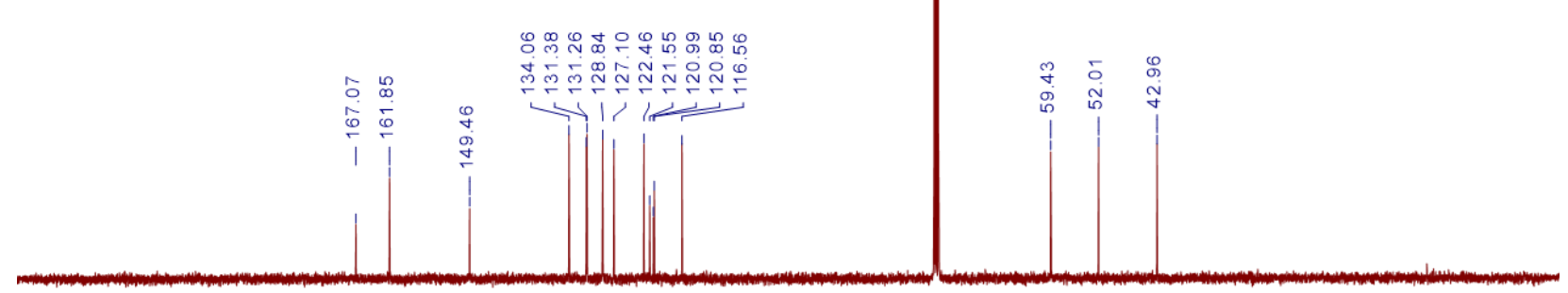

Figure S36. ${ }^{1} \mathrm{H}$ NMR and ${ }^{13} \mathrm{C}\left\{{ }^{1} \mathrm{H}\right\}$ NMR spectra of $\mathbf{4 f}$ 
<smiles>CCc1cccc(N(CC)Cc2cccc(O)c2)c1</smiles>
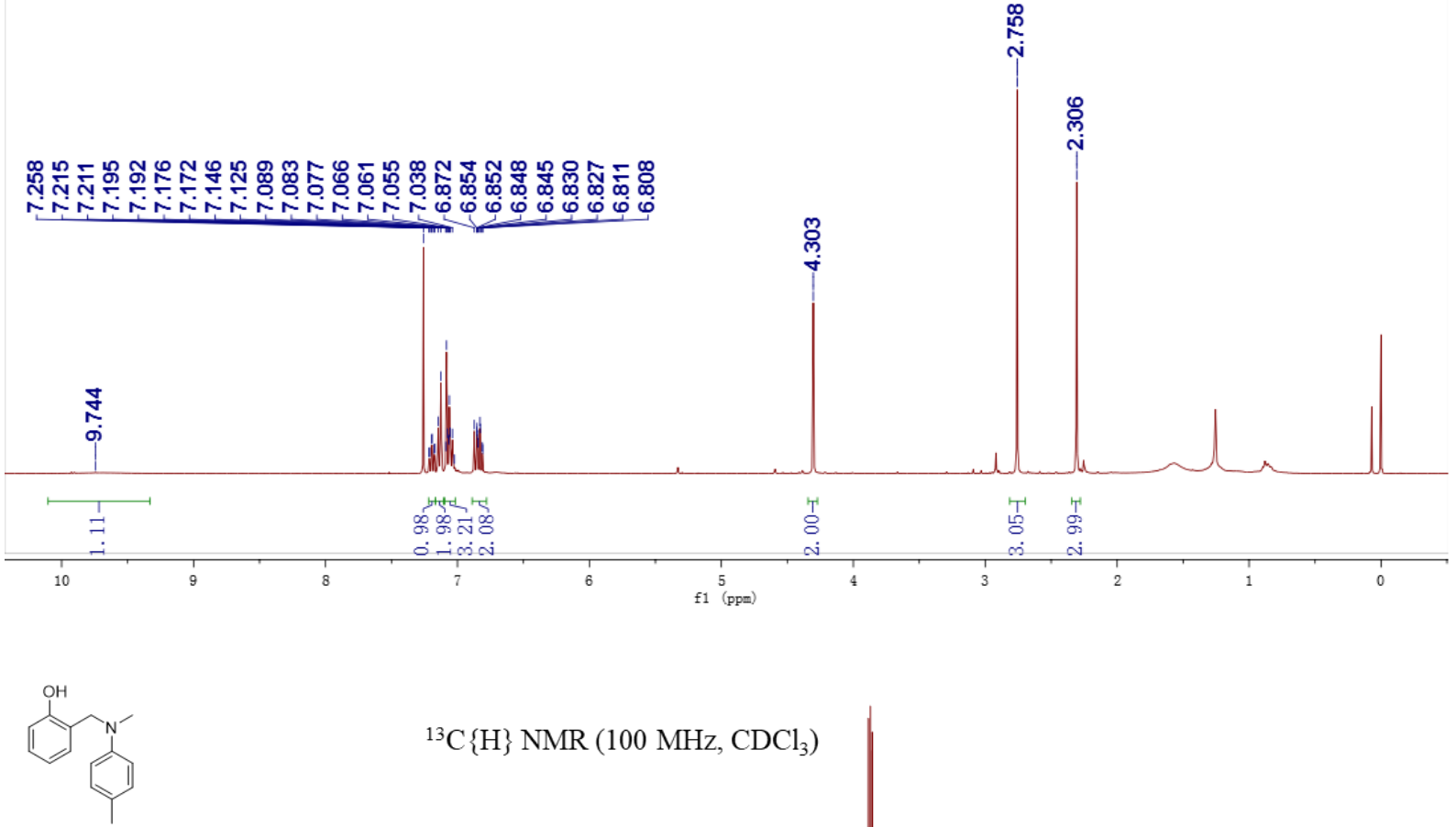

${ }^{13} \mathrm{C}\{\mathrm{H}\}$ NMR $\left(100 \mathrm{MHz}, \mathrm{CDCl}_{3}\right)$

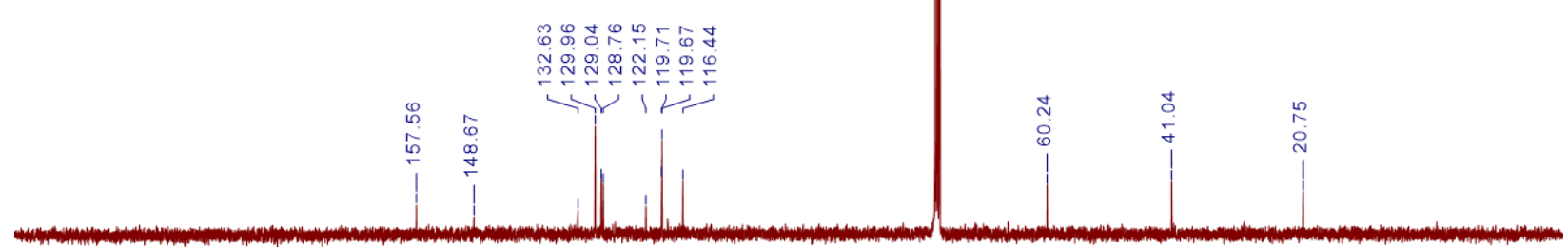

Figure S37. ${ }^{1} \mathrm{H}$ NMR and ${ }^{13} \mathrm{C}\left\{{ }^{1} \mathrm{H}\right\}$ NMR spectra of $\mathbf{4 g}$ 

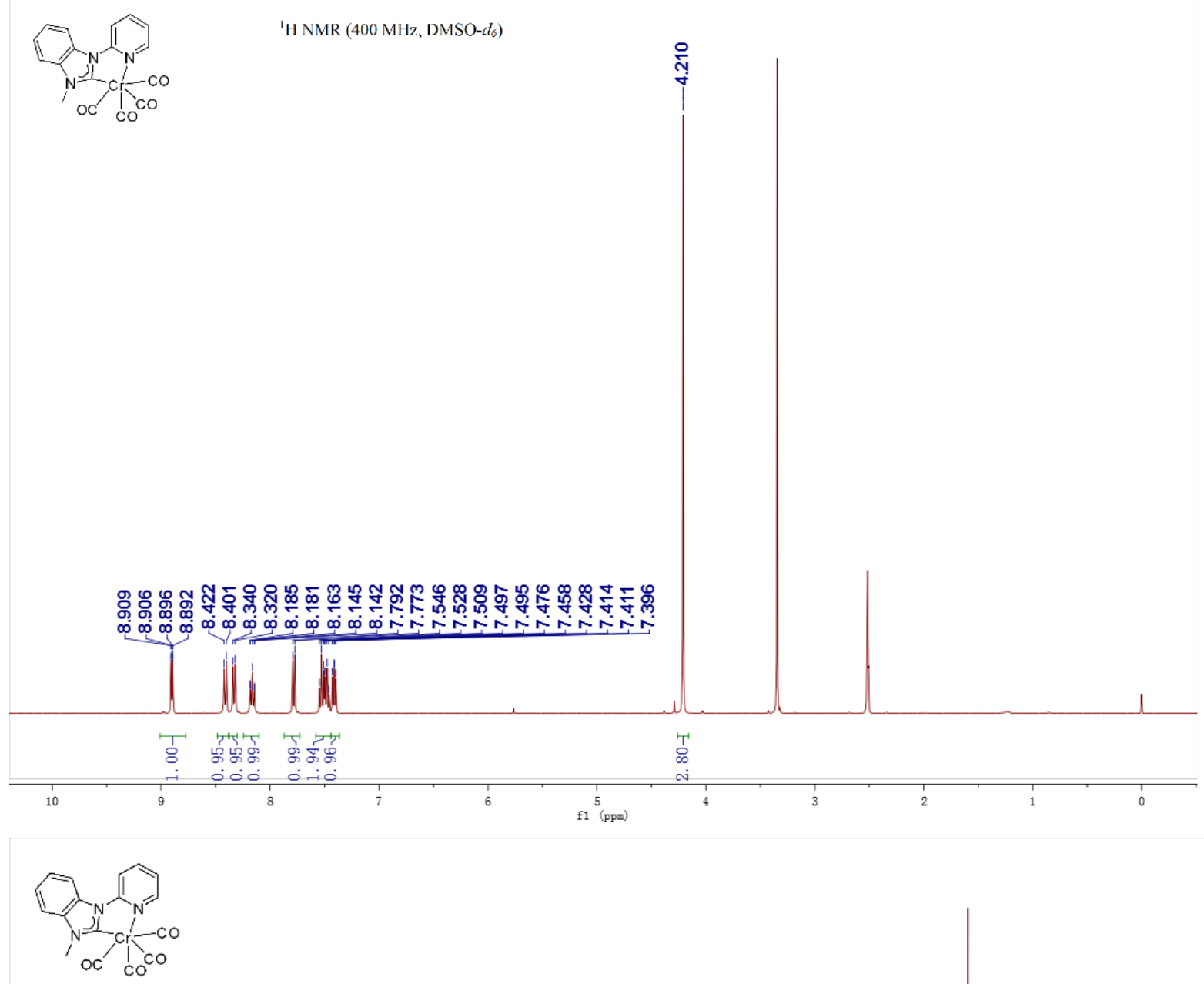

.${ }^{13} \mathrm{C}\left\{{ }^{1} \mathrm{H}\right\}$ NMR $\left(100 \mathrm{MHz}\right.$, DMSO-d $\left.d_{6}\right)$

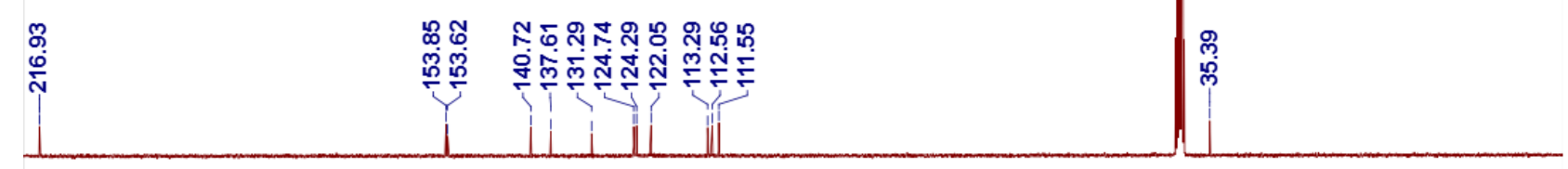

$200 \quad \frac{180}{160} \quad{ }_{140}^{1} \underbrace{100}_{120}$

Figure S38. ${ }^{1} \mathrm{H}$ NMR and ${ }^{13} \mathrm{C}\left\{{ }^{1} \mathrm{H}\right\}$ NMR spectra of $\mathbf{C 1}$ 


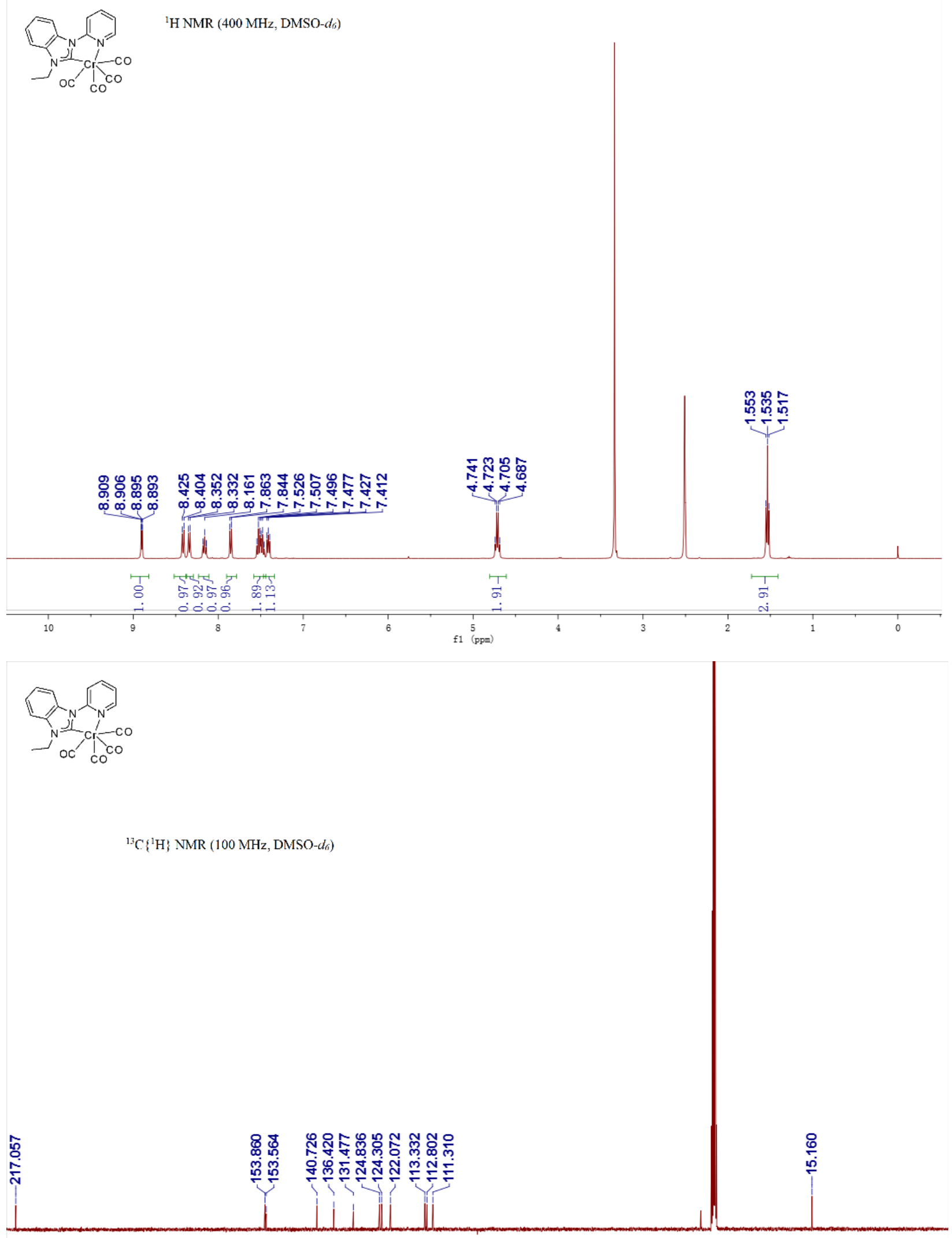

$200 \quad 180 \quad 160 \quad 140 \quad 120 \quad \underset{f 100}{100}$

Figure S39. ${ }^{1} \mathrm{H}$ NMR and ${ }^{13} \mathrm{C}\left\{{ }^{1} \mathrm{H}\right\}$ NMR spectra of $\mathbf{C 2}$ 


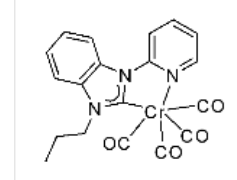

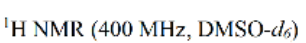
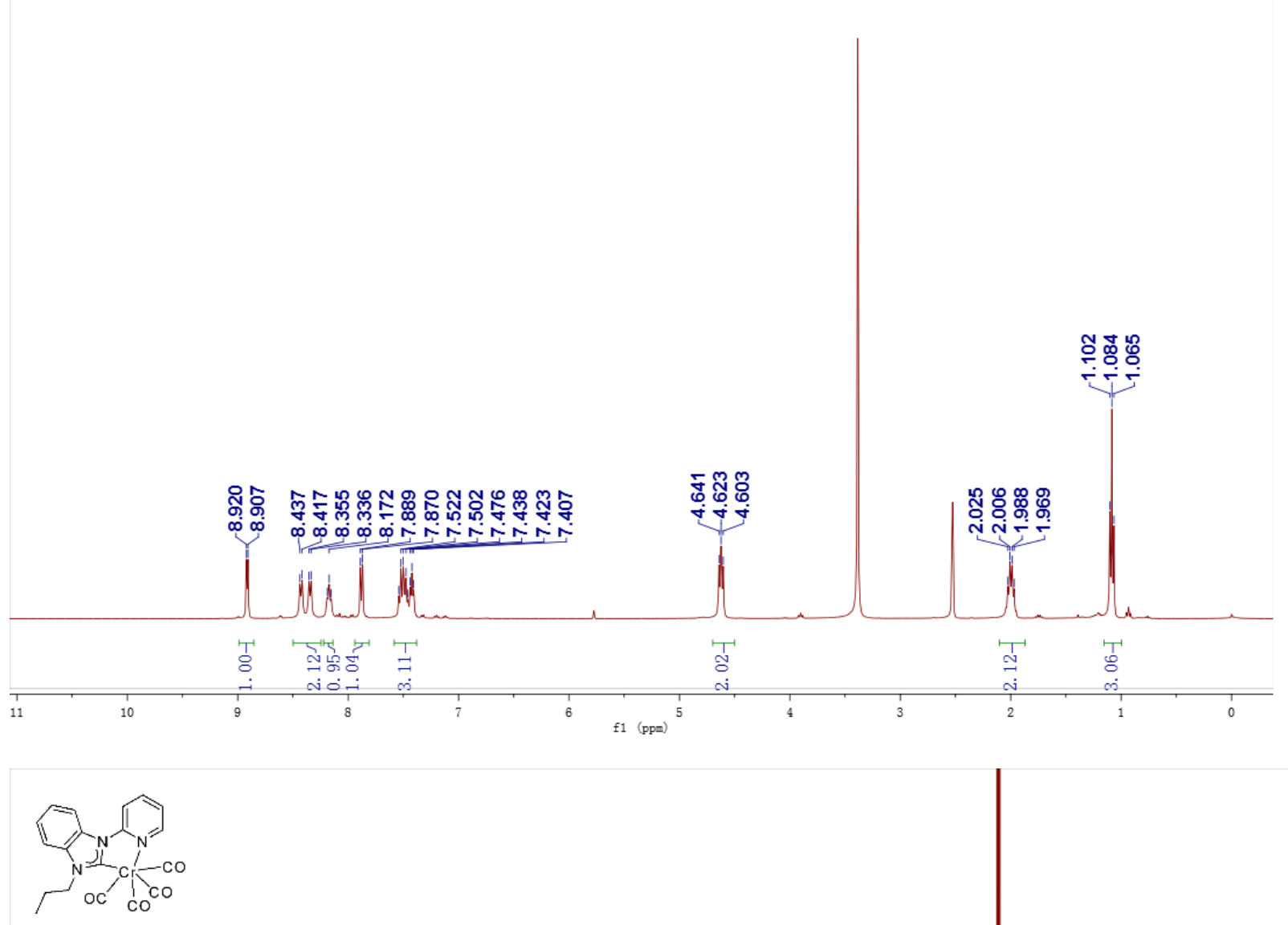

${ }^{13} \mathrm{C}\left\{{ }^{1} \mathrm{H}\right\}$ NMR $\left(100 \mathrm{MHz}\right.$, DMSO- $\left.d_{6}\right)$

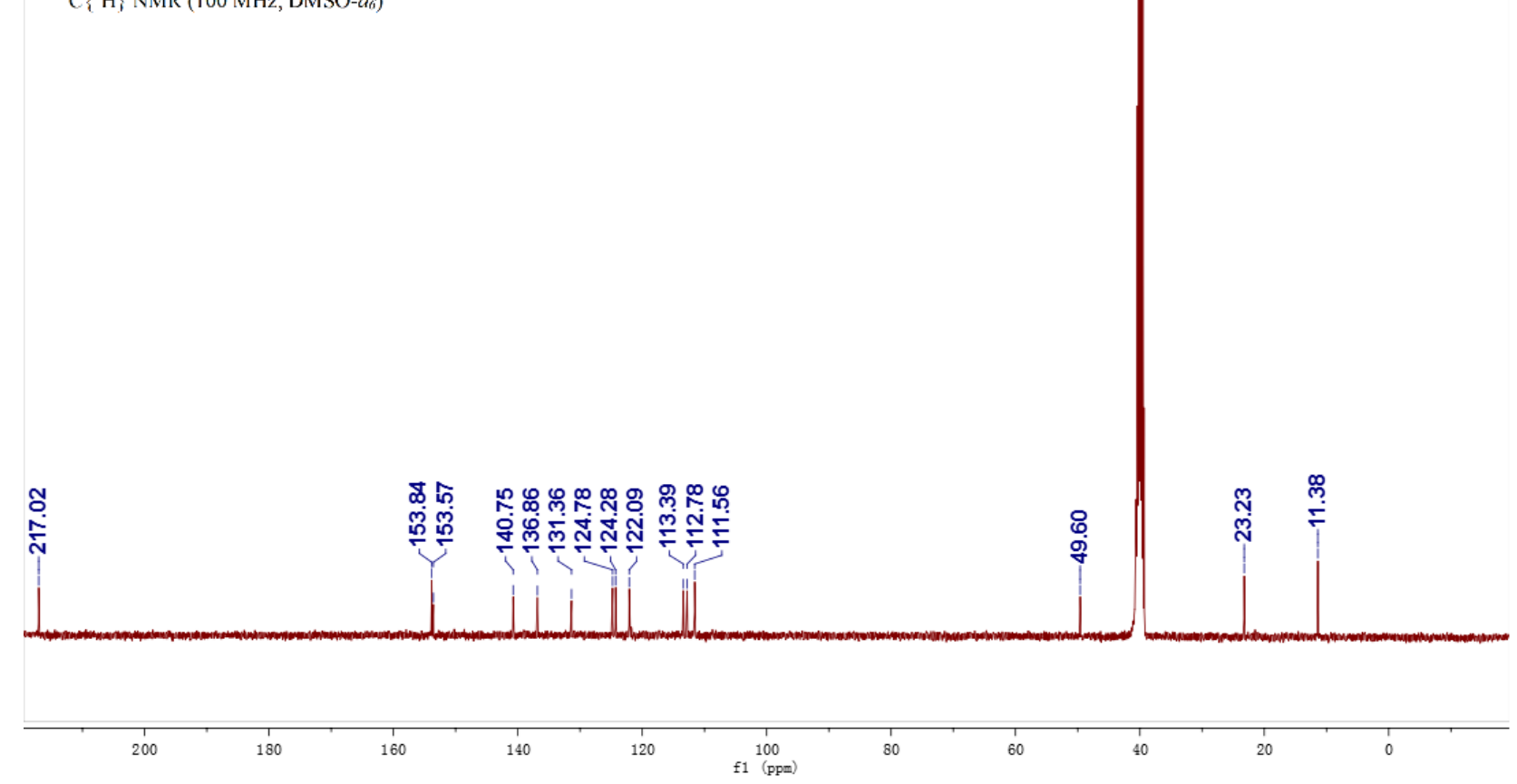

Figure S40. ${ }^{1} \mathrm{H}$ NMR and ${ }^{13} \mathrm{C}\left\{{ }^{1} \mathrm{H}\right\}$ NMR spectra of $\mathbf{C 3}$ 


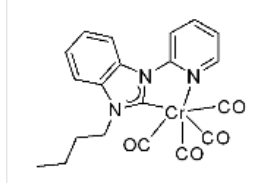

${ }^{\mathrm{I}} \mathrm{H}$ NMR $\left(400 \mathrm{MHz}, \mathrm{DMSO}-d_{6}\right)$
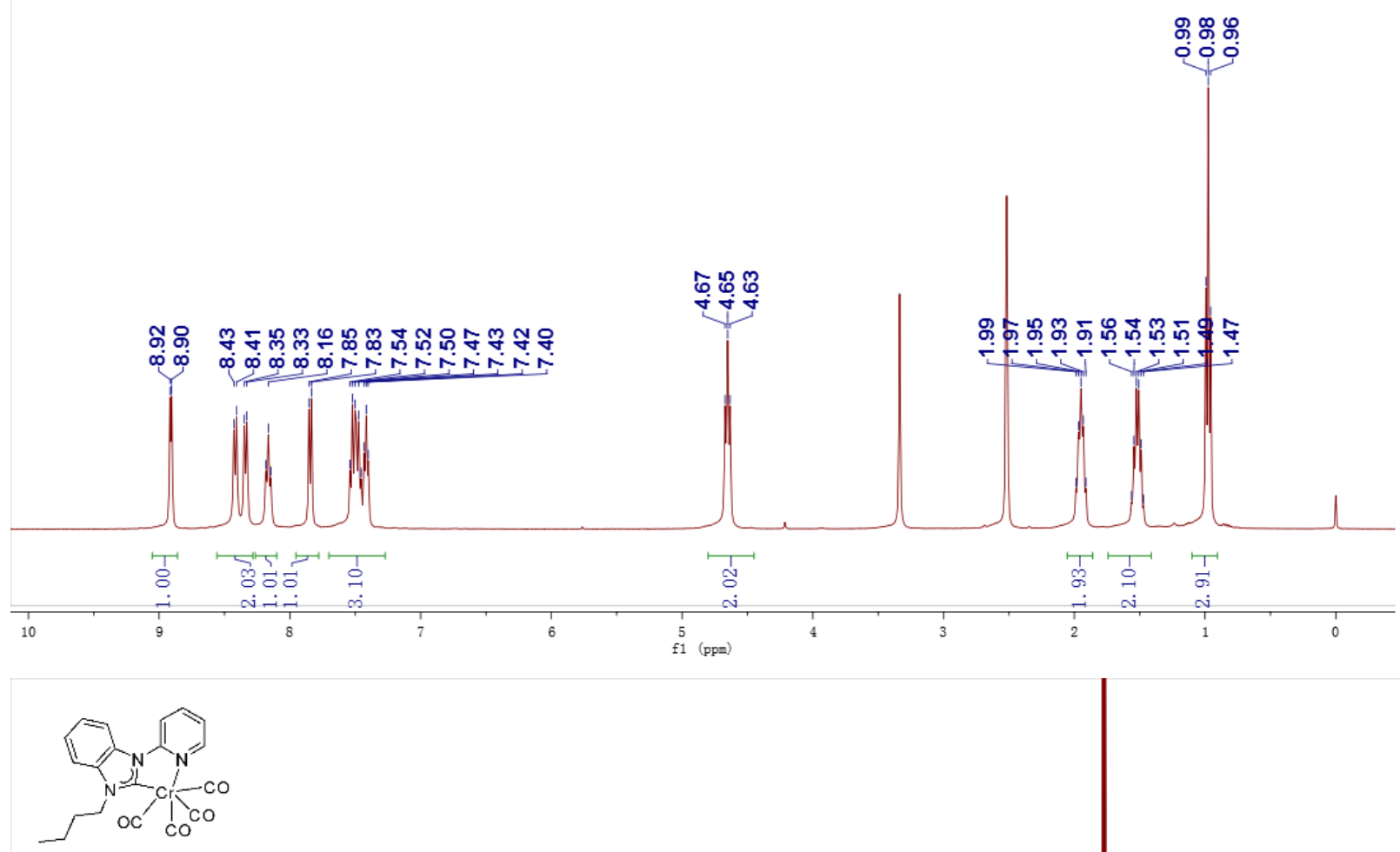

${ }^{13} \mathrm{C}\left\{{ }^{1} \mathrm{H}\right\}$ NMR $\left(100 \mathrm{MHz}, \mathrm{DMSO}-d_{6}\right)$

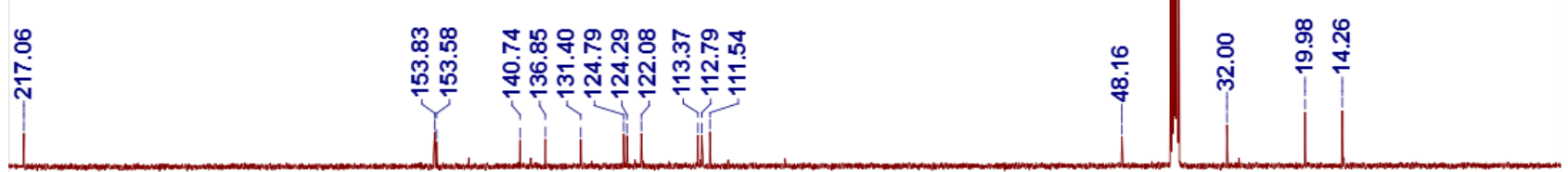

$200 \quad 180 \quad 160 \quad 140 \quad 120 \quad \frac{100}{f 1(\mathrm{ppm})}$

Figure S41. ${ }^{1} \mathrm{H}$ NMR and ${ }^{13} \mathrm{C}\left\{{ }^{1} \mathrm{H}\right\}$ NMR spectra of $\mathbf{C 4}$ 

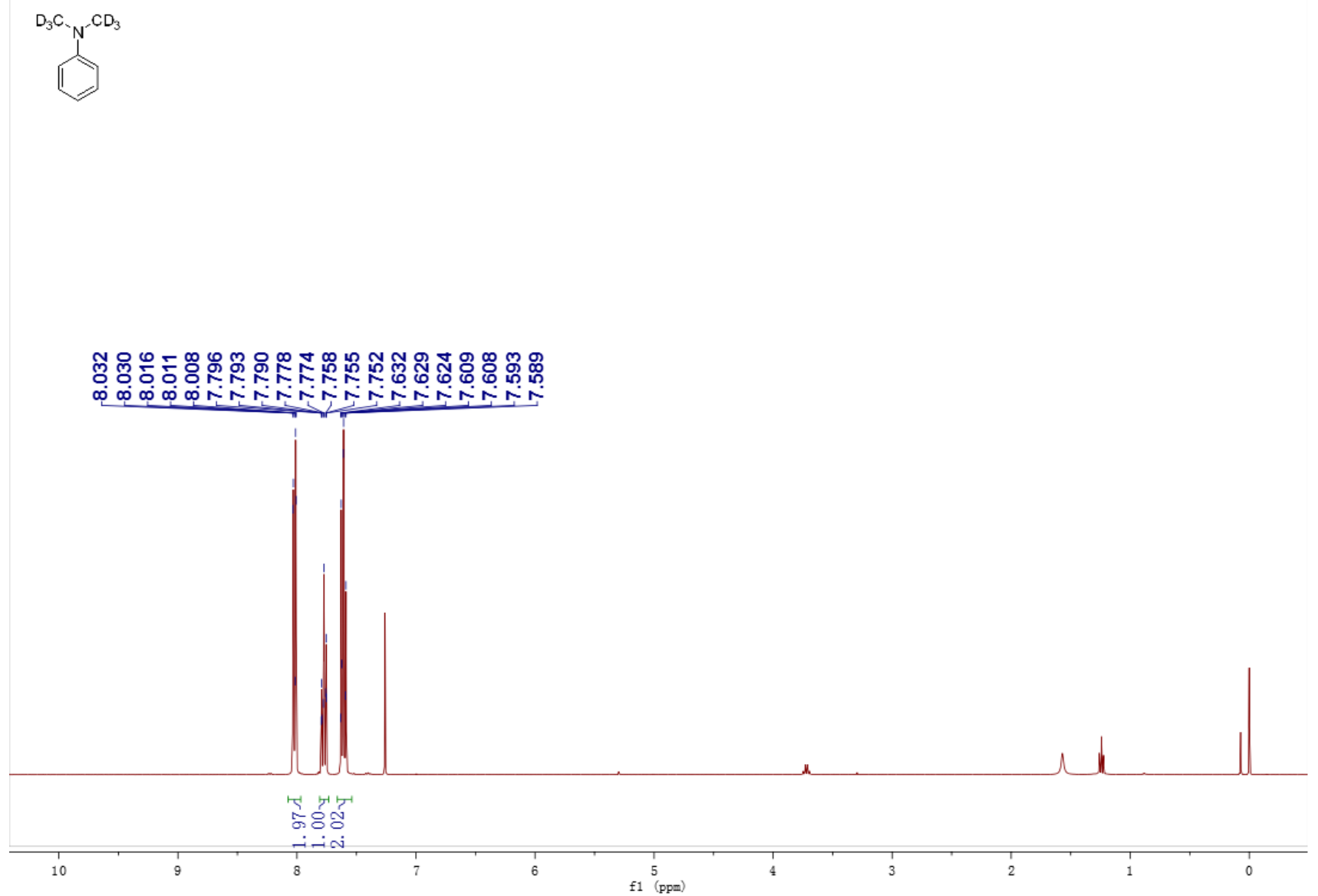

Figure S42. ${ }^{1} \mathrm{H}$ NMR spectra of $\left[\boldsymbol{d}_{\boldsymbol{b}}\right]-\mathbf{2 a}$ 